\title{
The threat of carbapenem-resistant gram-negative bacteria in a Middle East region
}

\author{
Effat Davoudi-Monfared \\ Hossein Khalili \\ Department of Clinical Pharmacy, \\ Faculty of Pharmacy, Tehran University \\ of Medical Sciences, Tehran, Iran
}

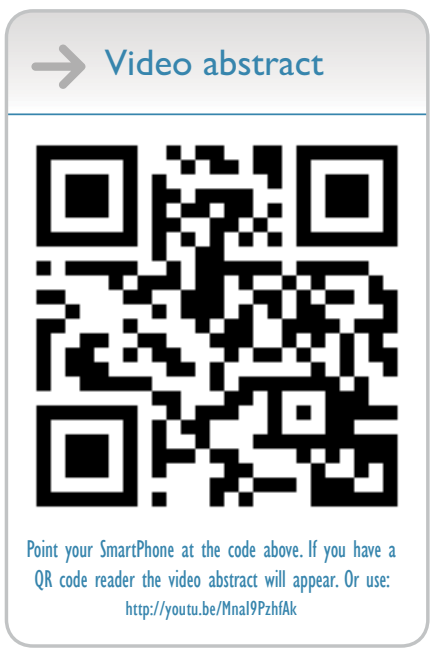

Correspondence: Hossein Khalili Department of Clinical Pharmacy, Faculty of Pharmacy, P.O. Box 14155/645I, Tehran University of Medical Sciences, Tehran 14176I44II, Iran $\mathrm{Tel} / \mathrm{Fax}+982166954709$

Email Khalilih@sina.tums.ac.ir
This article was published in the following Dove Press journal: Infection and Drug Resistance

\begin{abstract}
Data on the status of carbapenem-resistant microorganisms in the Middle East countries are scarce. The aim of this review was to collect available data regarding resistance to carbapenems in a Middle East region. Available data regarding carbapenem-resistant isolates were considered for evaluation in this review. Biomedical electronic databases were systematically searched to find related articles. The key terms used were "carbapenem-resistant, resistant gram-negative bacilli, Enterobacteriaceae, fermenting and non-fermenting gram-negative bacilli, Pseudomonas, Acinetobacter, Klebsiella and Iran". After primary screening, 275 relevant articles were selected to be assessed thoroughly. Resistance rate to carbapenems was reported between $1 \%$ and $86 \%$ during years 2006-2018. Most of the carbapenem-resistant microorganisms were isolated from burn patients. Modified Hodge test was a commonly used phenotypic test. Only in few studies, genotypic assays were considered. Pattern of antibiotic use can affect emergence of resistant microorganisms. Rational use of drugs, and specifically, antibiotics is a challenging issue in developing countries. Mean number of drugs per prescription in these countries was higher than the World Health Organization standards. Overuse of antibiotics, especially injectable ones, and easy access to antibiotics without prescription is a warning alarm for future antibiotic resistance in developing countries. Establishing antimicrobial stewardship's programs is new in the hospitals. Unfortunately, rules and regulatory issues to restrict antibiotic access in community pharmacies and prescription by general physicians are limited.
\end{abstract}

Keywords: carbapenem, resistant, gram-negative bacteria, antibiotics

\section{Introduction}

Carbapenem-resistant gram-negative bacteria are now a global concern around the world. Most of these strains are also resistant to other antimicrobial agents including aminoglycosides and fluoroquinolones. ${ }^{1}$ Few therapeutic options without the desired efficacy are available to treat infections caused by carbapenem-resistant microorganisms. ${ }^{2}$ This real threat necessitates applying reliable methods to determine prevalence of these isolates.

The methods to detect carbapenemase-producing microorganisms are divided into two classes: phenotypic and genotypic methods. Phenotypic methods are nonmolecular assays that detect structure of the carbapenemase enzyme (mostly active site) through a chemical or microbiological process. ${ }^{3}$ The carbapenemase enzymes are structurally classified according to their active sites. Ambler class A (known as Klebsiella-producing carbapenemase [KPC]) has serine amino acid in its active site and can be inhibited by $\beta$-lactamase inhibitors. Ambler class B has zinc in its active site and is called metallo$\beta$-lactamase (MBL), so it can react with EDTA and dipicolinic acid (DPA). The last 
class, Ambler class D, has serine in its active site, but it may or may not be inhibited by $\beta$-lactamase inhibitors. ${ }^{4}$ According to these classes, various phenotypic methods are proposed to detect carbapenemase enzyme in gram-negative isolates.

Genotypic methods are targeted to detect resistance genes (mostly bla type genes) and polymerase chain reaction (PCR) is a common method. Other genotypic method is clonal typing. ${ }^{5}$ Although detection of resistant-encoding genes is more accurate, however, these methods are usually expensive and not available anywhere. ${ }^{6}$ Some other mechanisms of resistance to carbapenems including loss of porins, efflux pump mutation, and target site inactivation have been identified. ${ }^{7}$ Figure 1 shows different genotypic and phenotypic methods for detection of resistance to carbapenems.

Data on the status of carbapenem-resistant microorganisms in the Middle East countries are scarce. The aims of this review were to collect available data regarding methods of detection and prevalence of resistance to carbapenems in a Middle East region.

\section{Methods}

\section{Databases}

Biomedical electronic databases (Scopus, Medline, Google Scholar, and Science Direct) were systematically searched to find related articles. The key terms used were "carbapenemresistant, resistant gram-negative bacilli, Enterobacteriaceae, fermenting and non-fermenting gram-negative bacilli, Pseudomonas, Acinetobacter, Klebsiella and Iran". A total of 586 articles were found. After primary screening, 275 relevant articles were selected to be assessed thoroughly.

\section{Study settings}

Of the 275 articles, case reports, systematic reviews, metaanalysis, and articles in Persian language were excluded, and finally 97 English-language articles were included in the present review. These studies were published between 2006 and 2018 and were reported from different regions of Iran. Forty-eight studies were from Tehran and most of them were done at Motahari hospital (Level I Iranian burn hospital). The number of publications from other areas were as follows: ten in Isfahan, eight in northwest of Iran, five in south of Iran, four in Shiraz, three each in Hamadan, Arak and Mazandaran, two each in Shahrekord, Kermanshah, Mashhad, and Zanjan, and one each in Kerman, Khorramabad, and Qom. All the studies considered the standards and guidelines of the clinical and laboratory standards institute (CLSI) for the preparation and interpretation of the tests. Figure 2 illustrates data processing in this review.

\section{Clinical and microbiological setting}

All the studies included inpatients, with eight also considering outpatients. If the source of the samples was specific, they

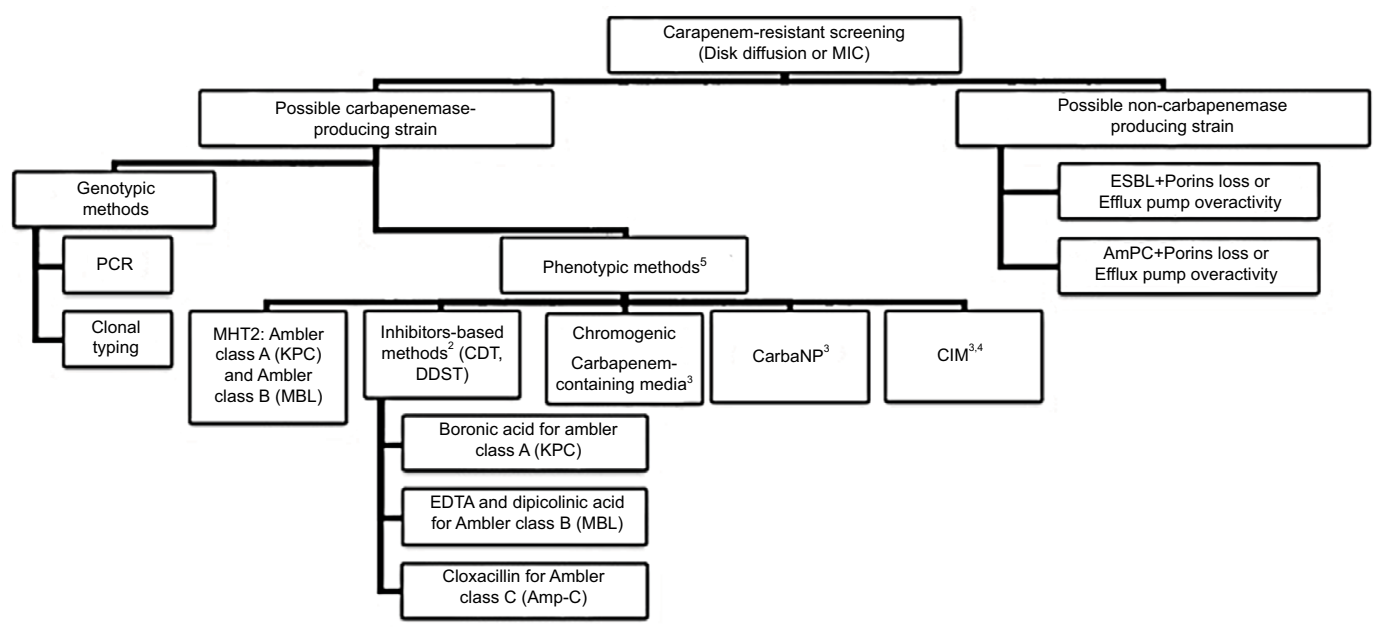

Figure I Screening methods for carbapenem-resistant microorganisms.

Notes: 'MHT was the most used phenotypic method in Iranian studies. MHT originally detects KPC, but if zinc sulfate is added to MHT culture media, it can detect MBL. ${ }^{2}$ It is based on carbapenemase inhibition by betalactamase inhibitors. CDT consists of two disks: a carbapenem and the other combination of a carbapenem and a betalactamase inhibitor. If the disk with inhibitor shows a bigger inhibition zone, the result is considered positive. DDST consists of carbapenem discs at a variable distance to inhibitor discs. The observation of synergy between disks is noted as a positive result. ${ }^{3}$ These phenotypic methods can detect different Ambler classes. ${ }^{4} \mathrm{CIM}$ is a newer phenotypic method that was introduced in 2015 by van der Zwaluw. A carbapenem disk is inserted in culture media of suspected strain. Then it is transferred to another culture media with known control strain. If the suspected strain contains carbapenemase enzyme, the carbapenem disk has been degraded and the control strain in second culture will grow. ${ }^{5}$ Some other phenotypic methods like spectrometric assays are also used and have higher sensitivity and specificity, but they are costly and time consuming.

Abbreviations: CDT, combination disk test; CIM, carbapenem inactivation method; DDST, double disk synergy test; ESBL, extended spectrum $\beta$-lactamase; KPC, Klebsiellaproducing carbapenemase; MBL, metallo- $\beta$-lactamase; MHT, modified Hodge test; MIC, minimum inhibitory concentration; PCR, polymerase chain reaction. 


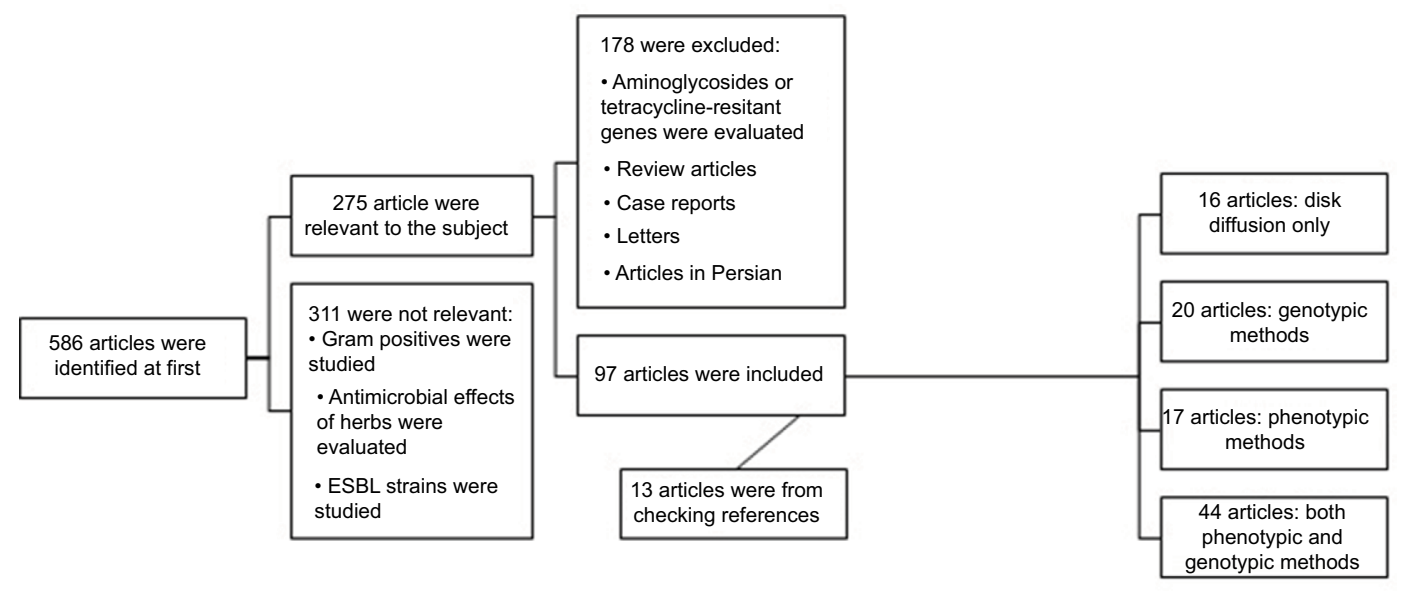

Figure 2 Consort flowchart of study.

Abbreviation: ESBL, extended spectrum $\beta$-lactamase.

are mentioned and if they were collected from different sites, they are named as "different sites".

All studies have been categorized into four distinct groups:

1. Studies that reported carbapenem-resistant microorganisms according to the disk diffusion method

2. Studies that considered phenotypic methods

3. Studies that used genotypic methods

4. Studies that applied both genotypic and phenotypic assays

\section{Results}

\section{Studies that reported carbapenem- resistant microorganisms according to the disk diffusion method (early detection of resistance to a carbapenem)}

In this category, detection of resistance to a carbapenem was described only by disk diffusion method. However, in some of them, minimum inhibitory concentration (MIC) values were determined. No phenotypic or genotypic assay was considered for carbapenemase detection. A total of 3,396 isolates were reported in this group (Table 1).

Screening of resistance to a carbapenem according to the disk diffusion method was common among the studies. ${ }^{8-23}$ Although this method may be applicable for many antimicrobials, however, for carbapenems more confirmatory tests beyond the disk diffusion assay are needed. In this setting, MIC would help for detection of resistant isolates.

Five studies were multicenter, ${ }^{8-12}$ but the sample sizes for three of them were small. ${ }^{10,13,14}$ The trend of resistance to a carbapenem did not follow a specific pattern. However, in two studies, ${ }^{12,15} 40 \%$ of the isolates were resistant to a carbapenem.

\section{Studies that considered phenotypic methods}

A total of 4,264 isolates were included in this category and Acinetobacter spp. and $K$. pneumonia were the common isolates. Modified Hodge test (MHT) was used as a common phenotypic test in most studies. MHT can detect Ambler class A (KPC), although it may be positive with the presence of other carbapenemase enzymes. Other applied tests were combination disk test (CDT) for detection of MBL or extended spectrum $\beta$-lactamase and the double disk synergy test for detection of MBL. In the study by Raategar Lari et al, ${ }^{24} 92 \%$ of $A$. baumannii isolates were resistant to imipenem and only $24 \%$ of them were MBL positive in the CDT test, but in the next study, ${ }^{25} 54 \%$ of isolates were resistant to imipenem and all of them were KPC producers according to the phenotypic tests.

The rates of resistance to aminoglycosides and fluoroquinolones were similar to those of carbapenems, although no special trend can be followed through different years. The results are provided in Table $2 .^{26-41}$

\section{Studies that included genotypic methods}

A total of 2,195 strains were included in this group and except for three studies, all assessed Acinetobacter spp. mostly $A$. baumannii. PCR was performed in order to determine types of bla genes. In some studies, MIC values were correlated with the presence of bla genes. In the study by Taherikalani et al the MIC values of $256 \mathrm{mcg} / \mathrm{mL}$ were detected in strains with more than two bla $a_{O X A}$ genes. ${ }^{42}$ In the study by Azizi et al, higher MIC value was associated with presence of blaOXA-24/40 like ${ }^{43}$ Bahador et al detected $I S_{A b a}$ genes. ${ }^{44}$ When these elements were placed upstream of OXA-type genes, they enhanced the expression of OXA-type genes. Presence of 


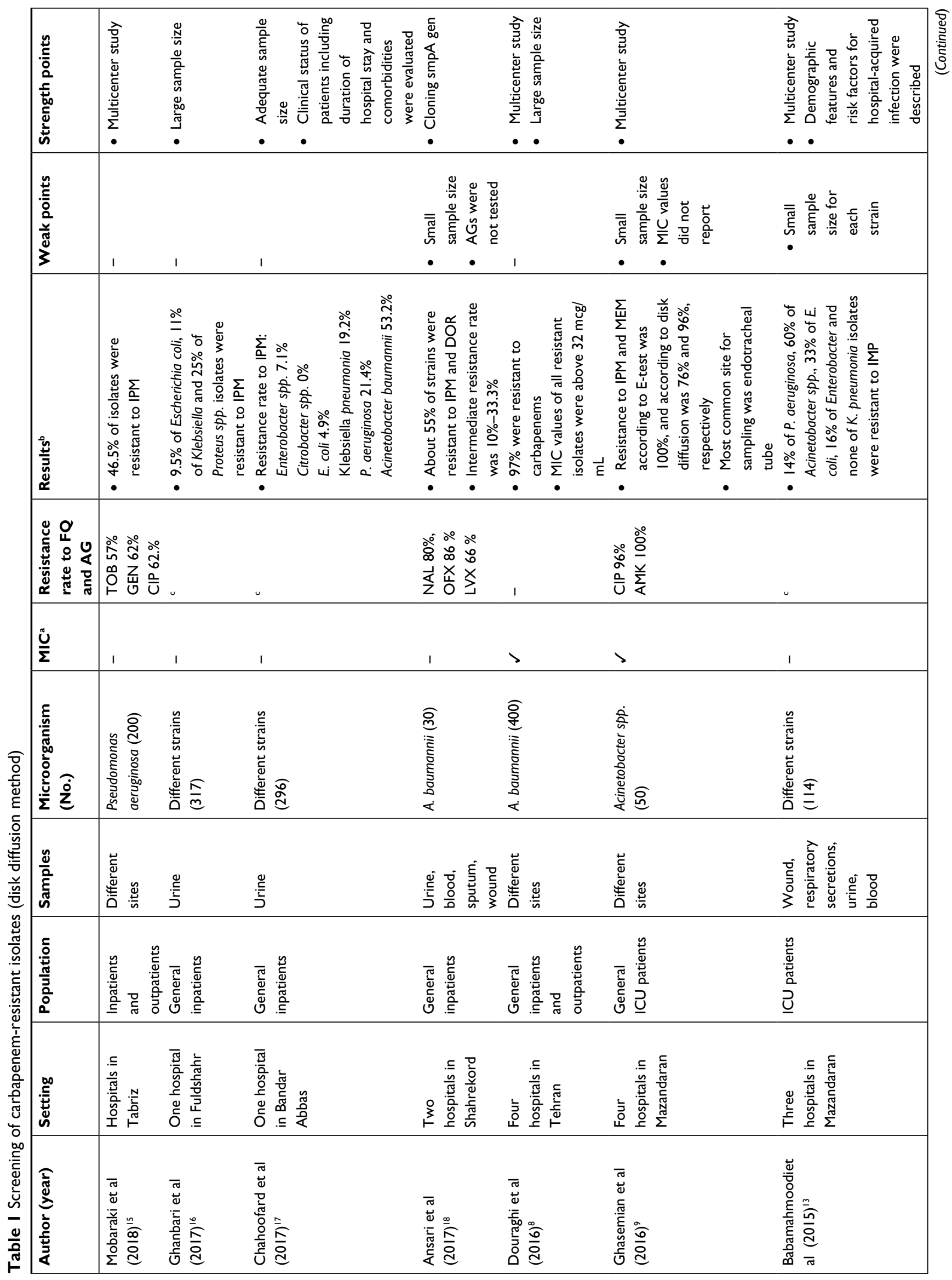




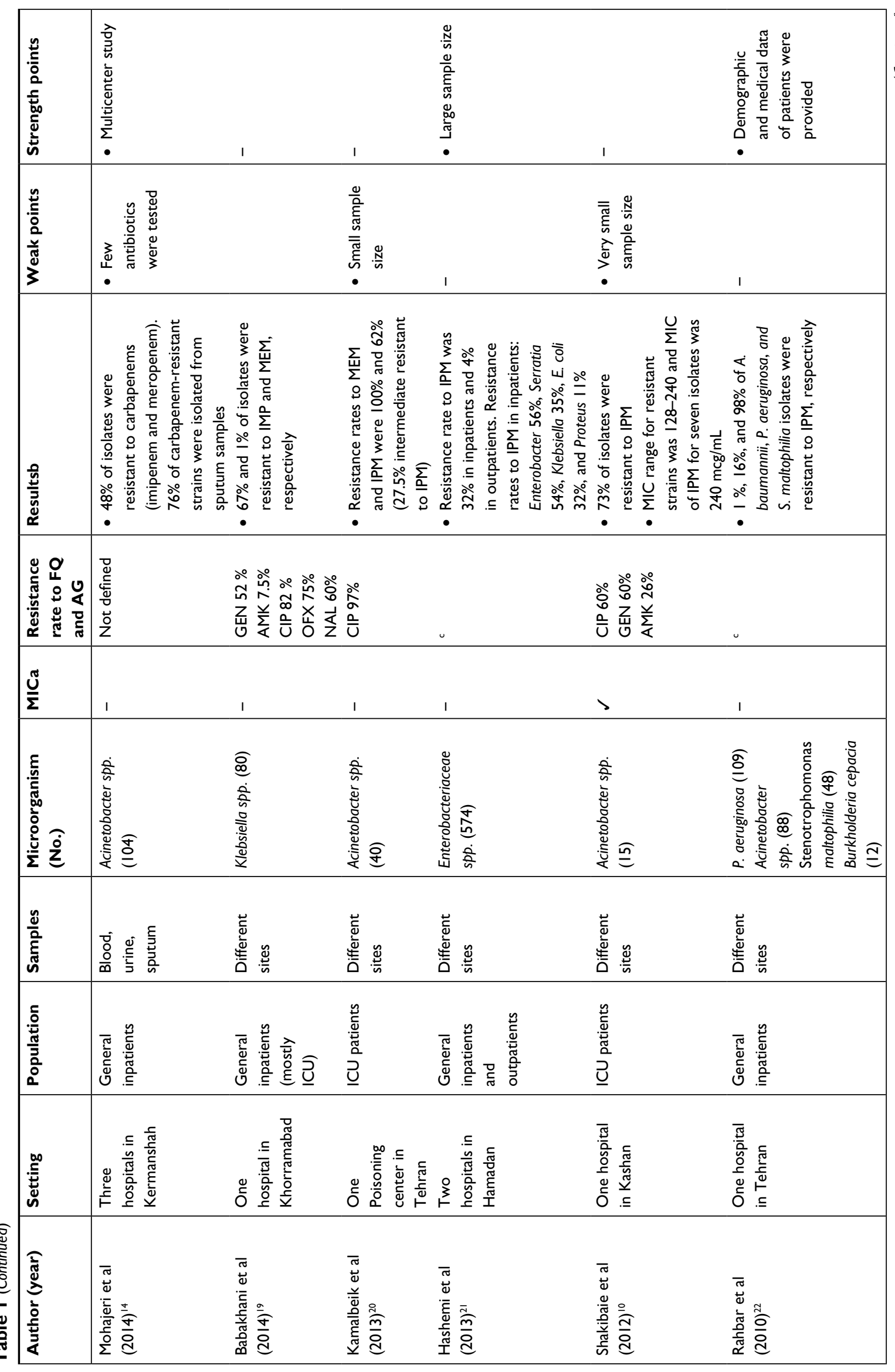




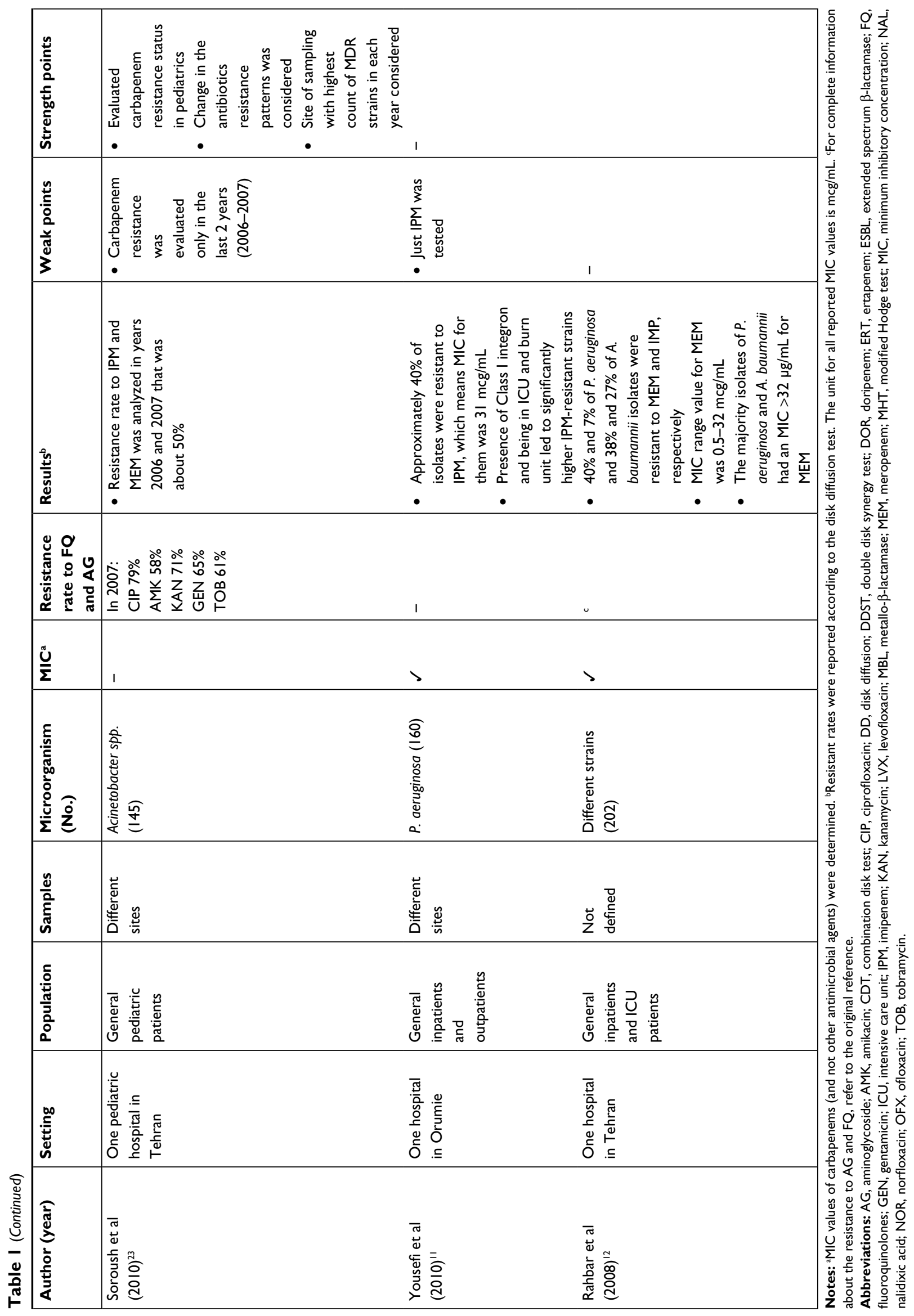




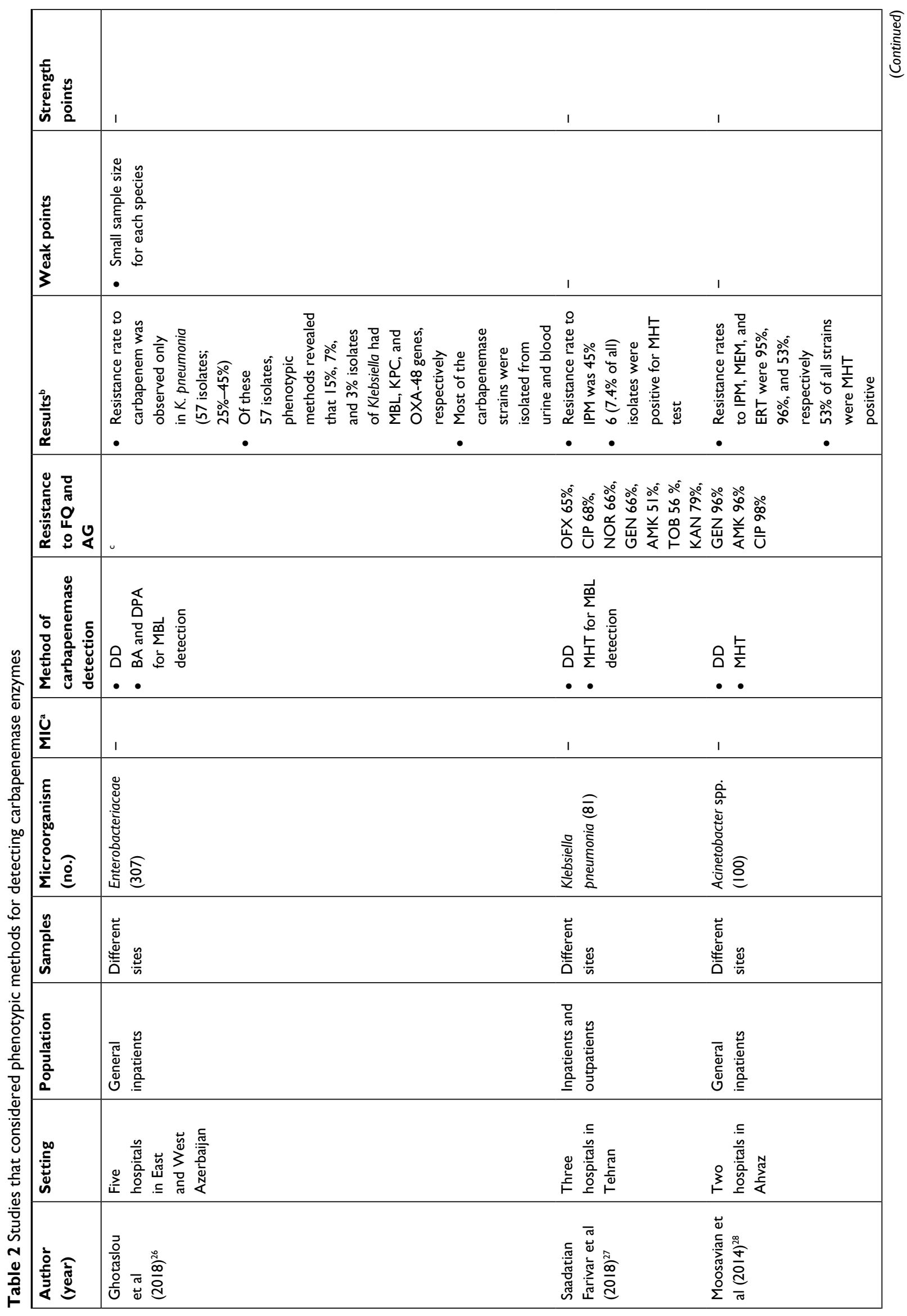




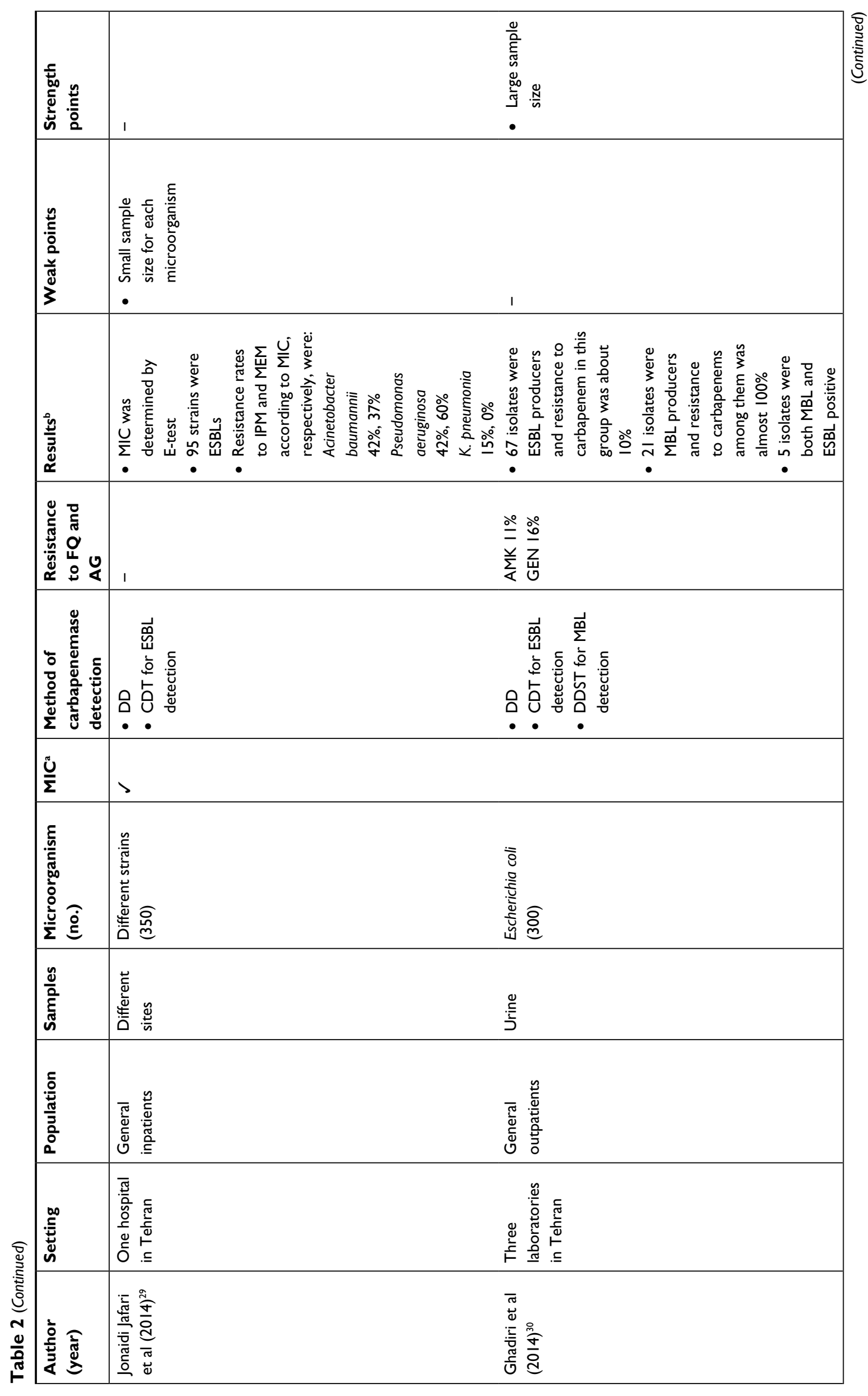




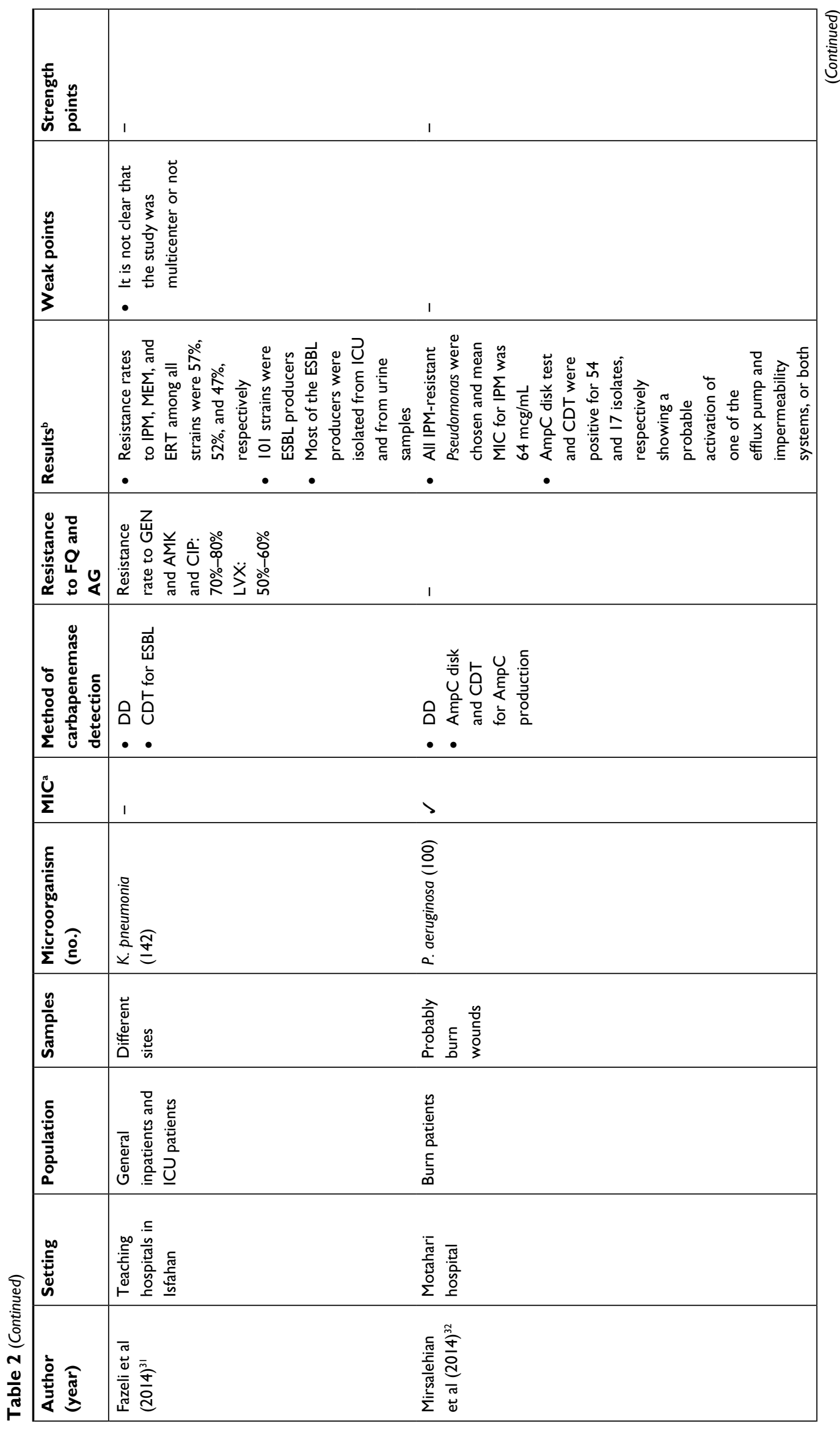




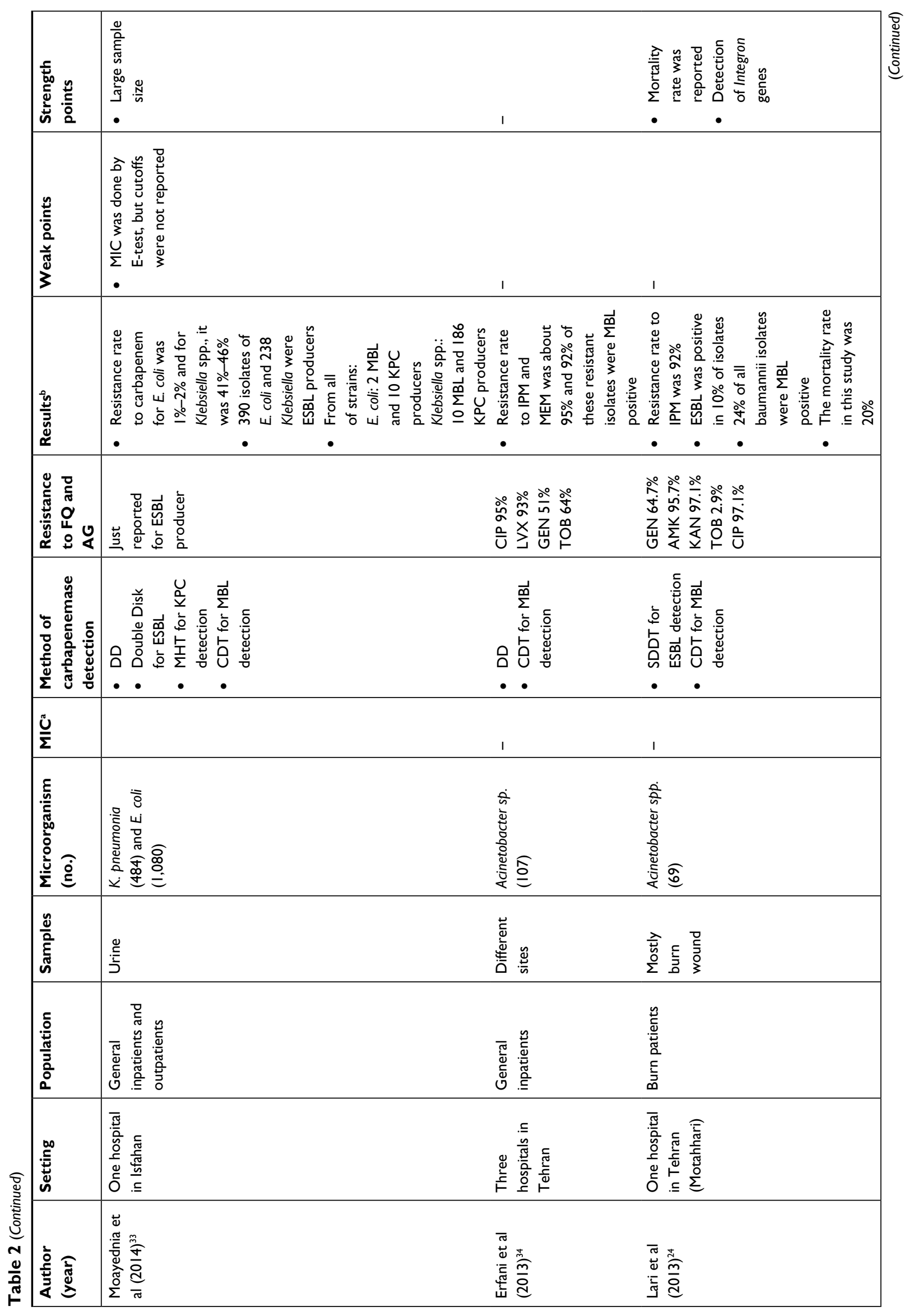




\begin{tabular}{|c|c|c|c|}
\hline 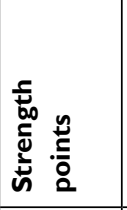 & 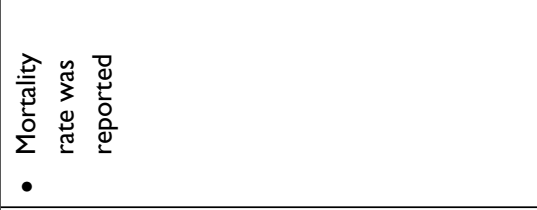 & 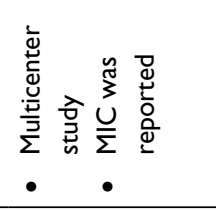 & 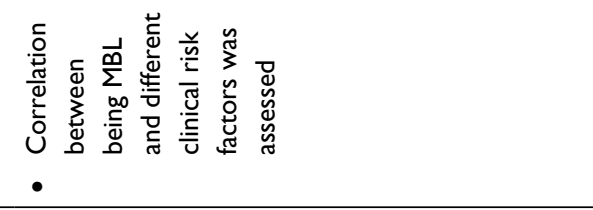 \\
\hline 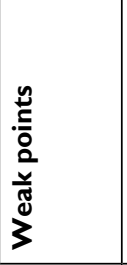 & 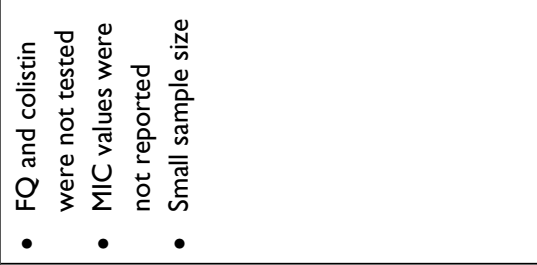 & - & 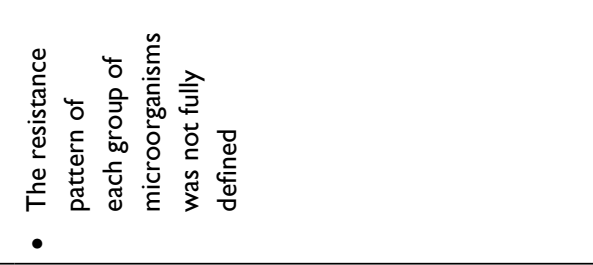 \\
\hline 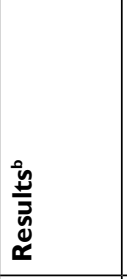 & 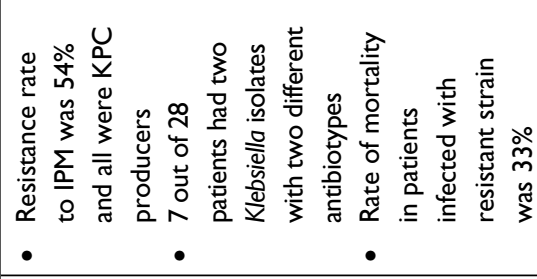 & 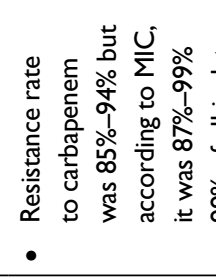 & 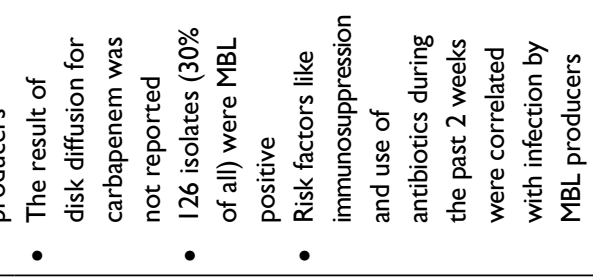 \\
\hline 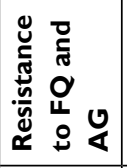 & 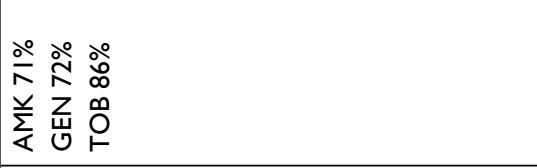 & 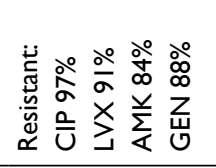 & 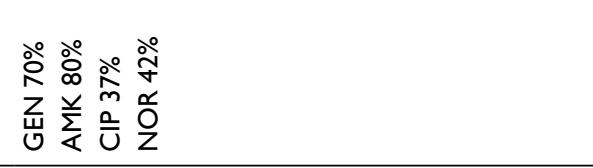 \\
\hline 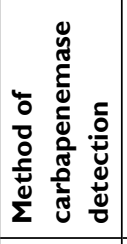 & 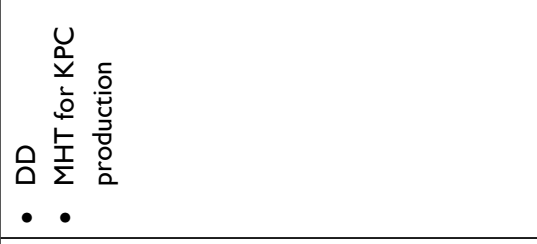 & 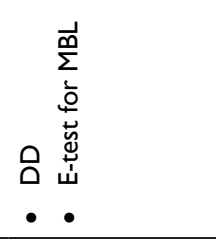 & 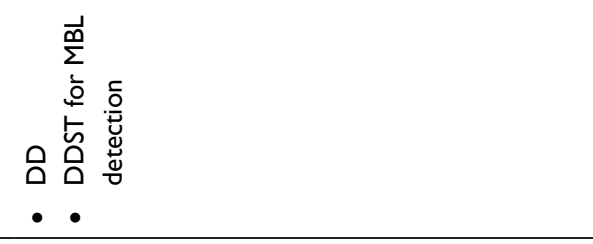 \\
\hline$\frac{\tilde{U}}{\Sigma}$ & 1 & $>$ & 1 \\
\hline 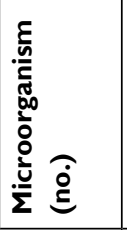 & 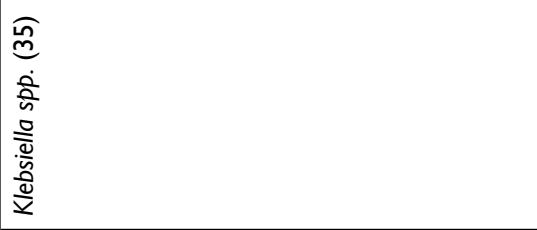 & 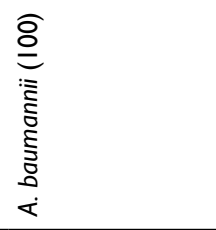 & 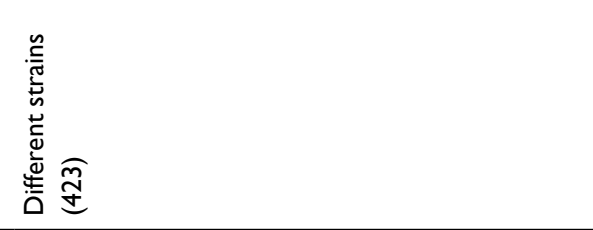 \\
\hline 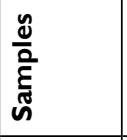 & 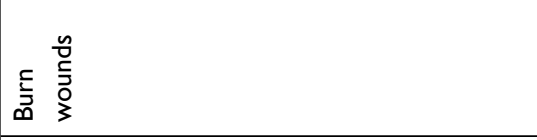 & 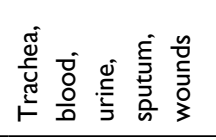 & 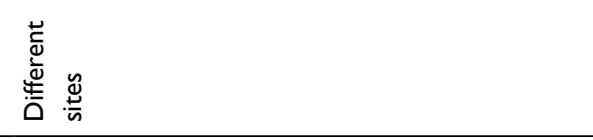 \\
\hline $\begin{array}{l}\frac{2}{2} \\
\frac{0}{7} \\
\frac{\partial}{2} \\
0 \\
0\end{array}$ & 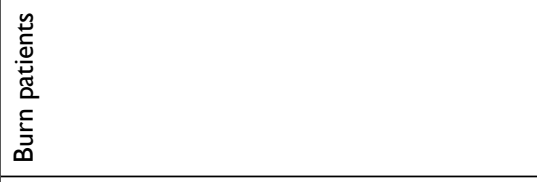 & 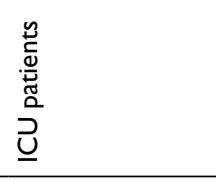 & 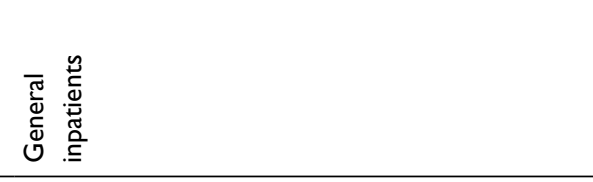 \\
\hline 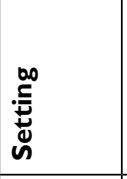 & 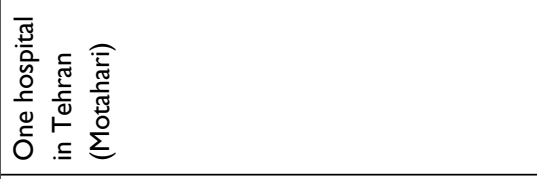 & 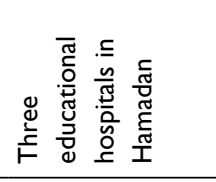 & 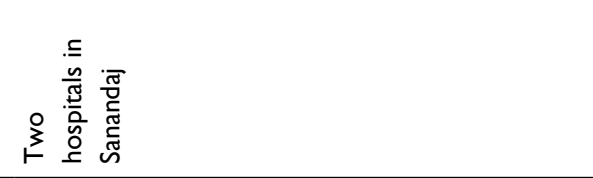 \\
\hline 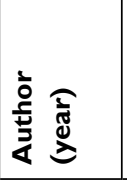 & 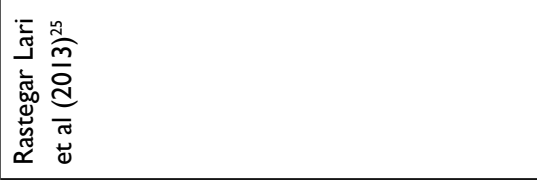 & 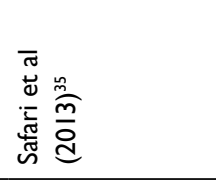 & 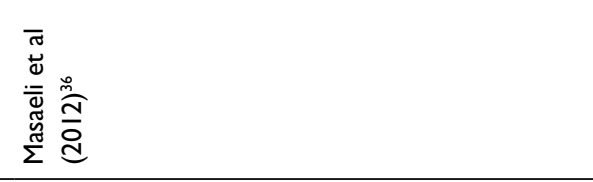 \\
\hline
\end{tabular}




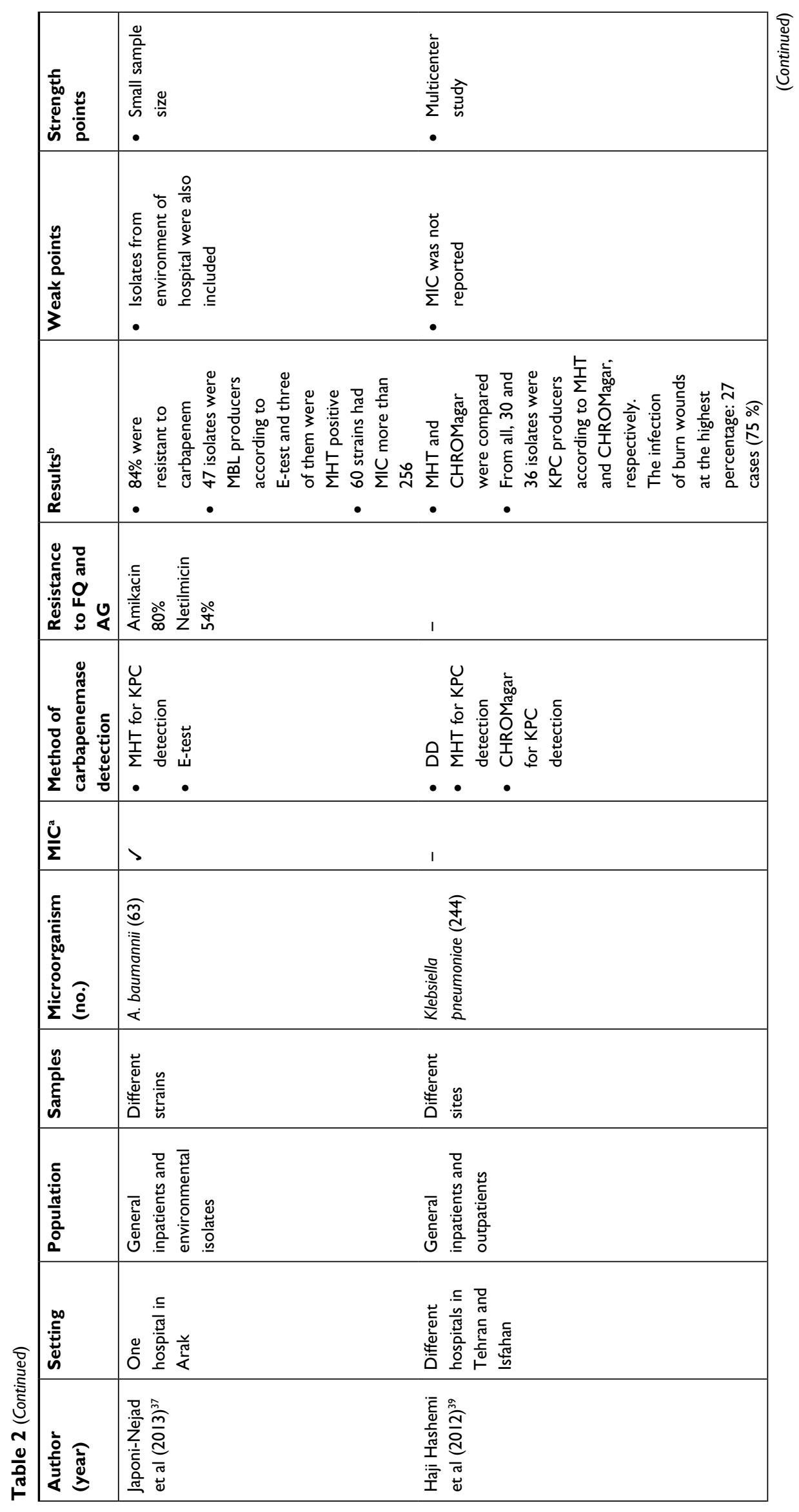




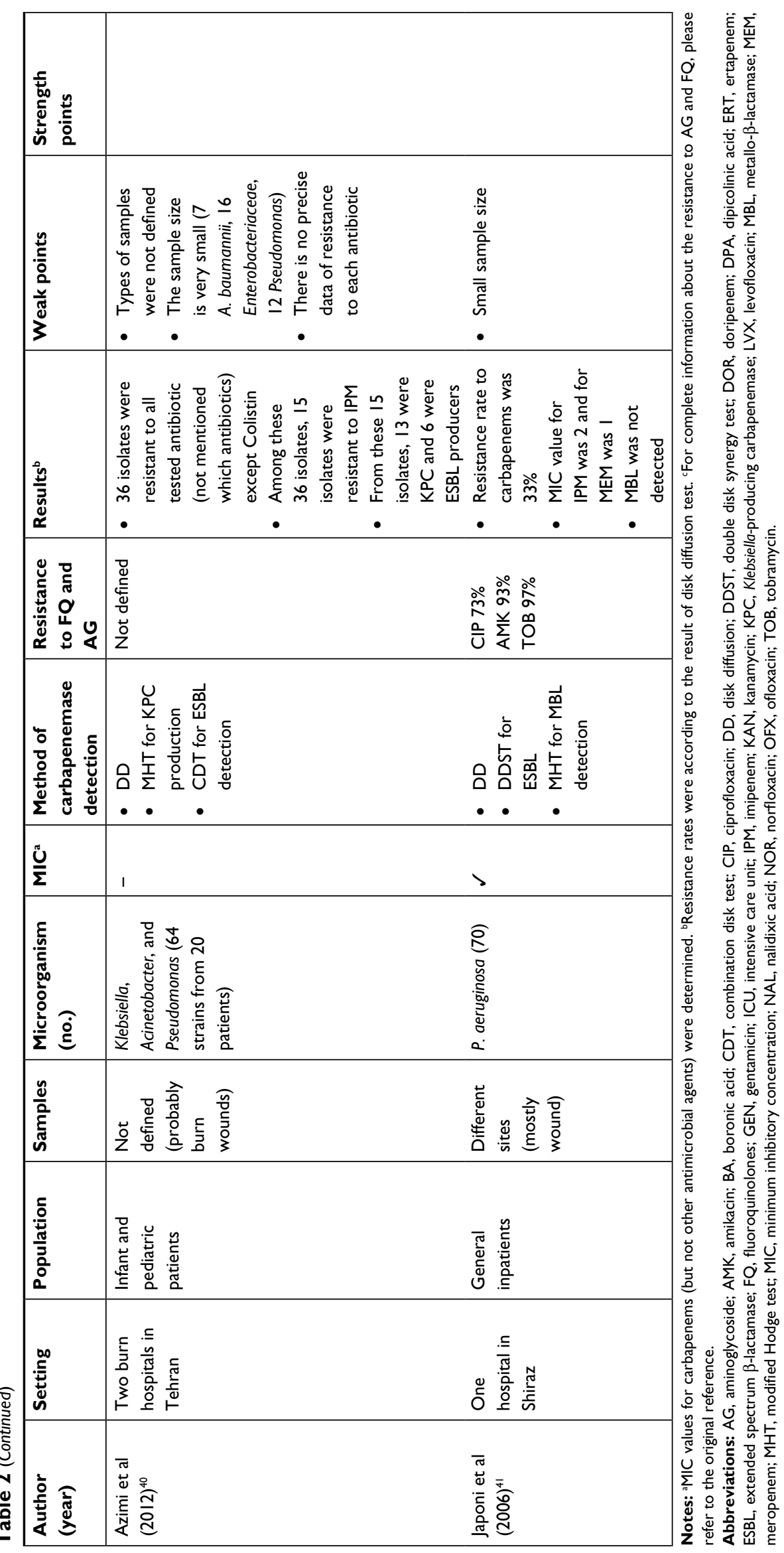


these elements in genetic contents of gram-negative isolates would lead to higher rate of resistance to carbapenems. Table 3 describes the details of each study in this category. ${ }^{42,45-61}$

\section{Studies that considered both phenotypic and genotypic methods}

A total of 6,759 isolates were identified in this category. In most studies more than one phenotypic method was applied. In the study by Hosseinzadeh et al, 29 strains were carbapenem resistant, in which 27 and 23 of them were MHT positive and carried $b l a_{N D M-1}$ gene, respectively. ${ }^{62}$ However, in another study by Bina et al, although MHT tests were positive, no resistance gene was found. ${ }^{63}$

The detection of resistance genes was much lower for strains other than A. baumannii. In the study by Lari et al in 2015, only 9 strains of $P$. aeruginosa (out of 255) contained resistance genes, ${ }^{64}$ but in the study by Bagheri Josheghani et al, at the same time, more than 90 strains (out of 124) of $A$. baumannii harbored resistance genes. ${ }^{65}$ Data are summarized in Table $4 .{ }^{66-105}$

\section{Discussion}

Increase in the rate of resistance to carbapenem antibiotics among gram-negative isolates is a worldwide concern, especially in developing countries. The results of this review also showed this threat in the recent decade in a country of Middle East area, Iran. Although the prevalence of carbapenemresistant gram-negative rods was reported according to the disk diffusion method in most studies, phenotypic and genotypic assays confirmed this pattern in some available surveys.

Resistance to carbapenem antibiotics in the same years in a country of neighborhood, Saudi Arabia, shows lower resistance rate in comparison with Iran. ${ }^{106}$ In 2010, resistance to carbapenems was reported in $10 \%-66 \%$ of gram-negative isolates in Saudi Arabia, which was lower than that in Iran $(86 \%) .{ }^{11}$ The results were different in Europe. In the year 2006-2007, 4\% and 85\% of gram-negative isolates were carbapenem resistant in North and South of Europe, respectively. Although data were limited to year 2006, Iran had a better condition compared with the South of Europe, but worse than North of Europe. ${ }^{107}$ The results of another study in year 2012 also confirmed this pattern in North and South of Europe. ${ }^{108}$ In case of $P$. aeruginosa, MIC values that were reported for carbapenem-resistant strains were dramatically different from European countries. In year 2011, Castanheira et al detected a mean $\mathrm{MIC}$ value $>2 \mathrm{mcg} / \mathrm{mL}$ for carbapenem-resistant $P$. aeruginosa in 14 European countries. ${ }^{109}$ Yousefi et al in Iran reported an $\mathrm{MIC}>32 \mathrm{mcg} / \mathrm{mL}$ for most of carbapenem- resistant $P$. aeruginosa isolates. At these times, the CLSI and European Committee on Antimicrobial Susceptibility Testing cutoff values for carbapenem resistance were 2 and $8 \mathrm{mcg} / \mathrm{mL}$, respectively. ${ }^{11}$

Incremental trend of resistance to carbapenem antibiotics was evident through 2006-2018. The least resistance rate was reported by Rahbar et al in year 2010 at Milad Hospital. In this year, $1.1 \%$ of $A$. baumannii isolates were resistant to imipenem. ${ }^{22}$ This conclusion may be misleading, because 2 years earlier (in 2008), in this hospital, $27 \%$ and $40 \%$ of the same isolates were resistant to imipenem and meropenem, respectively. ${ }^{12}$ Tarashi et al assessed the trend of antibiotic resistance in A. baumannii through years $2012-2015 .^{71}$ The results showed that resistance in $P$. aeruginosa increased from $83 \%$ in year 2012 to $96 \%$ in year 2015 . Also $100 \%$ of $A$. baumannii were resistant to carbapenem among these years.

The resistance patterns for other microorganisms did not follow specific trends. For example, $60 \%$ of $P$. aeruginosa isolates were imipenem resistant in the year $2010,{ }^{101}$ but this rate was $25 \%$ in another hospital in the year $2016 .{ }^{69}$ Outpatients-isolated $P$. aeruginosa strains showed less resistance rates (13\% in Ahangarzadeh Rezaee et $\mathrm{al}^{38}$ and $4.4 \%$ in Hashemi et $\mathrm{al}^{21}$ ). However, carbapenem-resistant rates were dramatically high in studies that included ICU samples. ${ }^{9,20}$ In an earlier study, ${ }^{9} 100 \%$ and $62 \%$ of $P$. aeruginosa isolates were resistant to imipenem and meropenem, respectively, and in a latter study, ${ }^{20}$ about $100 \%$ of them were resistant to both carbapenems.

Most of the carbapenem-resistant microorganisms were isolated from burned patients, and many studies placed in this group were from Motahari Hospital. Motahari is a referral teaching burn hospital in center of Iran and most complicated burned patients are referred from all areas of the country. Increasing resistance rates can be observed through different years in burn patients; $50 \%-60 \%$ in year 2008 to $90 \%$ in year $2017 .{ }^{42,46} \mathrm{Also}$, the presence of bla ${ }_{\text {OXA }}$ type genes has increased from half of the resistant strains to almost $80 \%$ of them. This can be a warning alarm regarding administration of antibiotics in burned patients.

Disk diffusion is the initial method for detection of resistant strains; however, it does not have enough accuracy for antimicrobial agents like carbapenem. Most evaluated studies considered disk diffusion method. Beside disk diffusion, MIC breakpoints can be used to confirm the results of disk diffusion (Figure 3).

Although MHT has been widely used as the preferred phenotypic method for detection of MBL, it is not recommended in latest version of CLSI, due to its low sensitiv- 


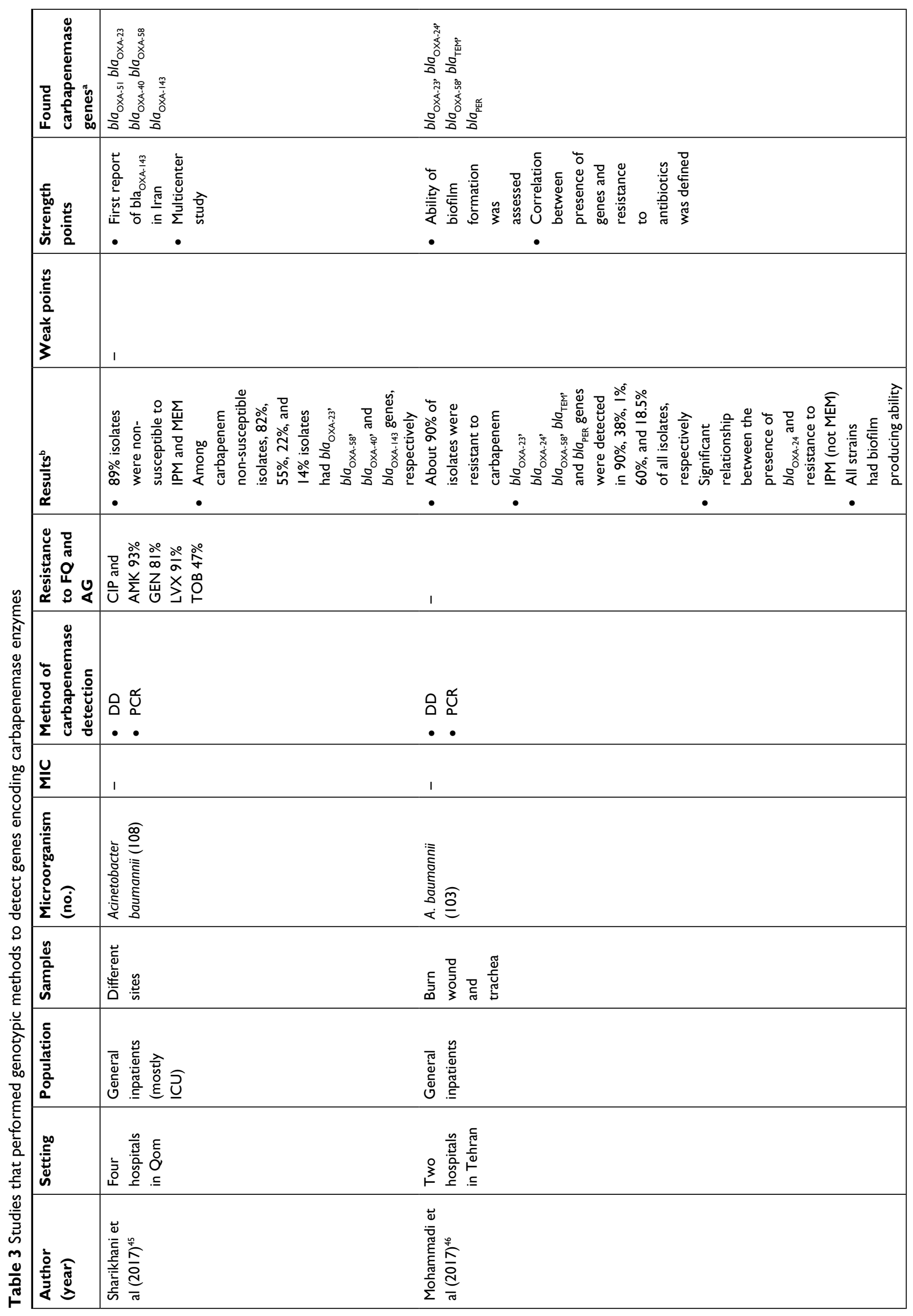




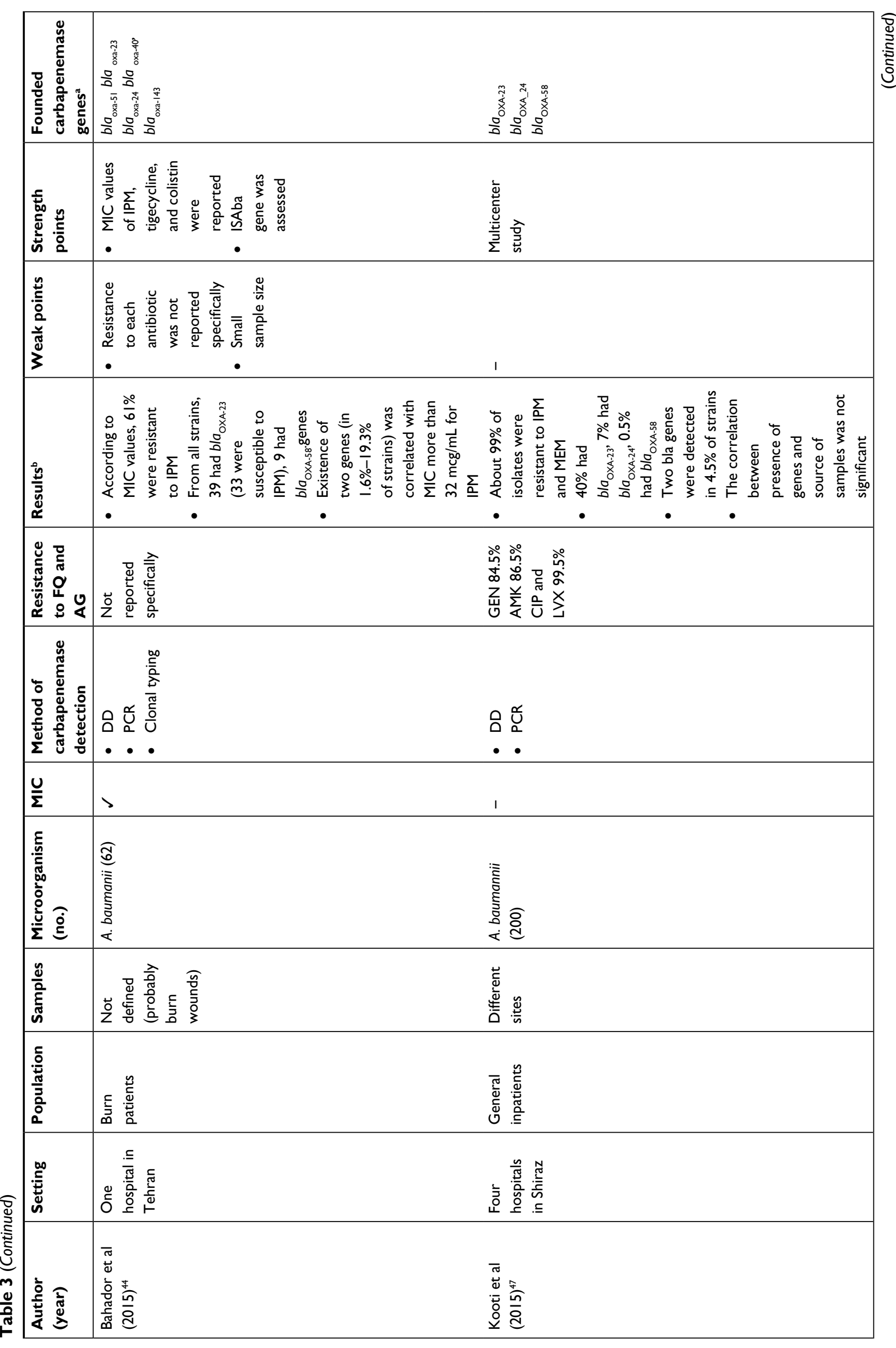




\begin{tabular}{|c|c|}
\hline 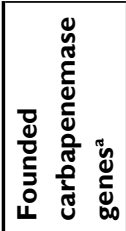 & 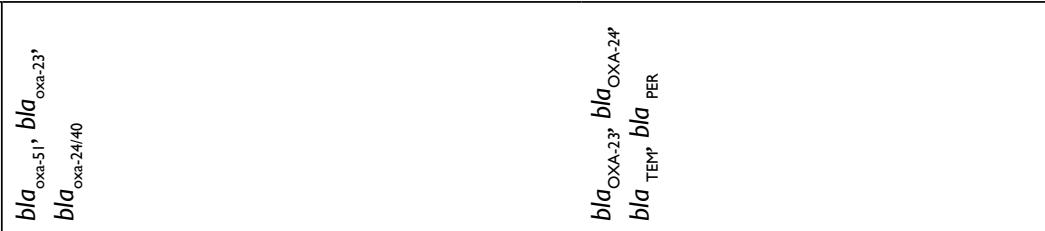 \\
\hline 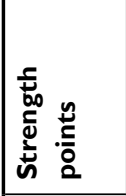 & 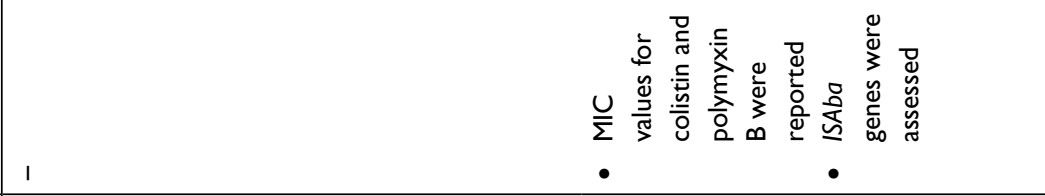 \\
\hline 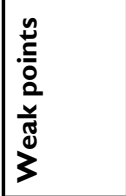 & 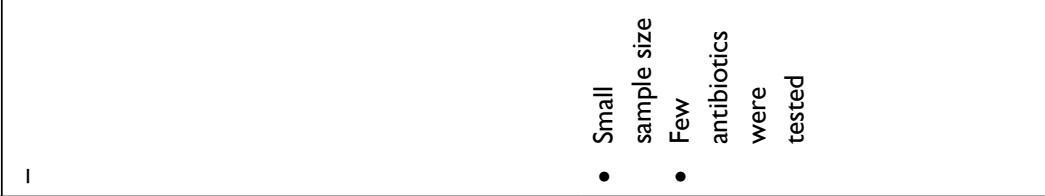 \\
\hline & 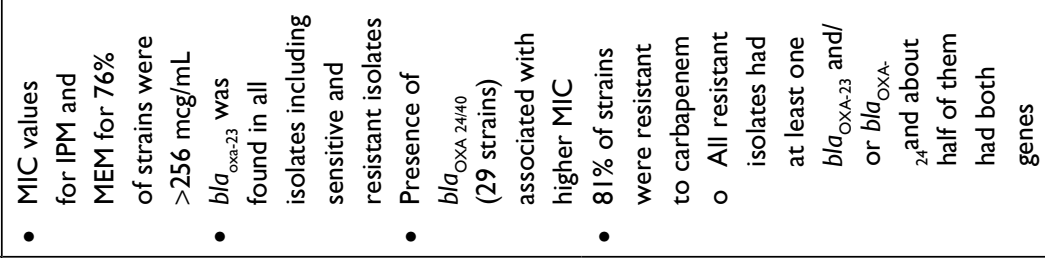 \\
\hline 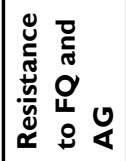 & 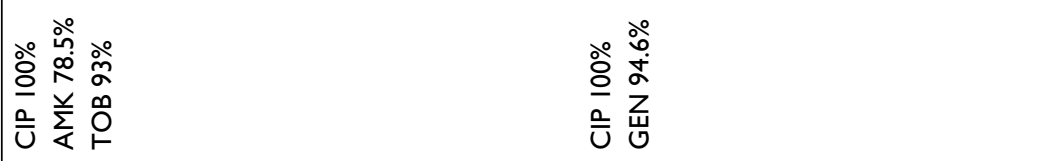 \\
\hline 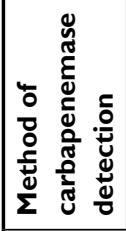 & 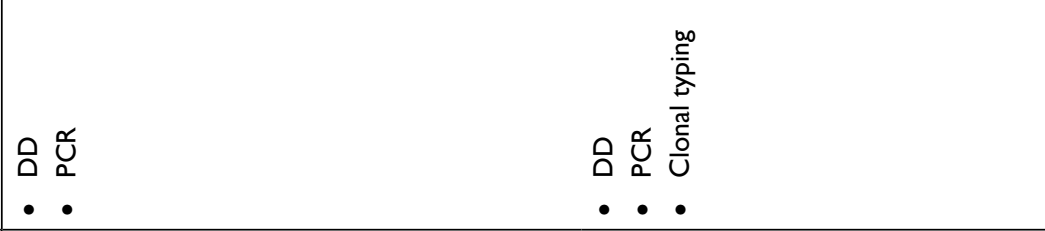 \\
\hline$\frac{u}{\Sigma}$ & $>$ \\
\hline 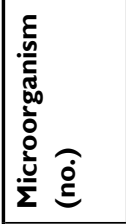 & 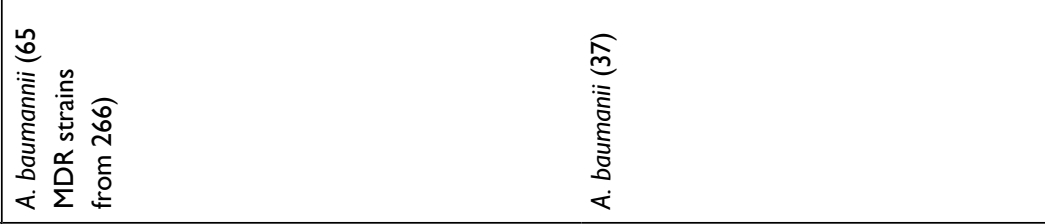 \\
\hline $\begin{array}{l}\frac{\tilde{\omega}}{a} \\
\frac{\tilde{c}}{\tilde{n}} \\
\tilde{n}\end{array}$ & 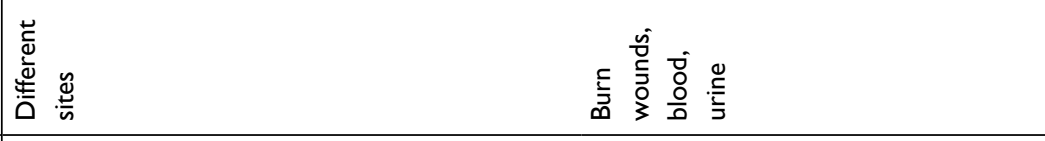 \\
\hline 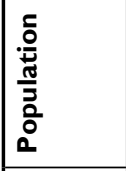 & 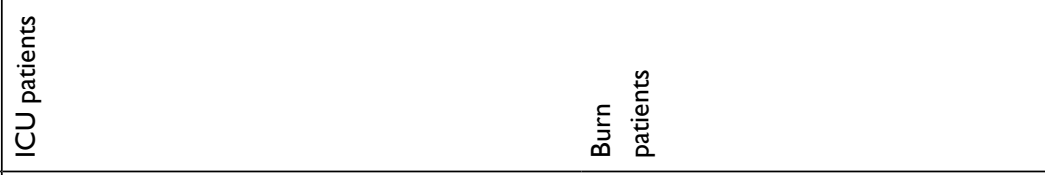 \\
\hline 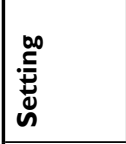 & 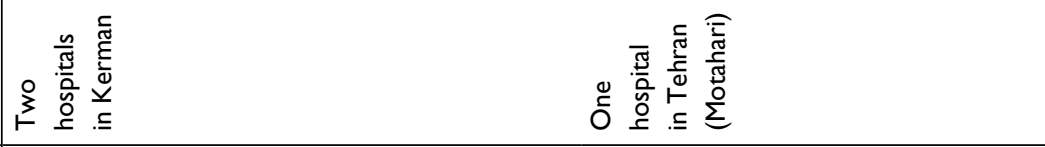 \\
\hline 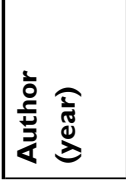 & 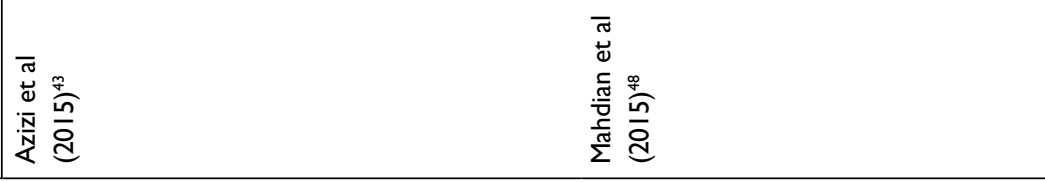 \\
\hline
\end{tabular}




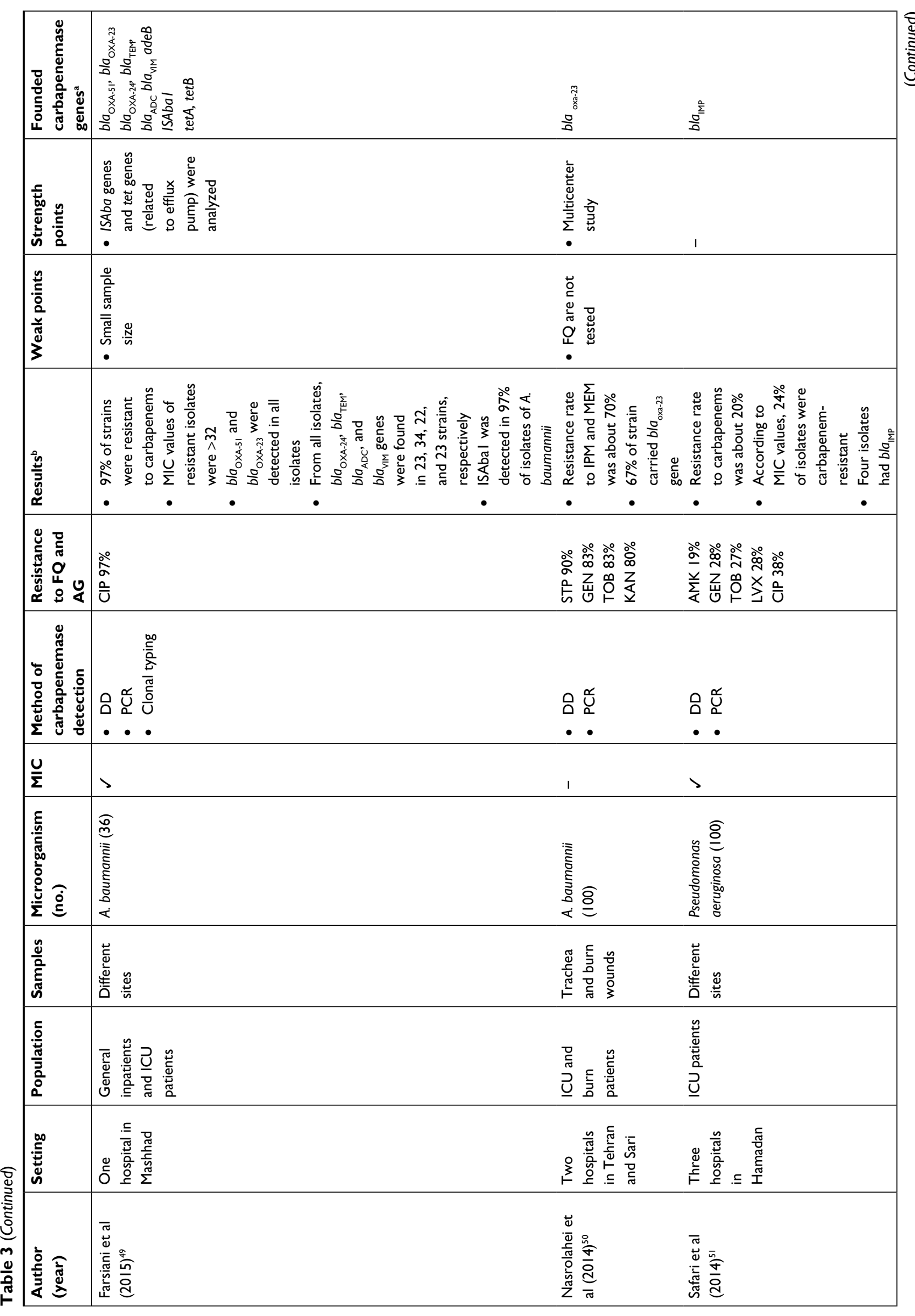




\begin{tabular}{|c|c|}
\hline 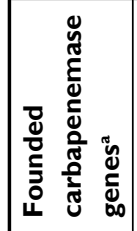 & 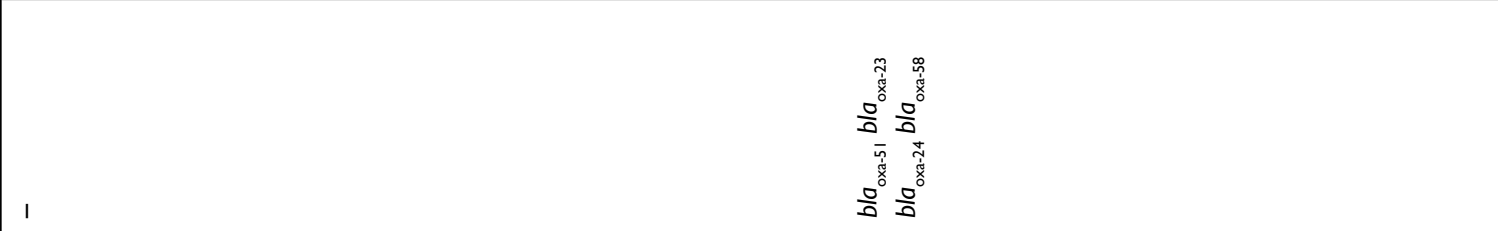 \\
\hline 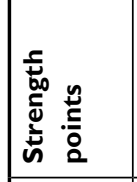 & 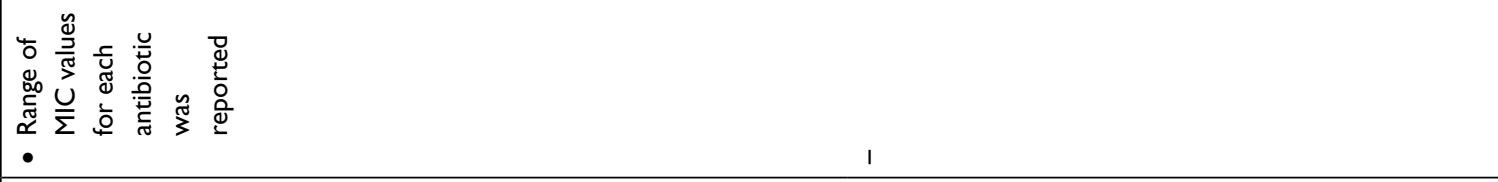 \\
\hline 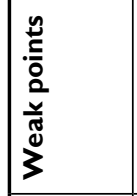 & 1 \\
\hline 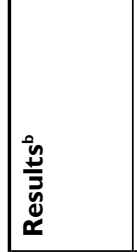 & 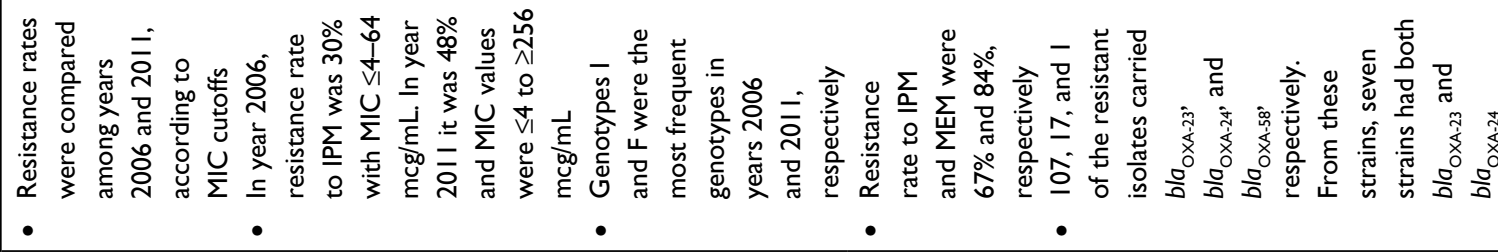 \\
\hline 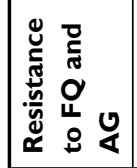 & 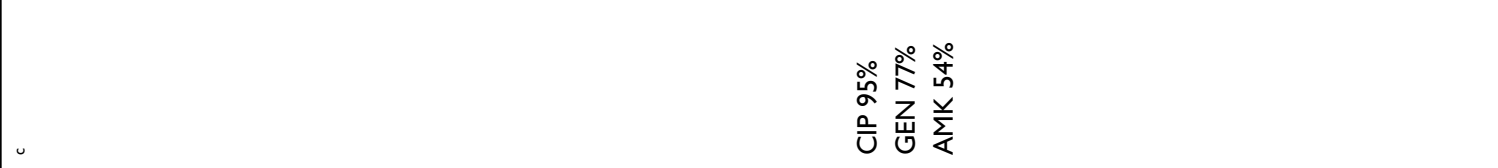 \\
\hline 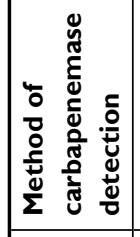 & 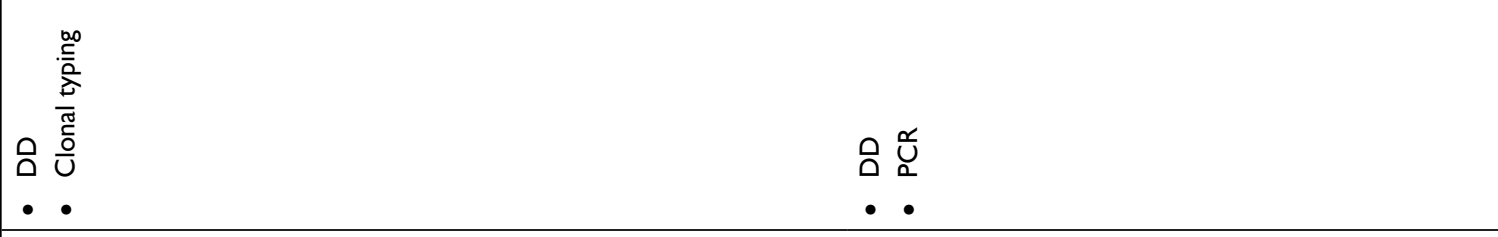 \\
\hline$\frac{U}{\Sigma}$ & $>$ \\
\hline 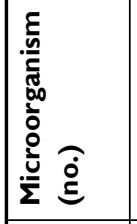 & 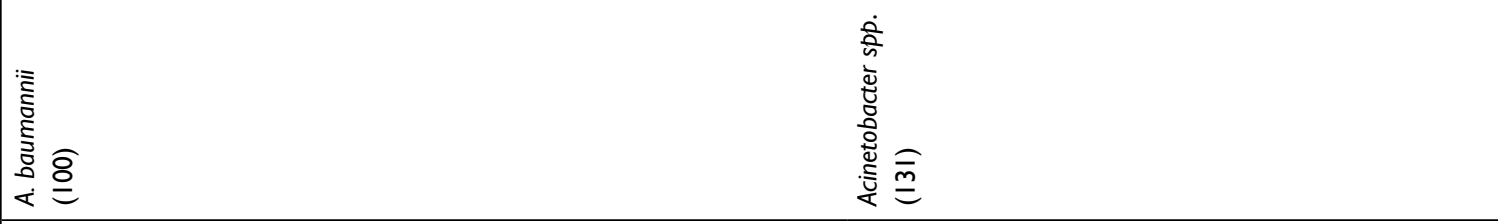 \\
\hline 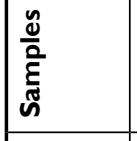 & 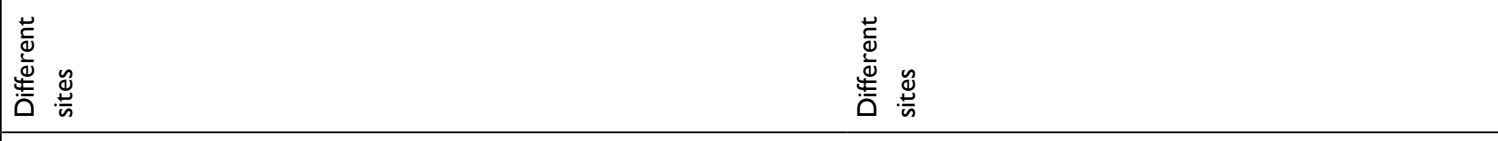 \\
\hline 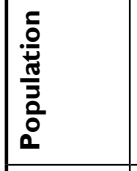 & 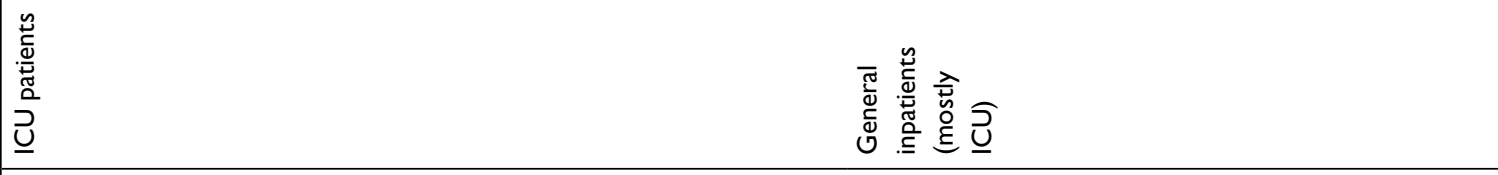 \\
\hline 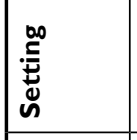 & 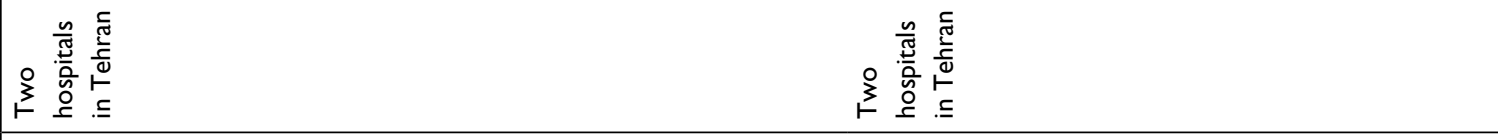 \\
\hline 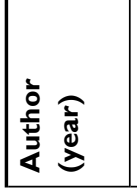 & 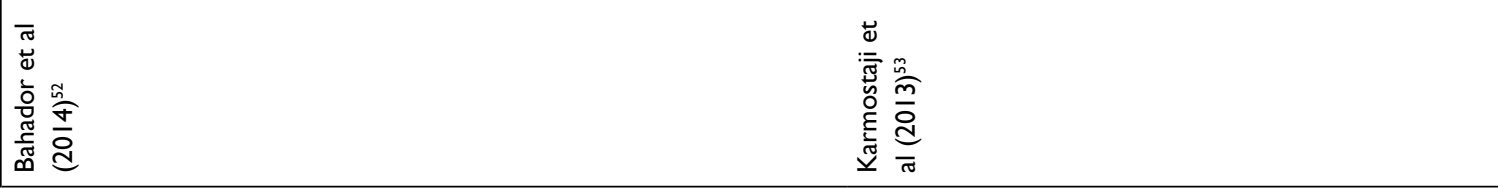 \\
\hline
\end{tabular}




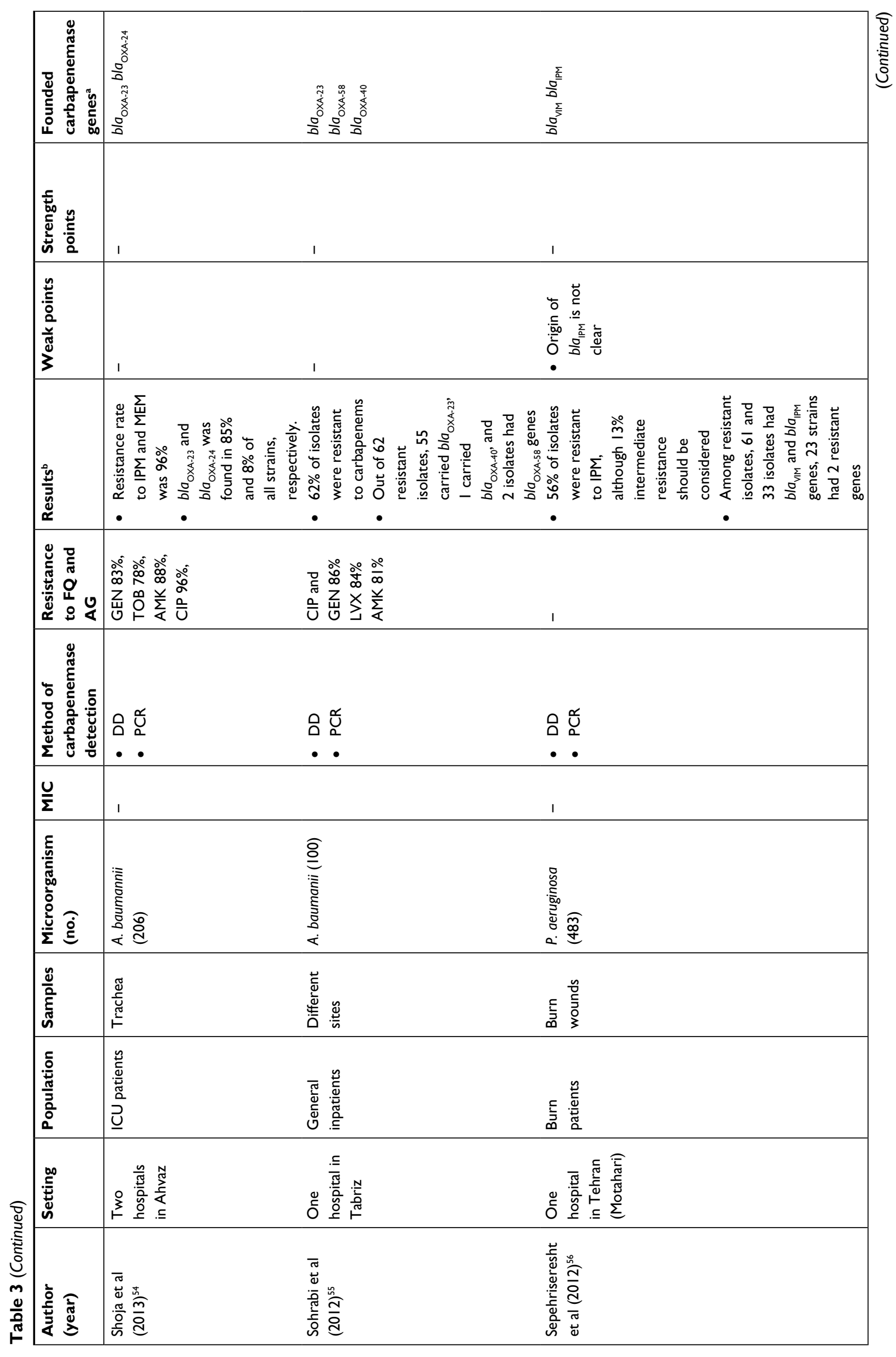




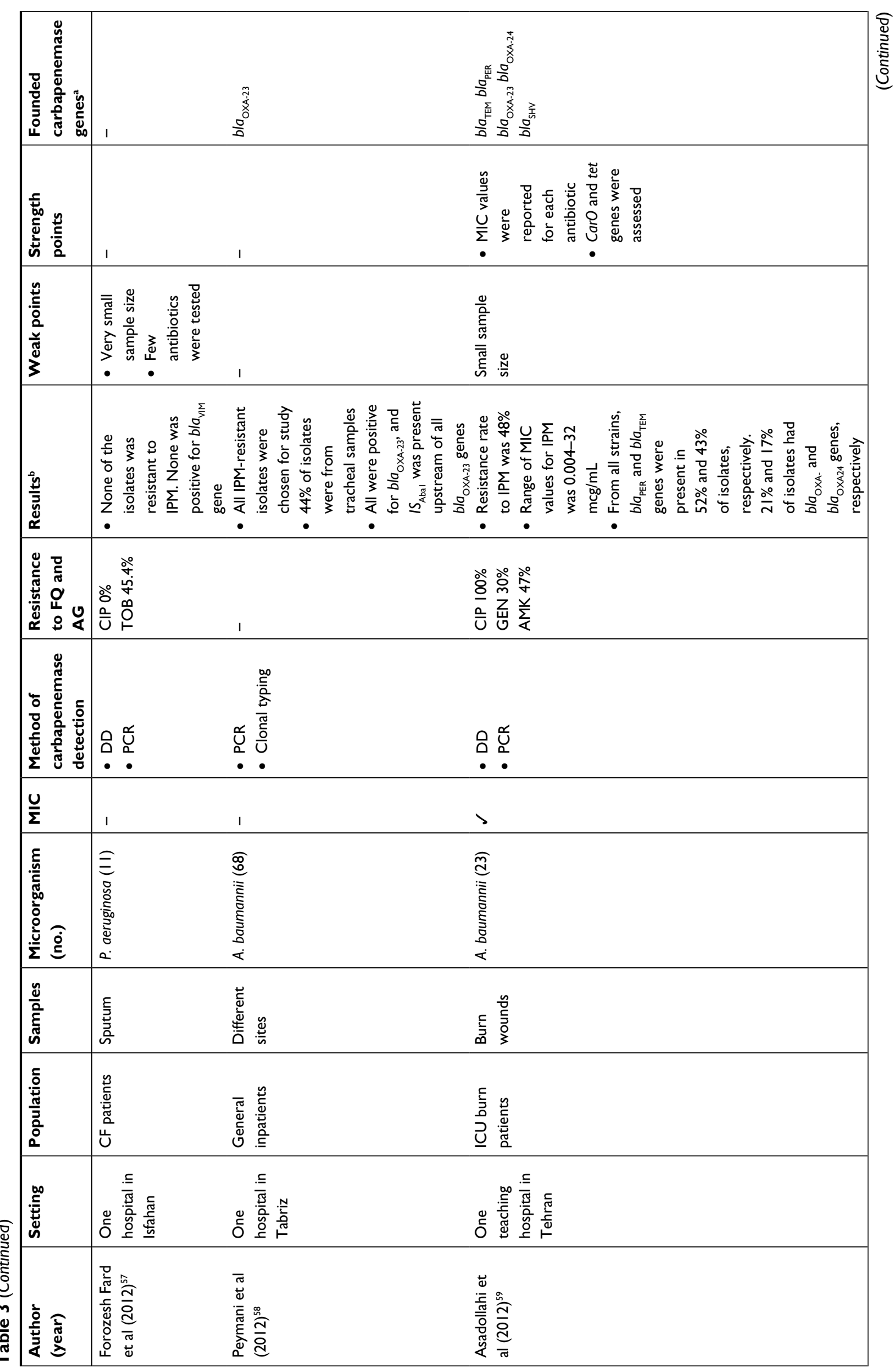




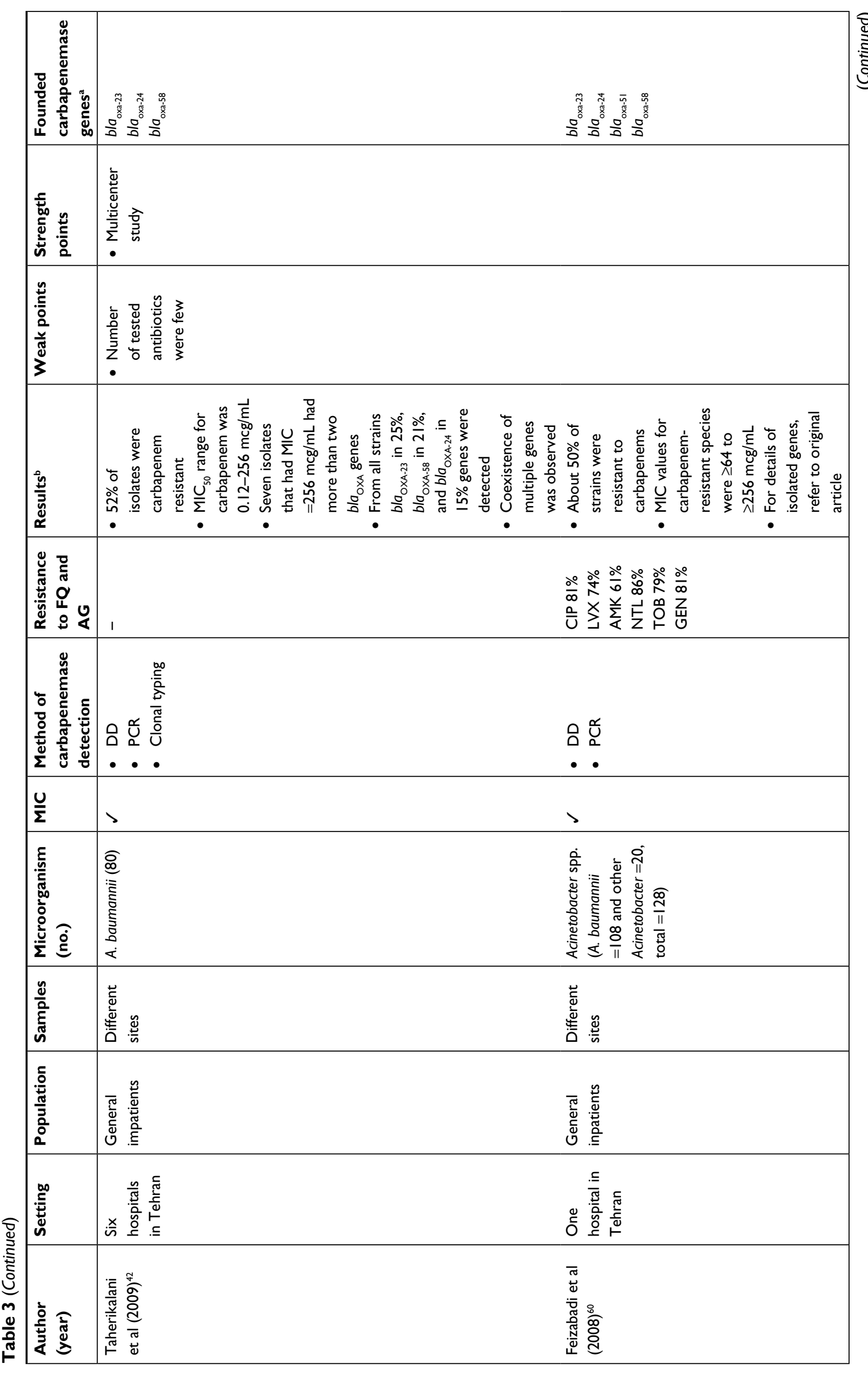




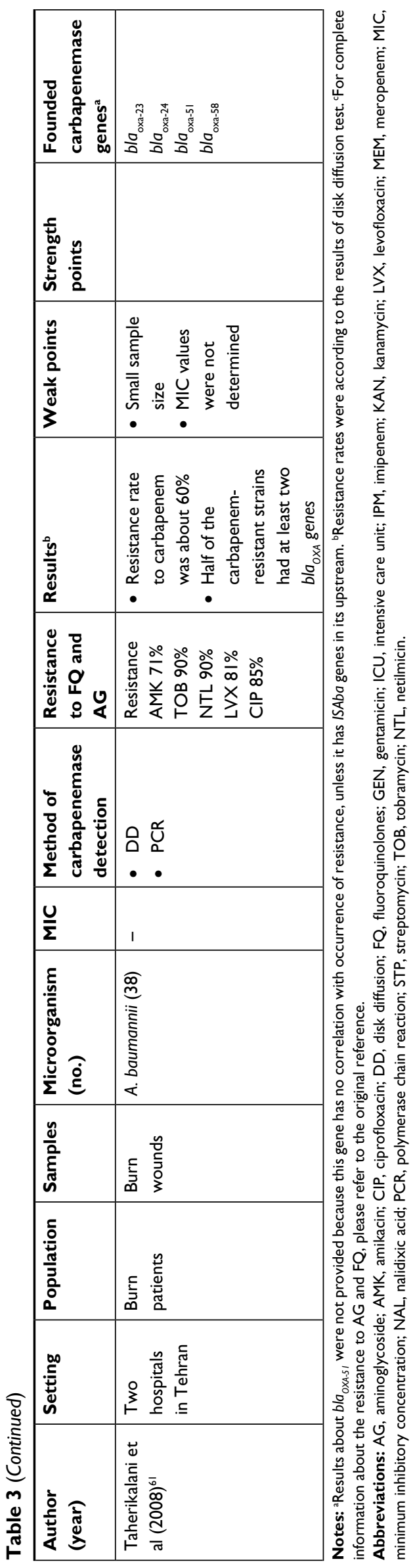

ity. ${ }^{110}$ In CLSI 2018, CarbaNP method is recommended instead. Kuchibiro et al compared some phenotypic methods and MHT and showed an acceptable specificity (100\%), but the sensitivity was very low (50\%). Another test, modified carbapenems inactivation method, has acceptable sensitivity and specificity values (both above 99\%) and does not require specific equipment. This method, beside CarbaNP, can be recommended for phenotypic detection of carbapenemase. ${ }^{111}$

Findings according to the phenotypic and genotypic methods were inconsistent. For example, in the study by Bina et al, ${ }^{63}$ although all strains were MHT positive, none of them carry $b l a_{K P C}$ gene. This may be due to low sensitivity of MHT in detecting carbapenemase enzyme.

The genotypic assays were mostly applied on central regions of Iran. However, there are no data regarding carbapenemase-encoding genes in most provinces. This may be due to technical and economic restrictions in these areas (Figure 4).

The presence of some bla $a_{\text {OXA-type }}$ genes were not necessarily associated to carbapenem-resistant. For example, $b l a_{O X A-5 I}$ in A. baumannii did not contribute to carbapenem resistance at all. In the study by Azizi et al, it was shown that $b l a_{O X A-23}$ may be found in both imipenem-sensitive and imipenem-resistant isolates. ${ }^{43}$ Also, in the study by Bahador et al, bla ${ }_{O X A-23}$ was found in both susceptible and nonsusceptible strains. ${ }^{44}$ However, higher carbapenem resistance in isolates harboring $b l a_{O X A-23}$ was reported (Shoja et $\mathrm{al}^{54}$ ). Table 5 shows the number of genes that were found in each city and related microorganisms.

Emergence of some genes including $b l a_{N D M-1}$ is a serious global warning. This gene is highly transmissible and was first discovered in a Swedish patient who had traveled to Pakistan. Although almost all identified cases were originally from Pakistan and India, the first case of bla $_{N D M-1}$ that was reported in Iran in the year 2012, did not have a history of traveling to these countries. In two studies from Shiraz and Isfahan, 27 and 6 strains of K. pneumonia harbored bla ${ }_{N D M}$ in years 2015 and 2017, respectively. ${ }^{62,78}$

Genotypic methods to identify other mechanisms of resistance to carbapenems have recently been considered by researchers. OmpK and carO genes that regulate expression of mutated efflux pump were detected in Hashemi et al and Pajand et al studies, respectively. ${ }^{83,93}$ In another study, efflux pump's activity and mutations in porins were investigated. ${ }^{112}$ These results can expand the view about true mechanisms of resistance to carbapenems in developing countries. 
Davoudi-Monfared and Khalili

Dovepress

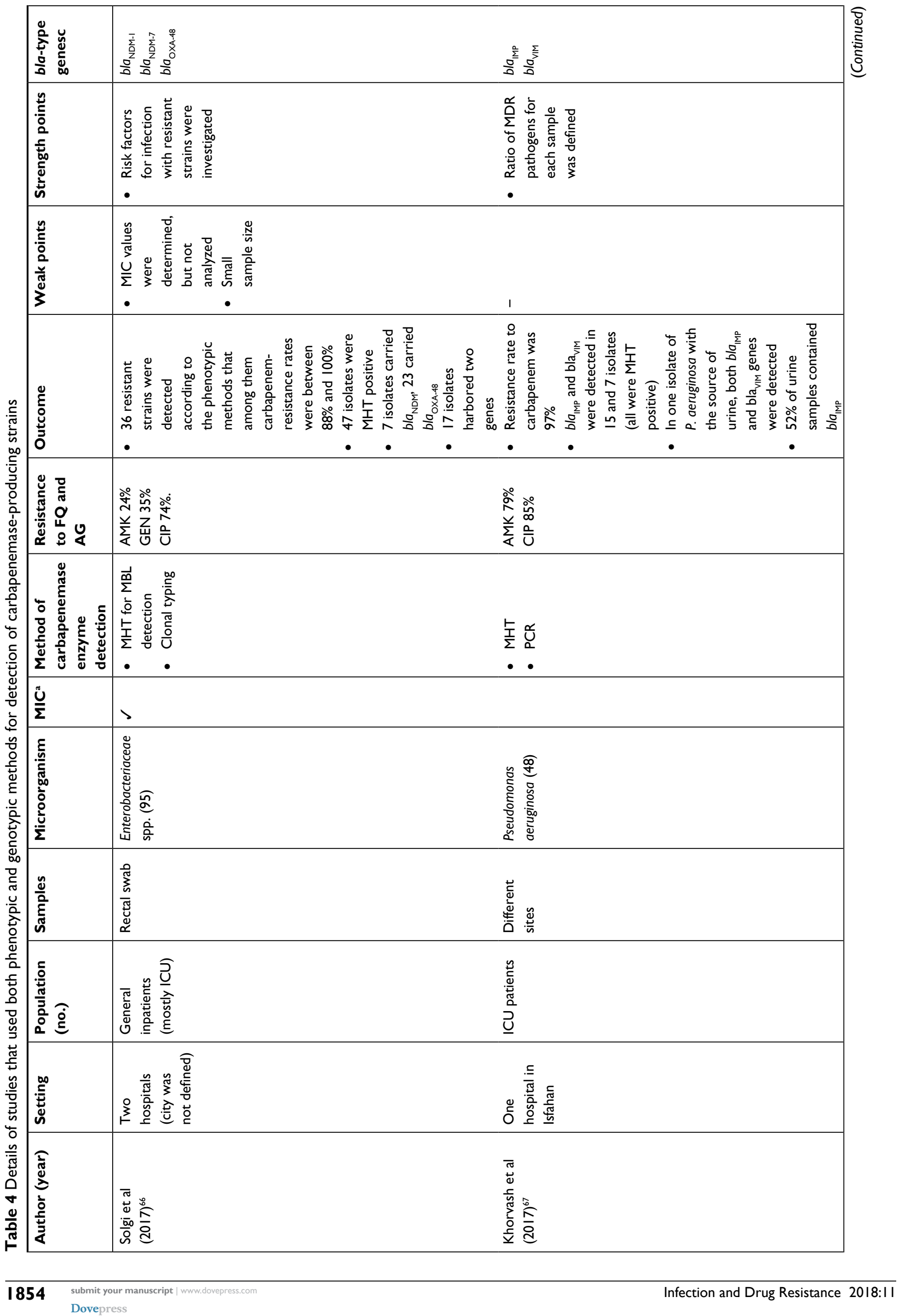




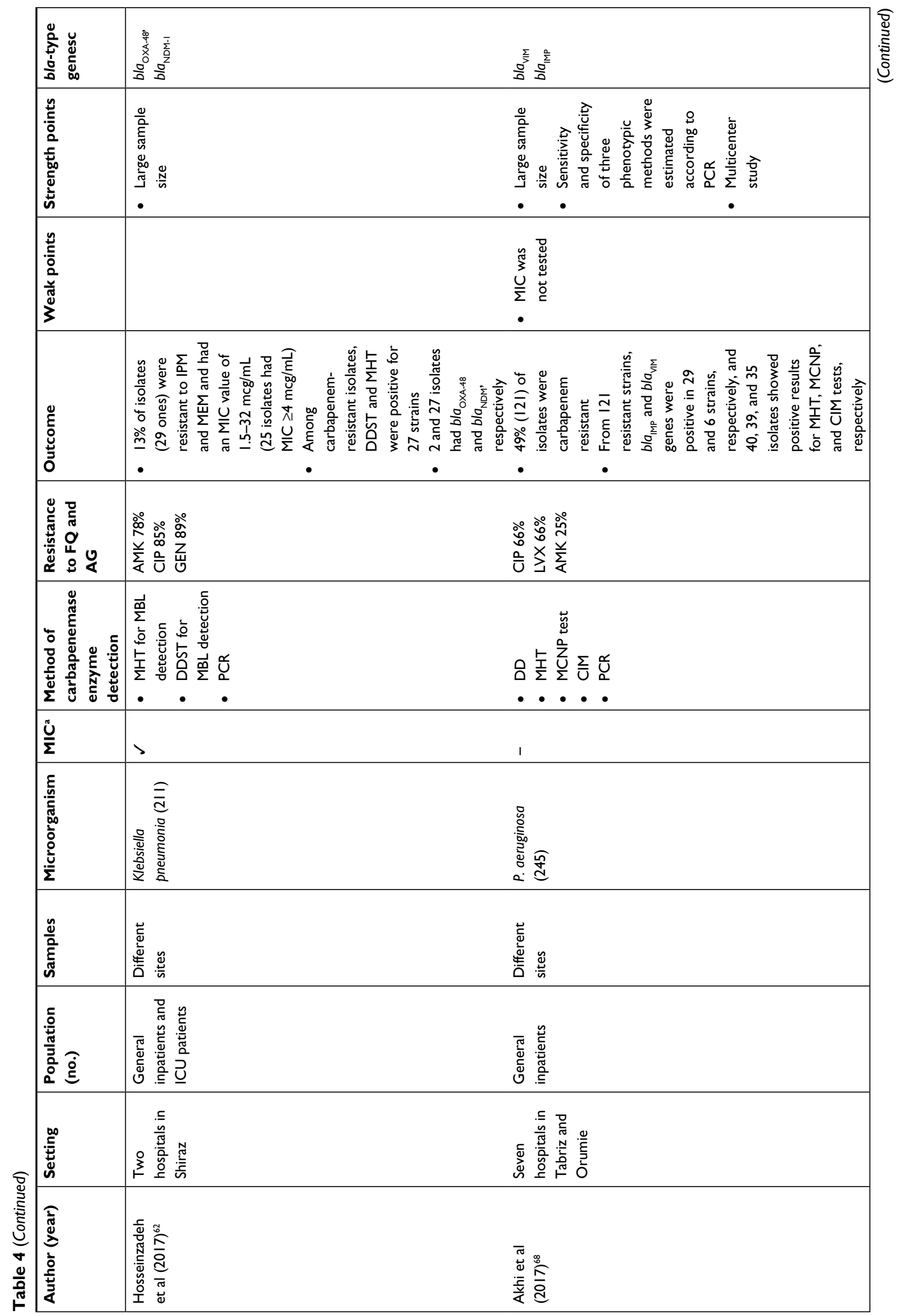




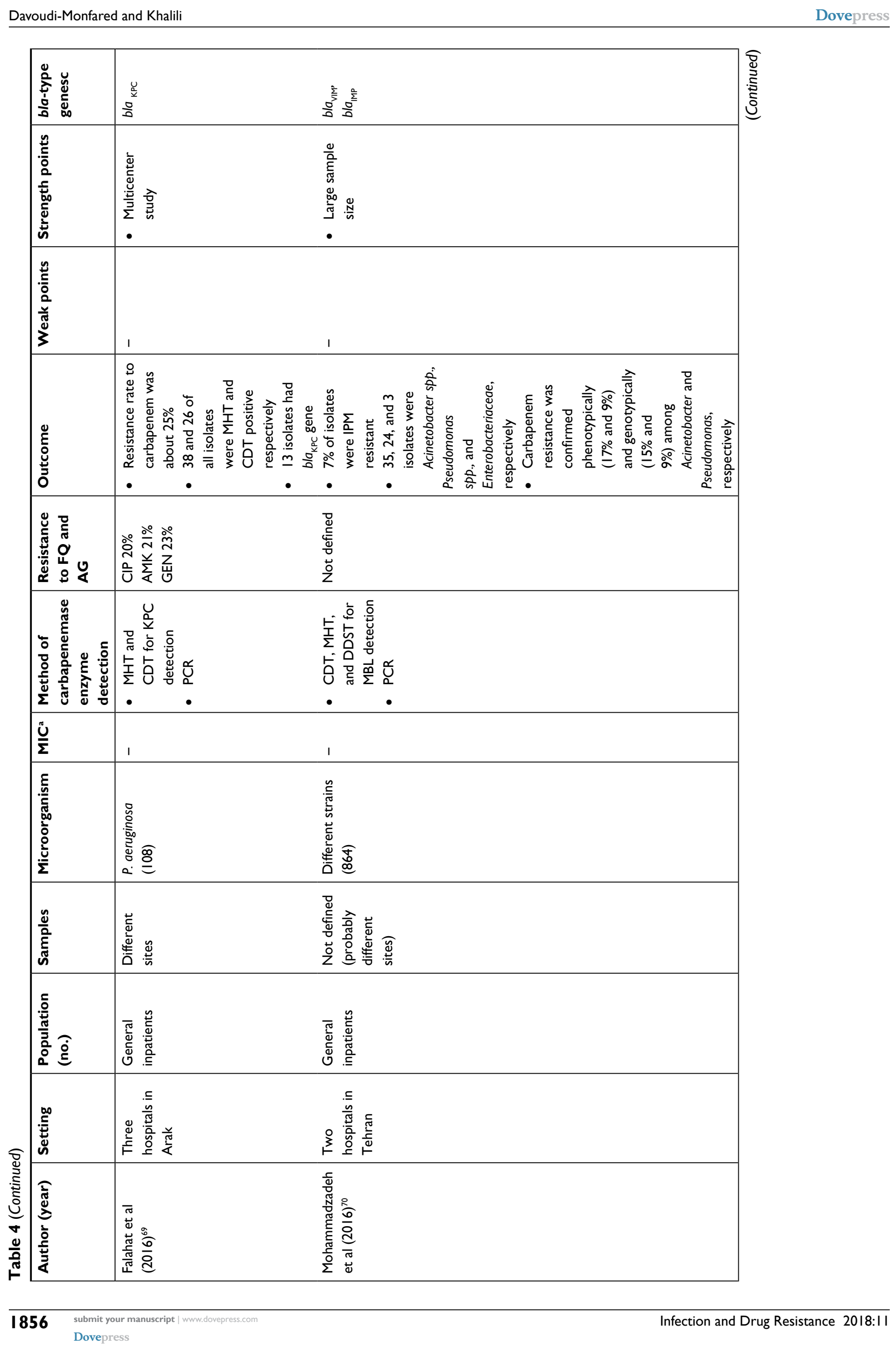




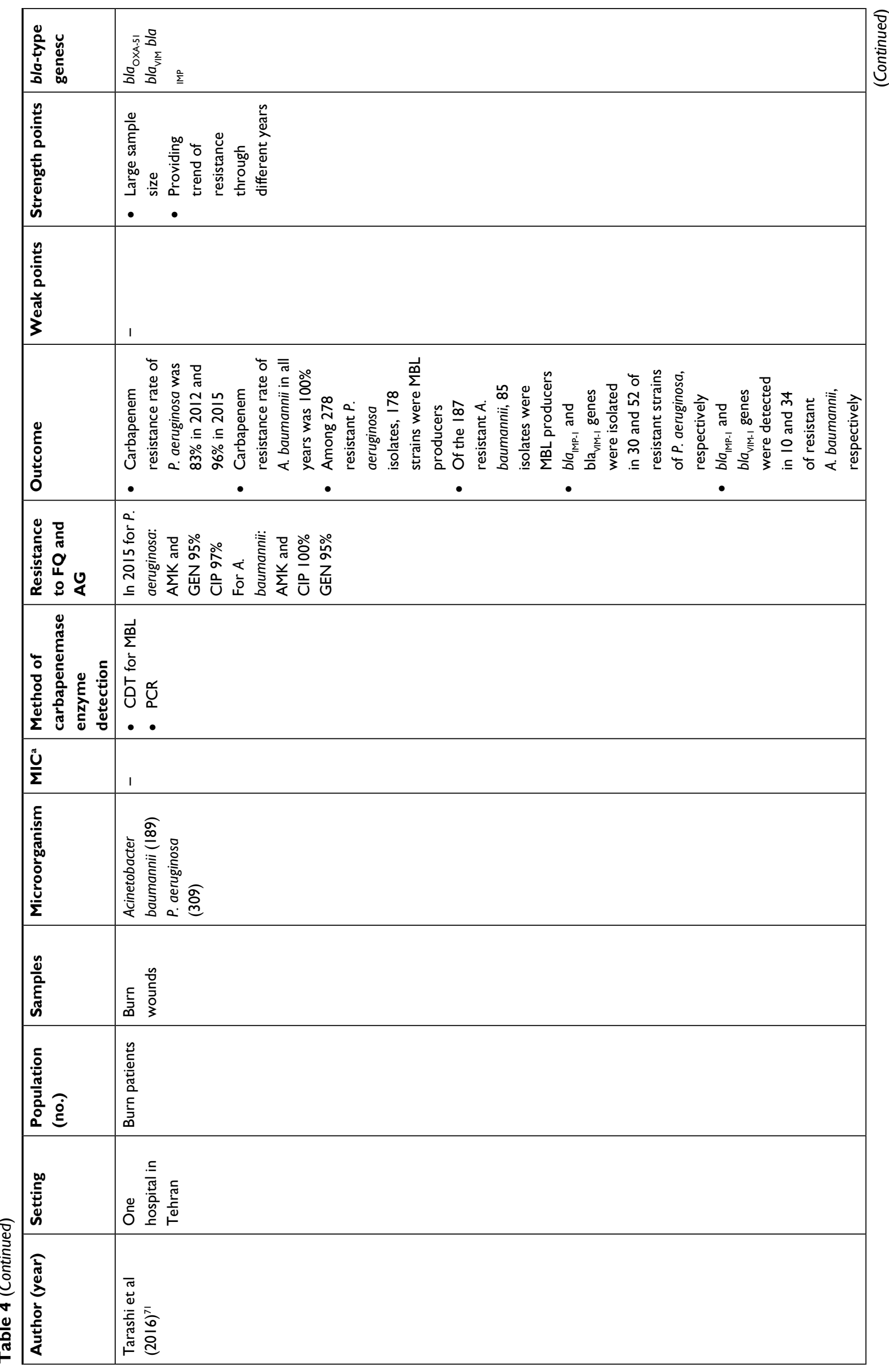




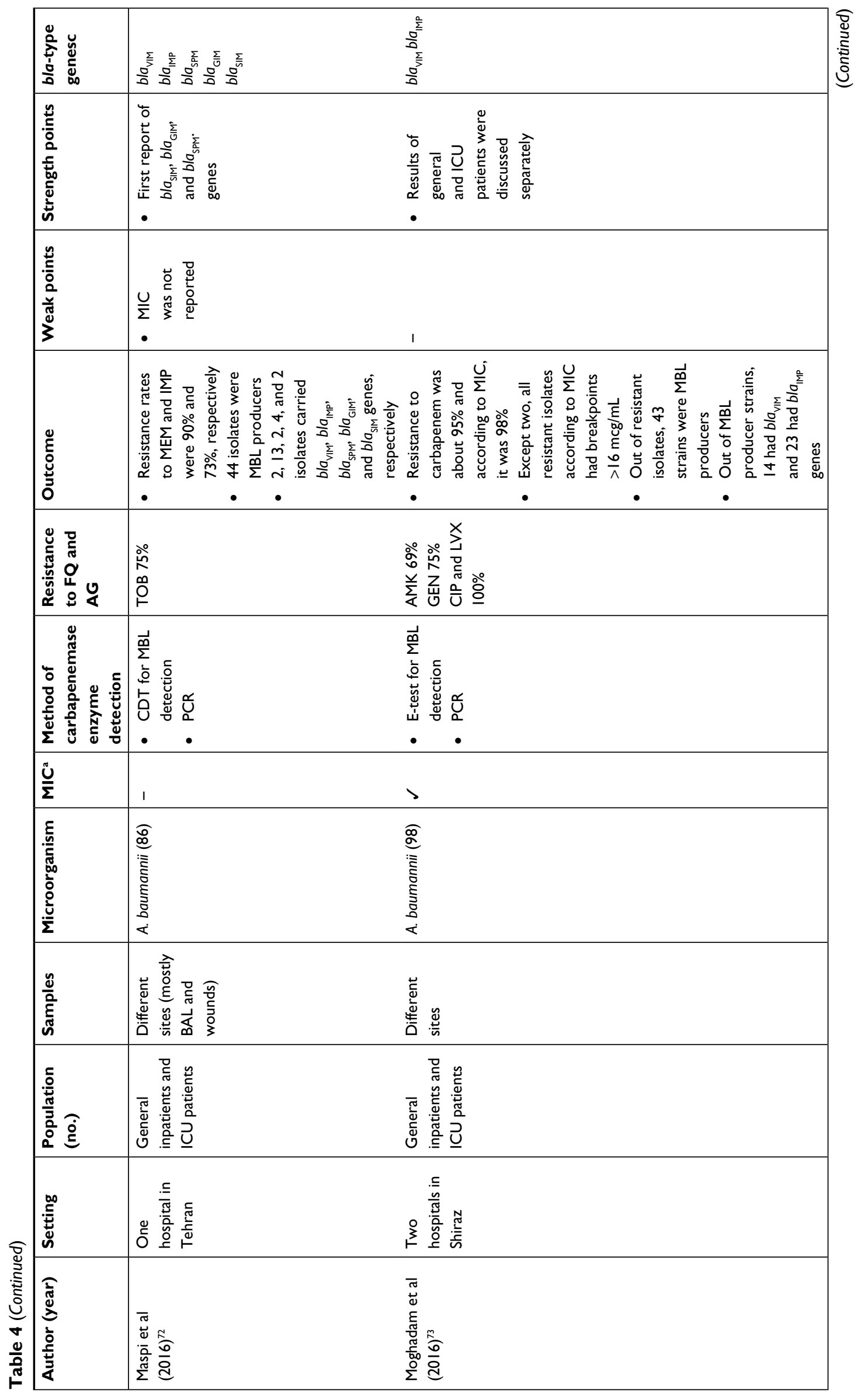




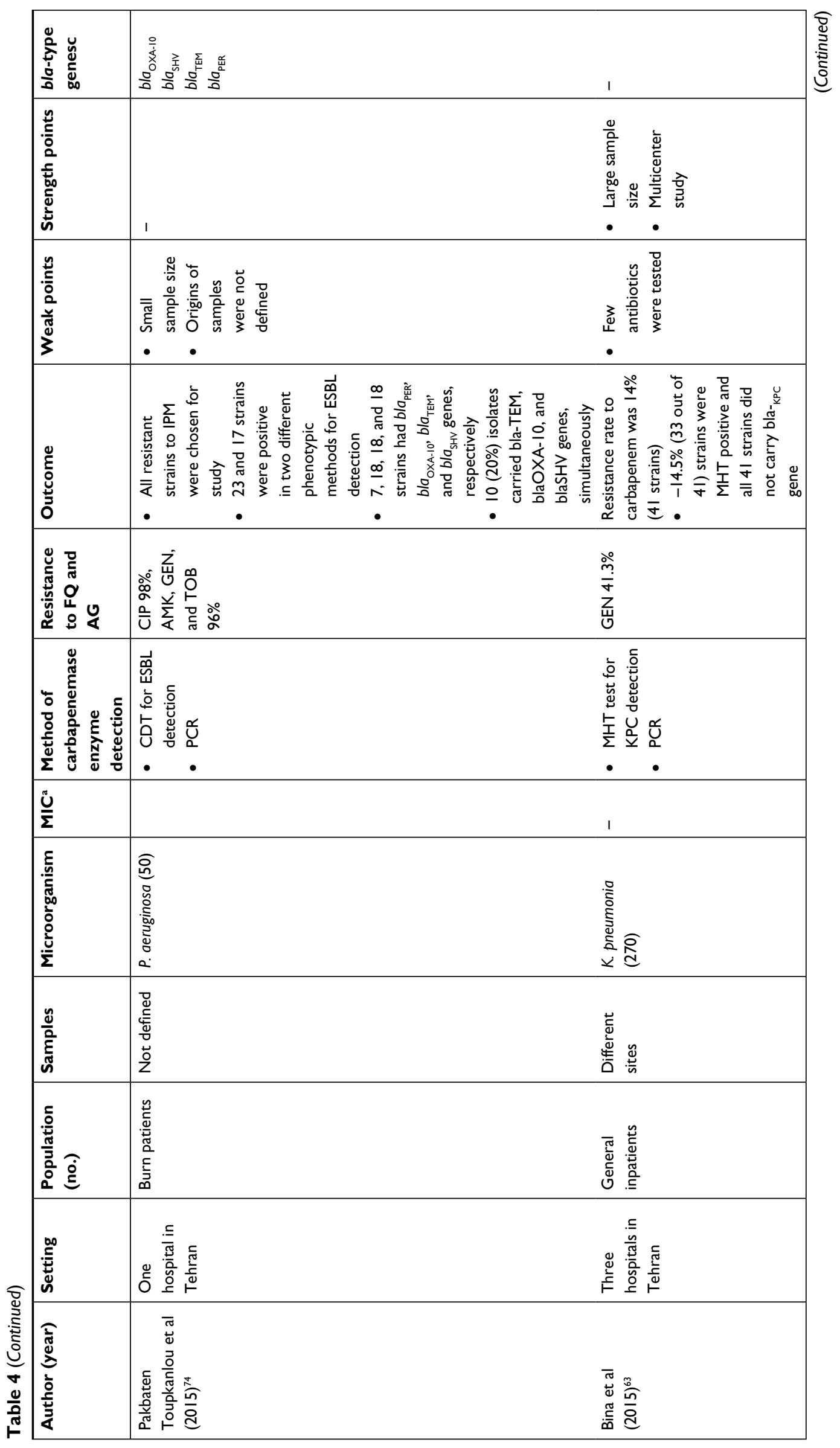




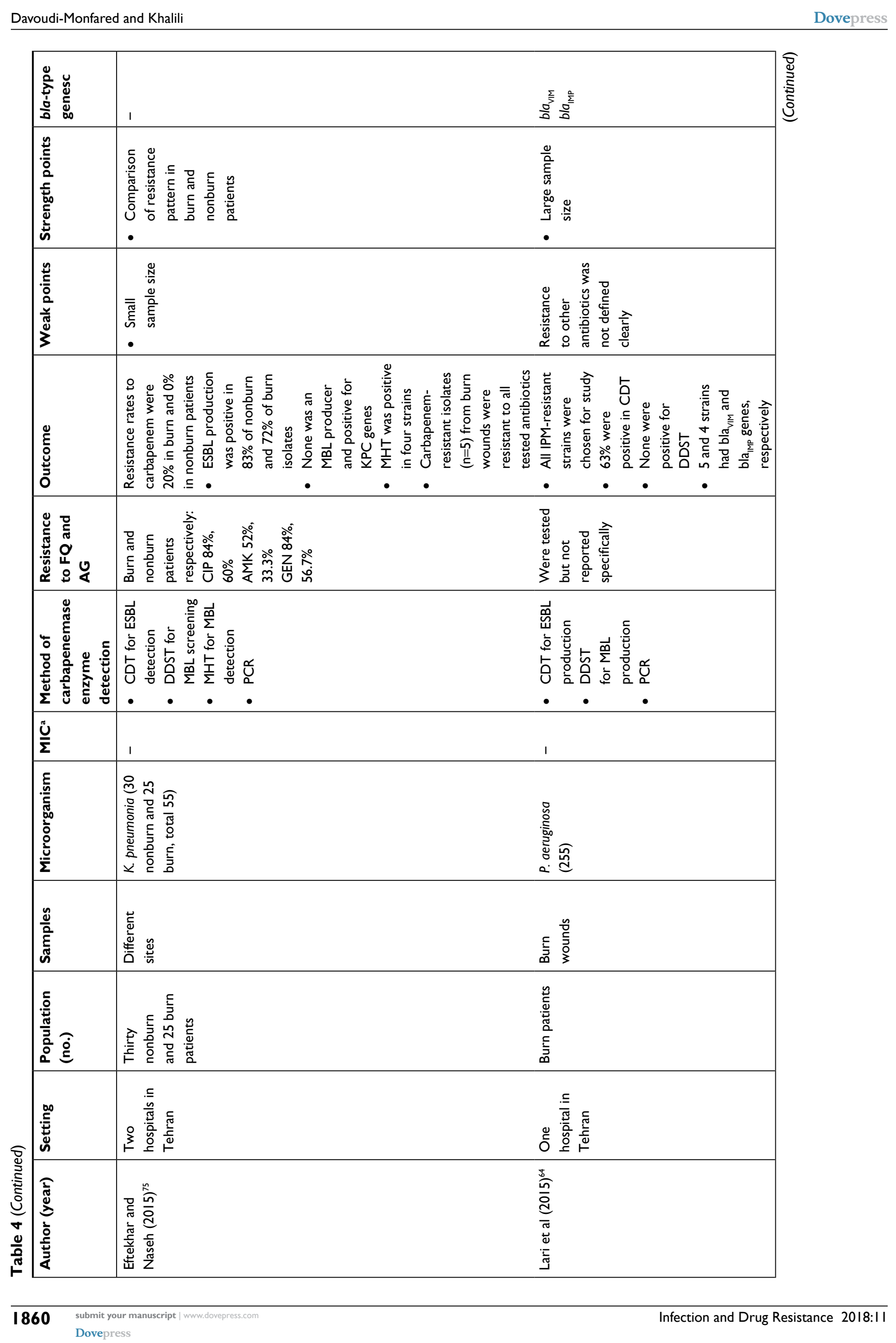




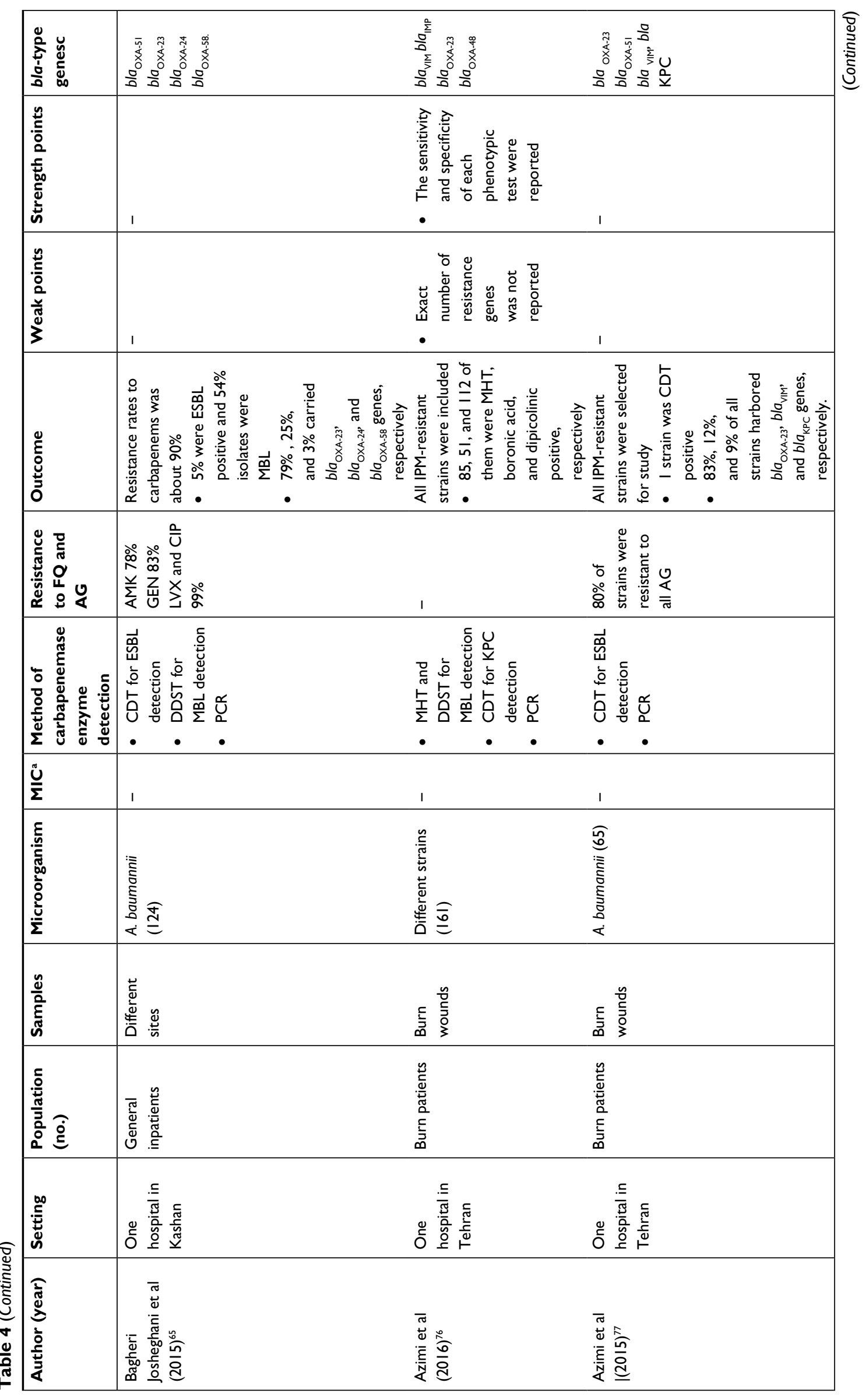




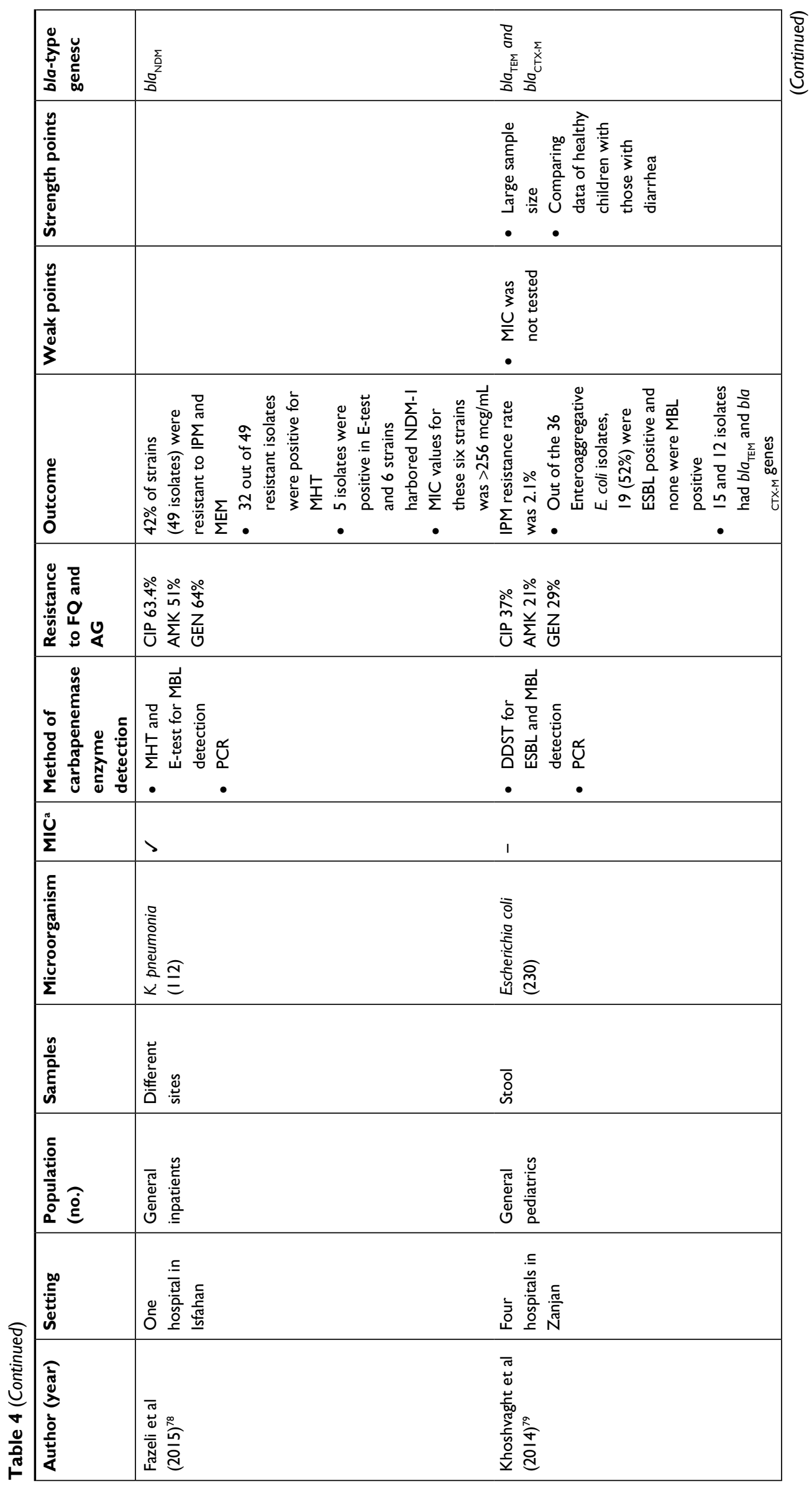


Dovepress

Carbapenem-resistant bacteria in Middle East

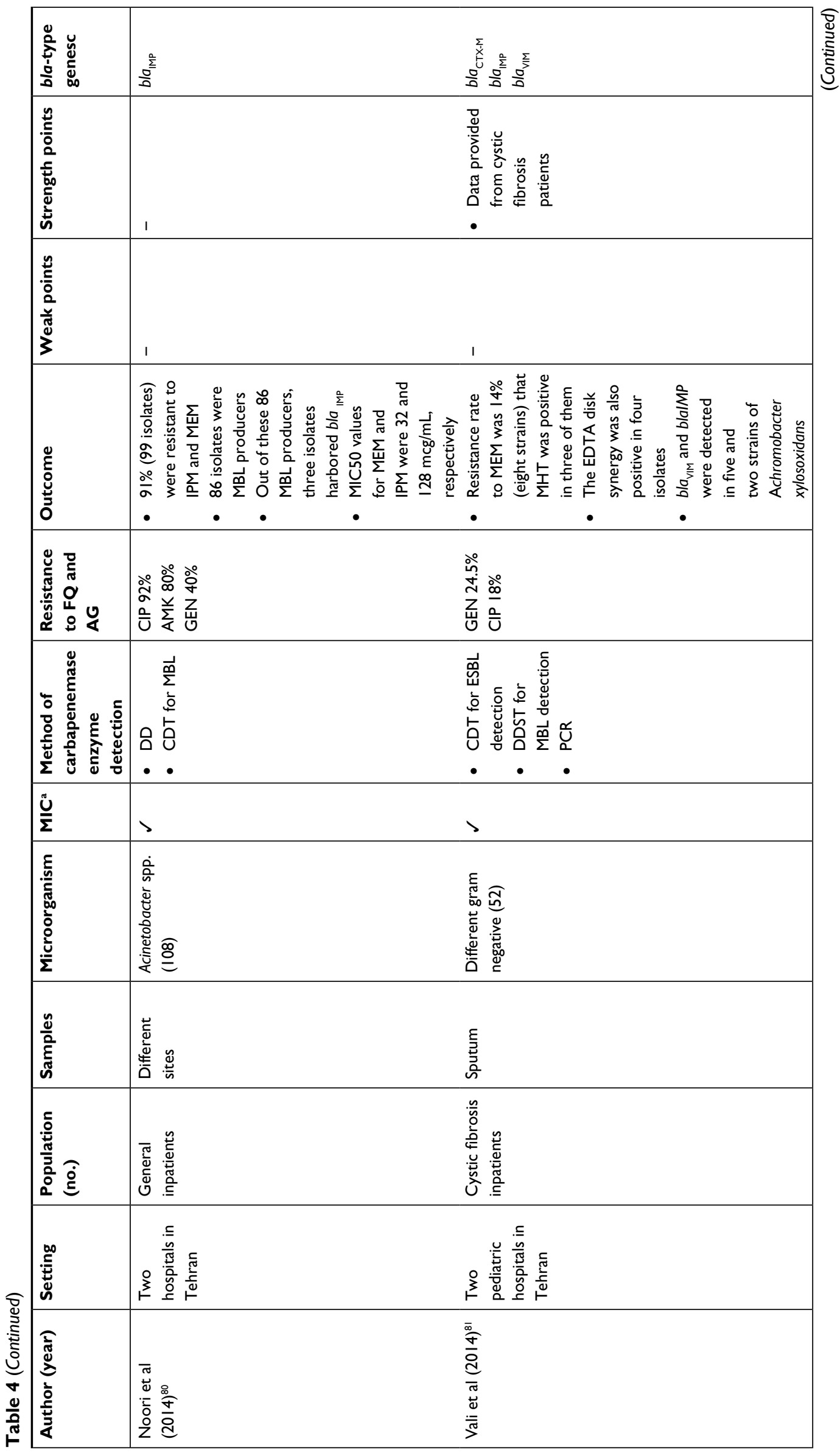

Infection and Drug Resistance 2018:1।

submit your manuscript | www.dovepress.com

Dovepress

1863 


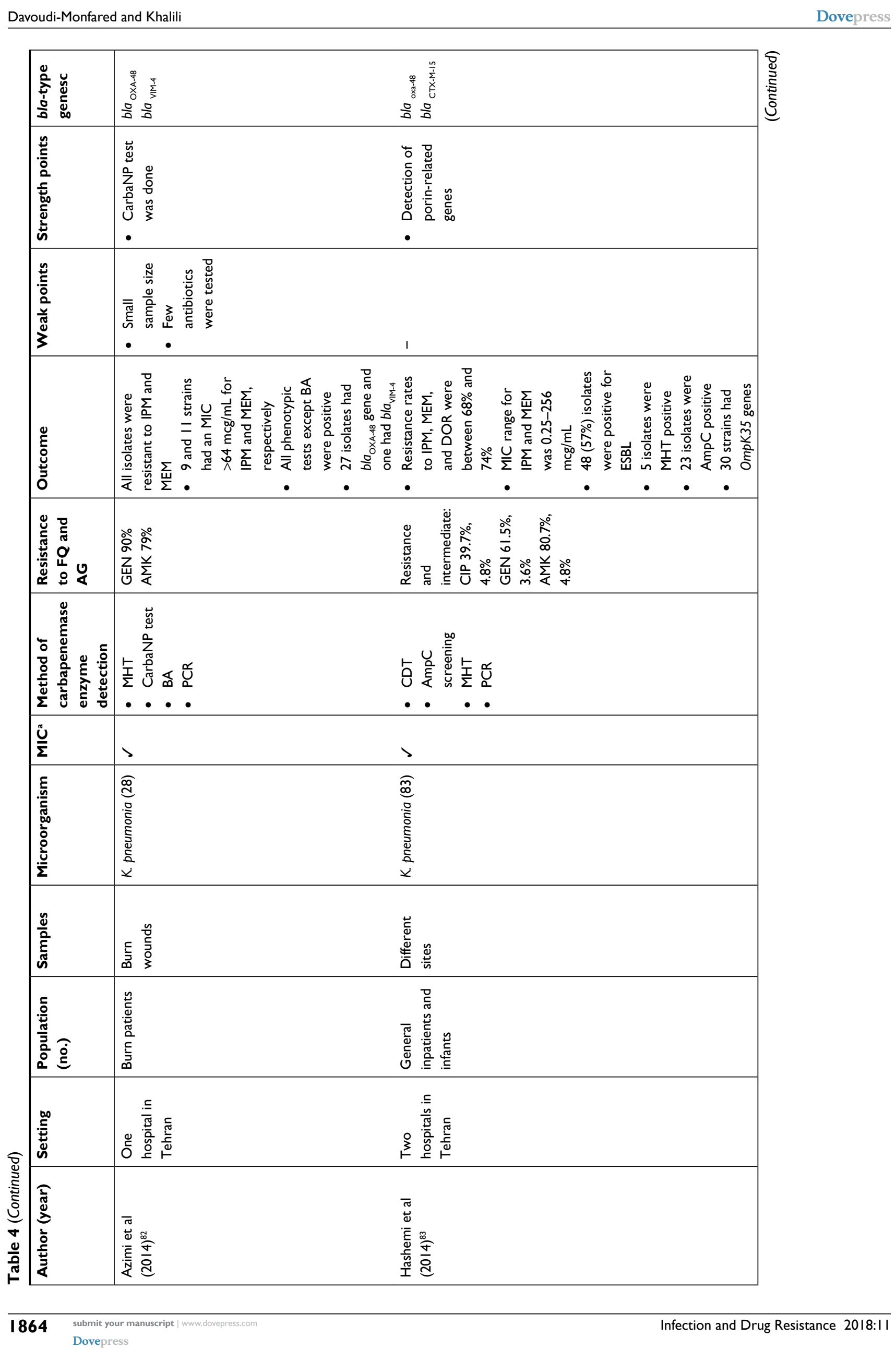


Dovepress

Carbapenem-resistant bacteria in Middle East

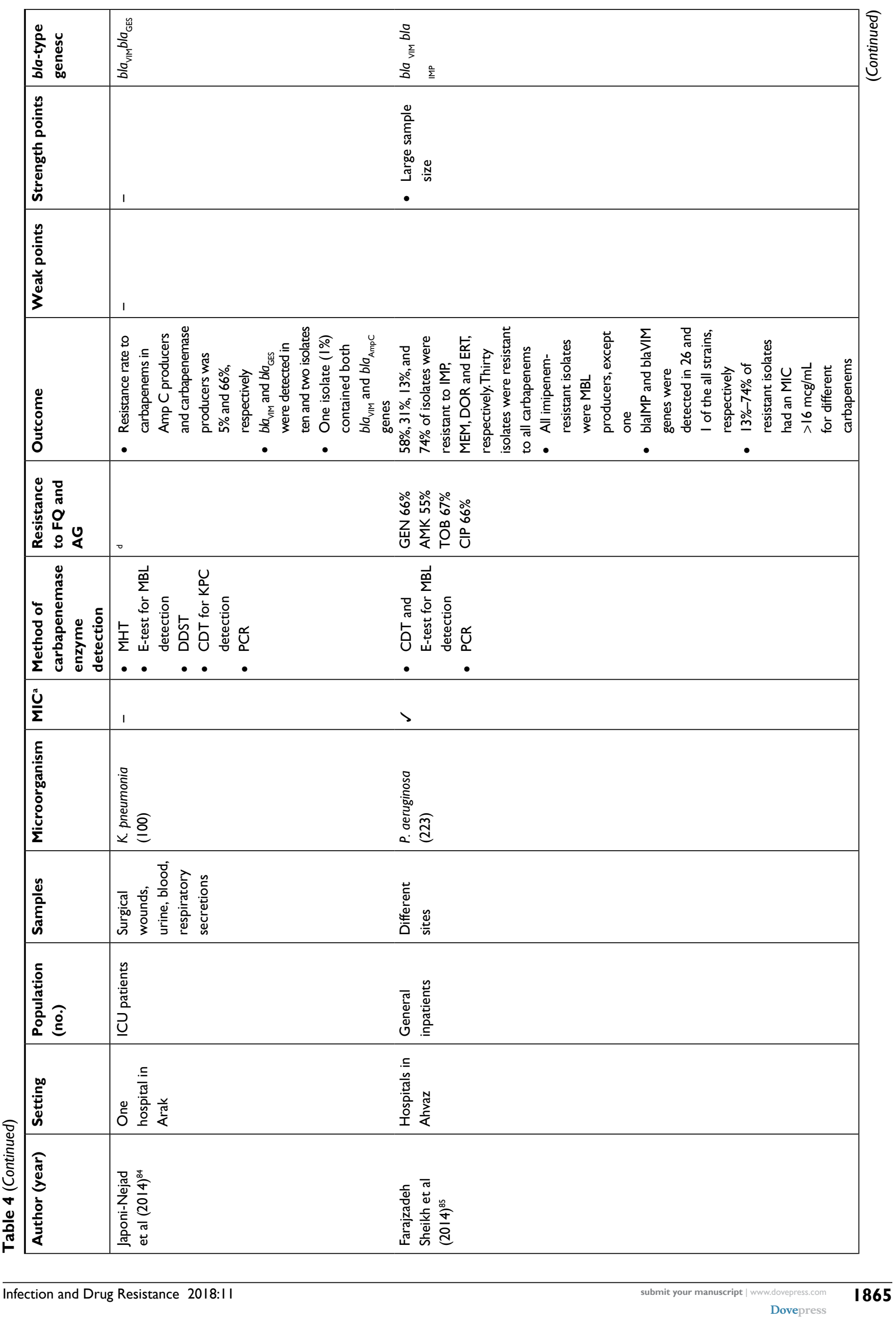




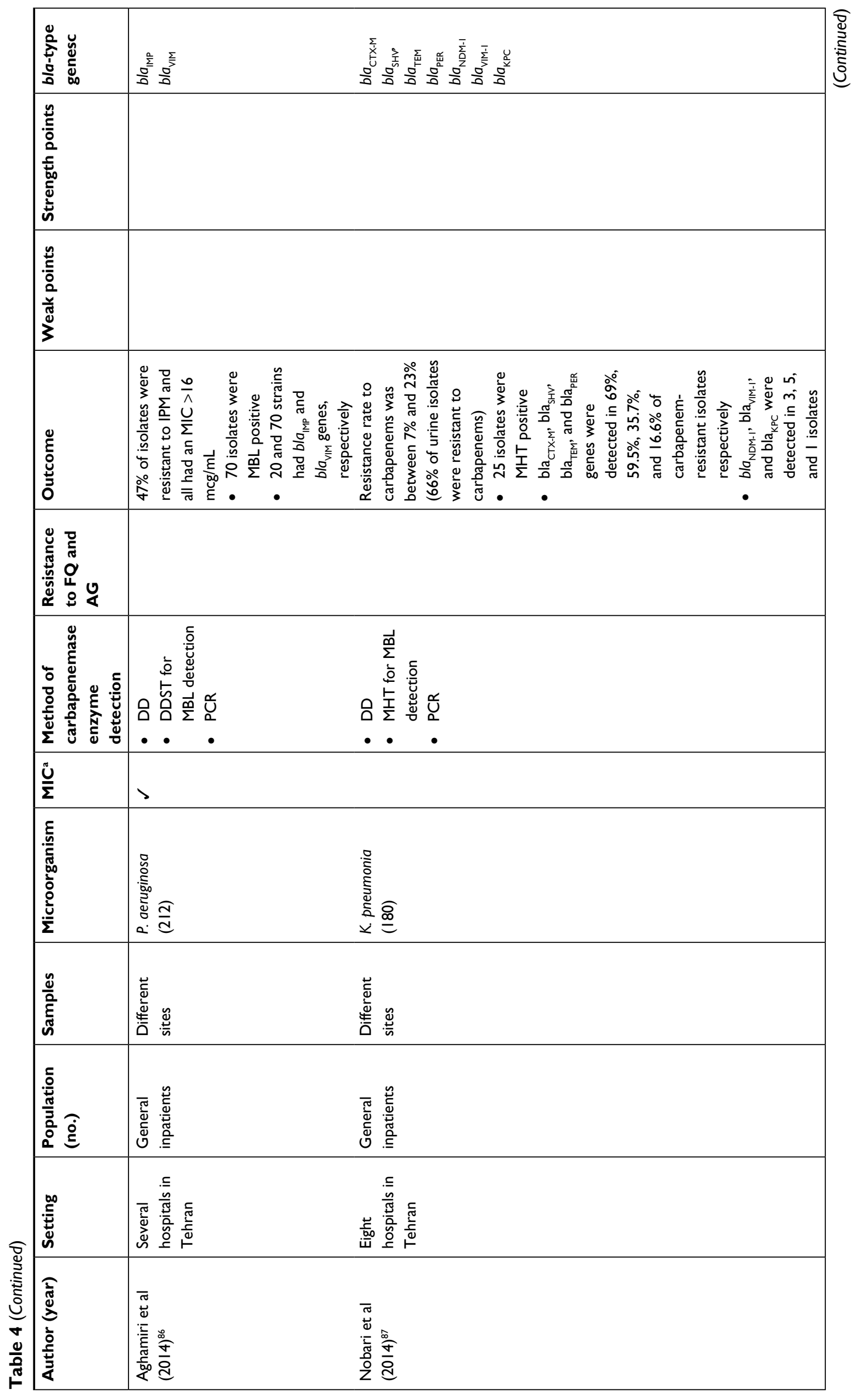




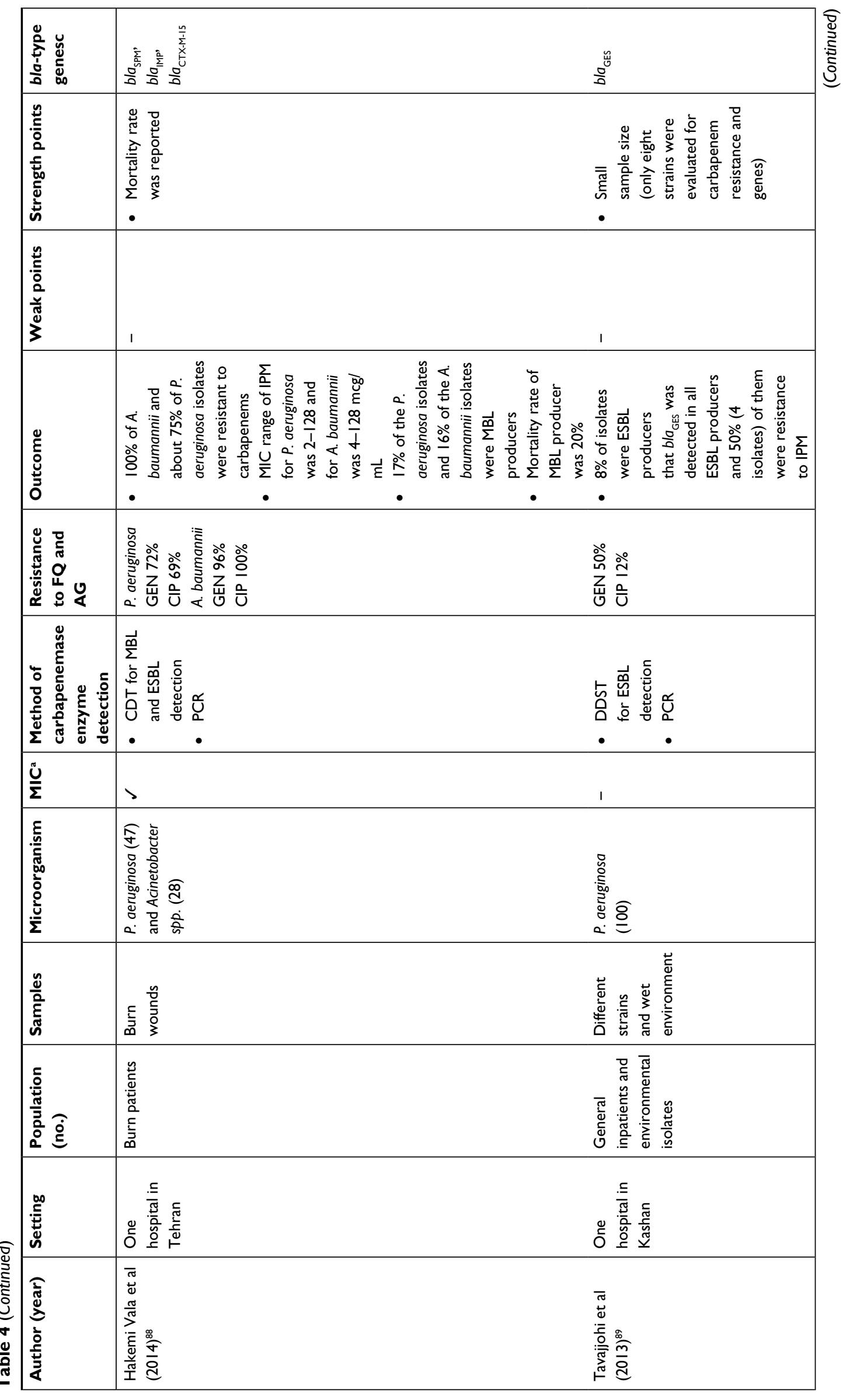




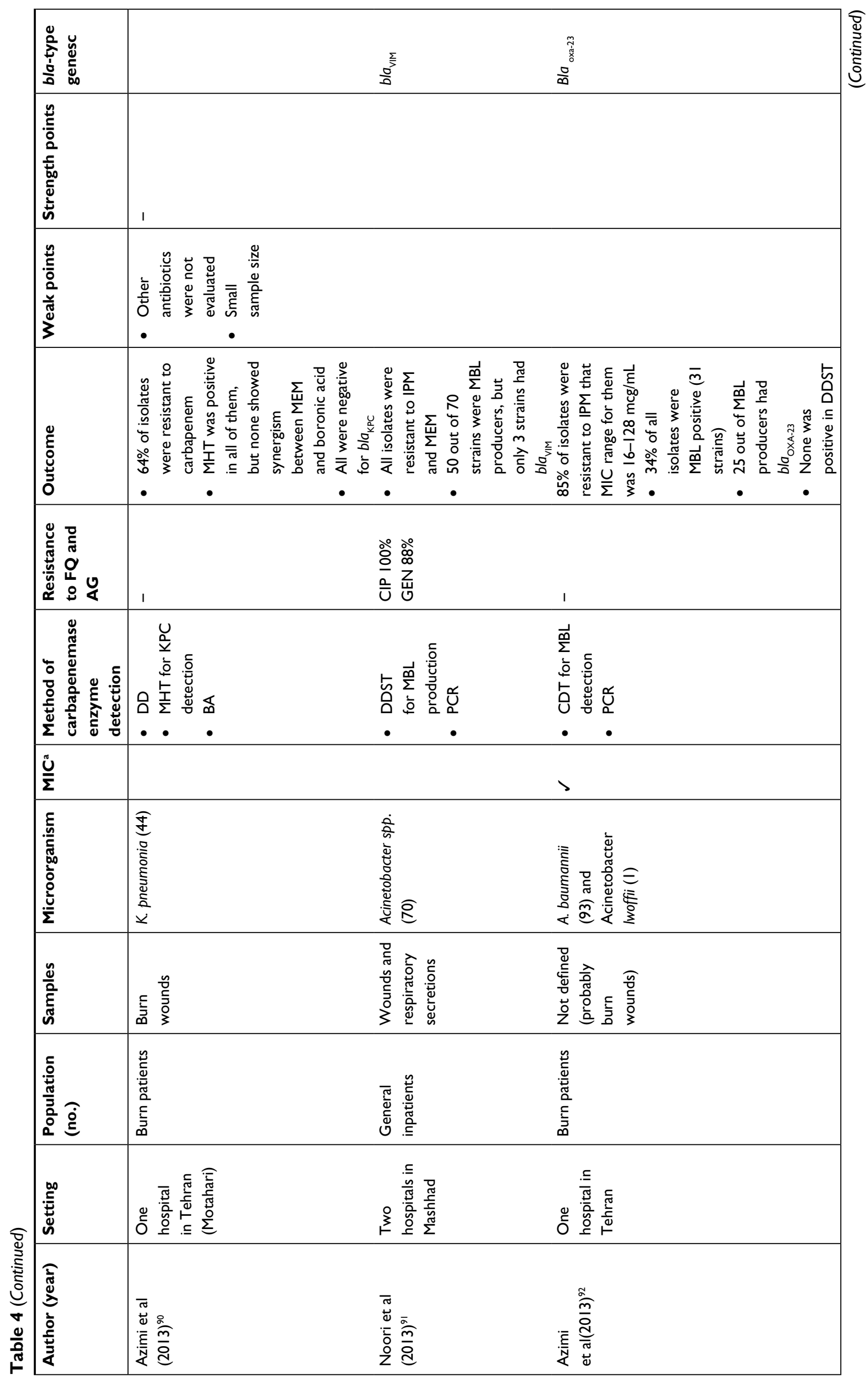




\begin{tabular}{|c|c|c|}
\hline 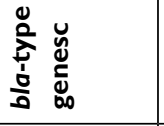 & 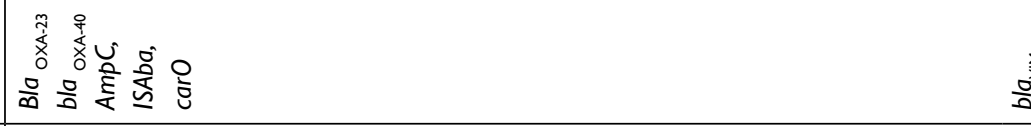 & $\frac{5}{0^{\frac{5}{3}}}$ \\
\hline 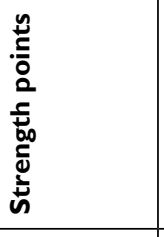 & 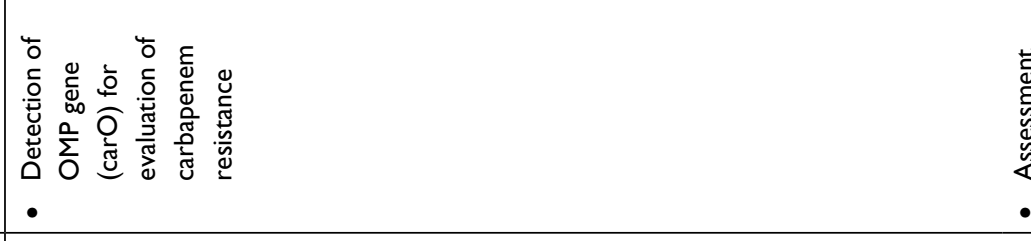 & 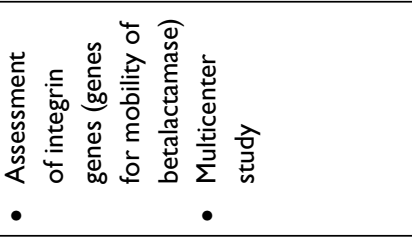 \\
\hline & 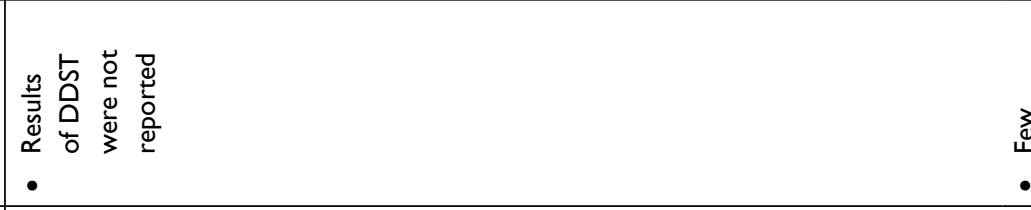 & 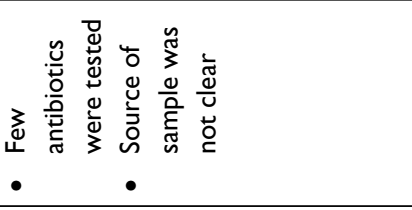 \\
\hline 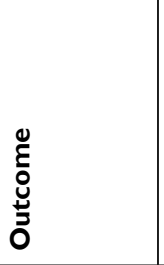 & 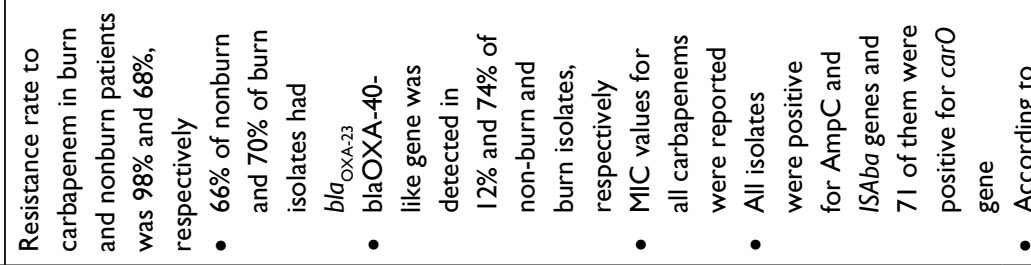 & 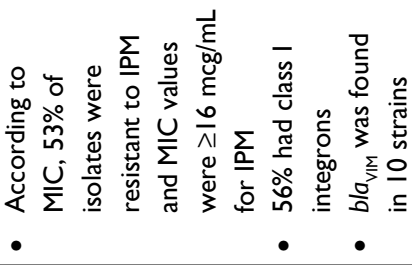 \\
\hline 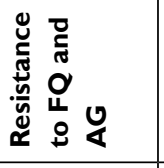 & 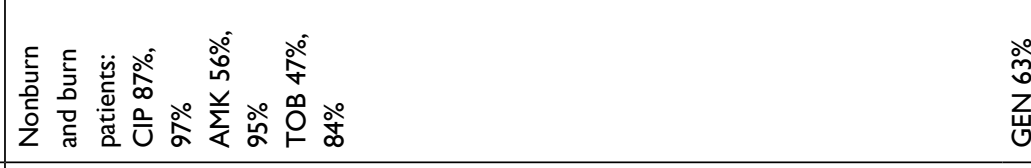 & 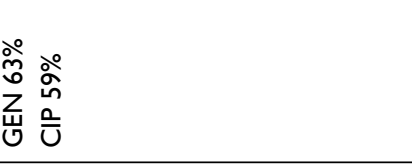 \\
\hline 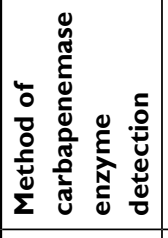 & 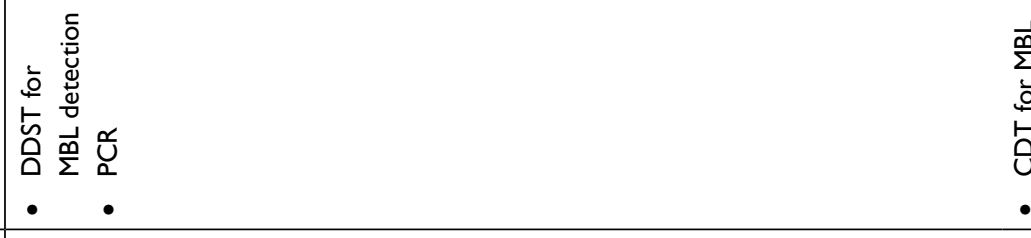 & 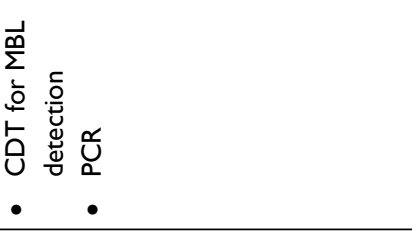 \\
\hline$\frac{\tilde{U}}{\Sigma}$ & $>$ & $>$ \\
\hline 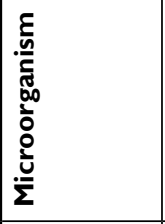 & 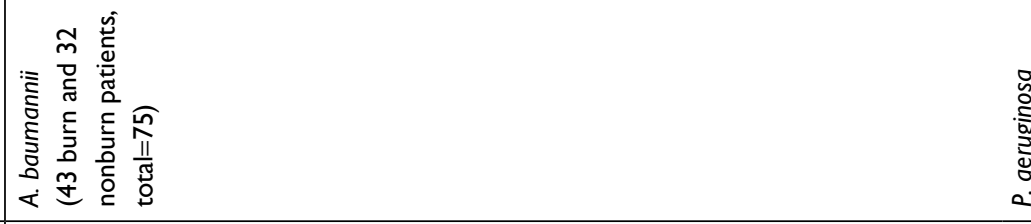 & 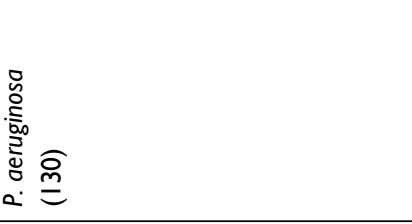 \\
\hline 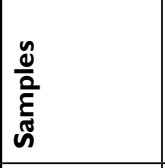 & 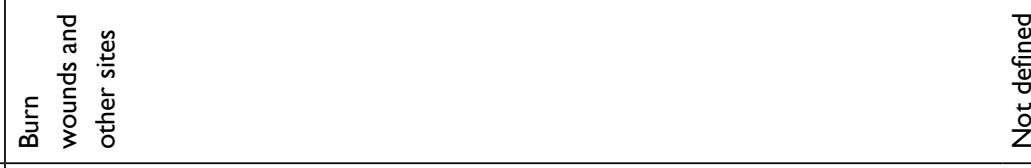 & 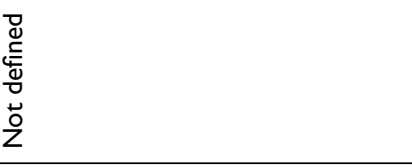 \\
\hline 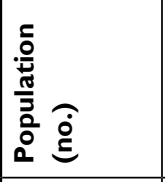 & 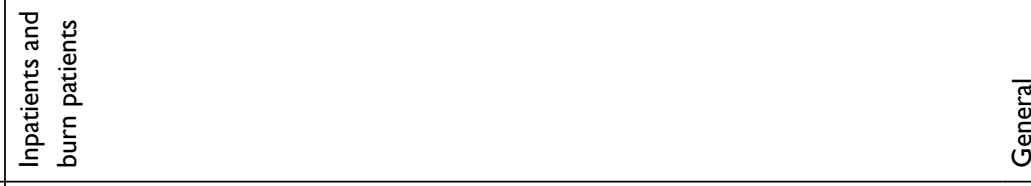 & 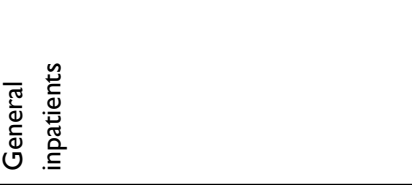 \\
\hline & 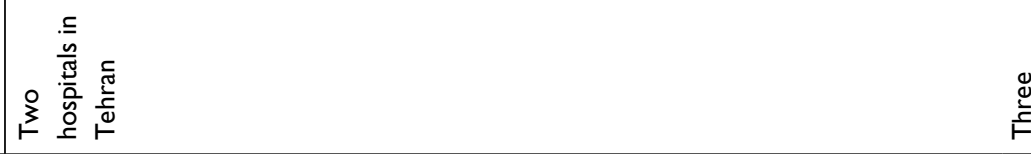 & 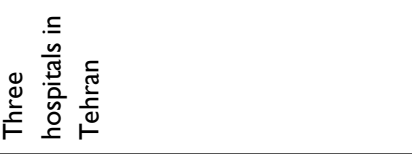 \\
\hline 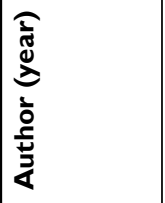 & 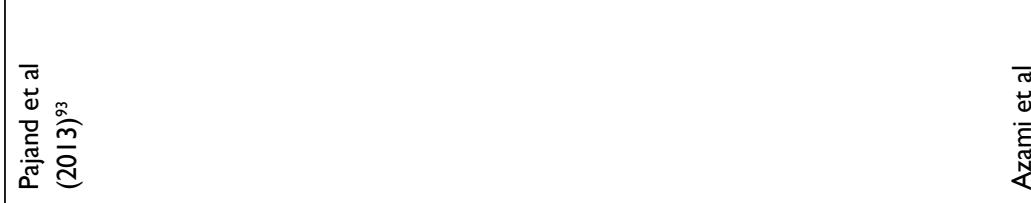 & 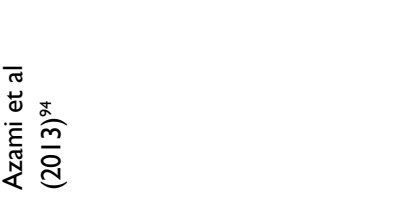 \\
\hline
\end{tabular}




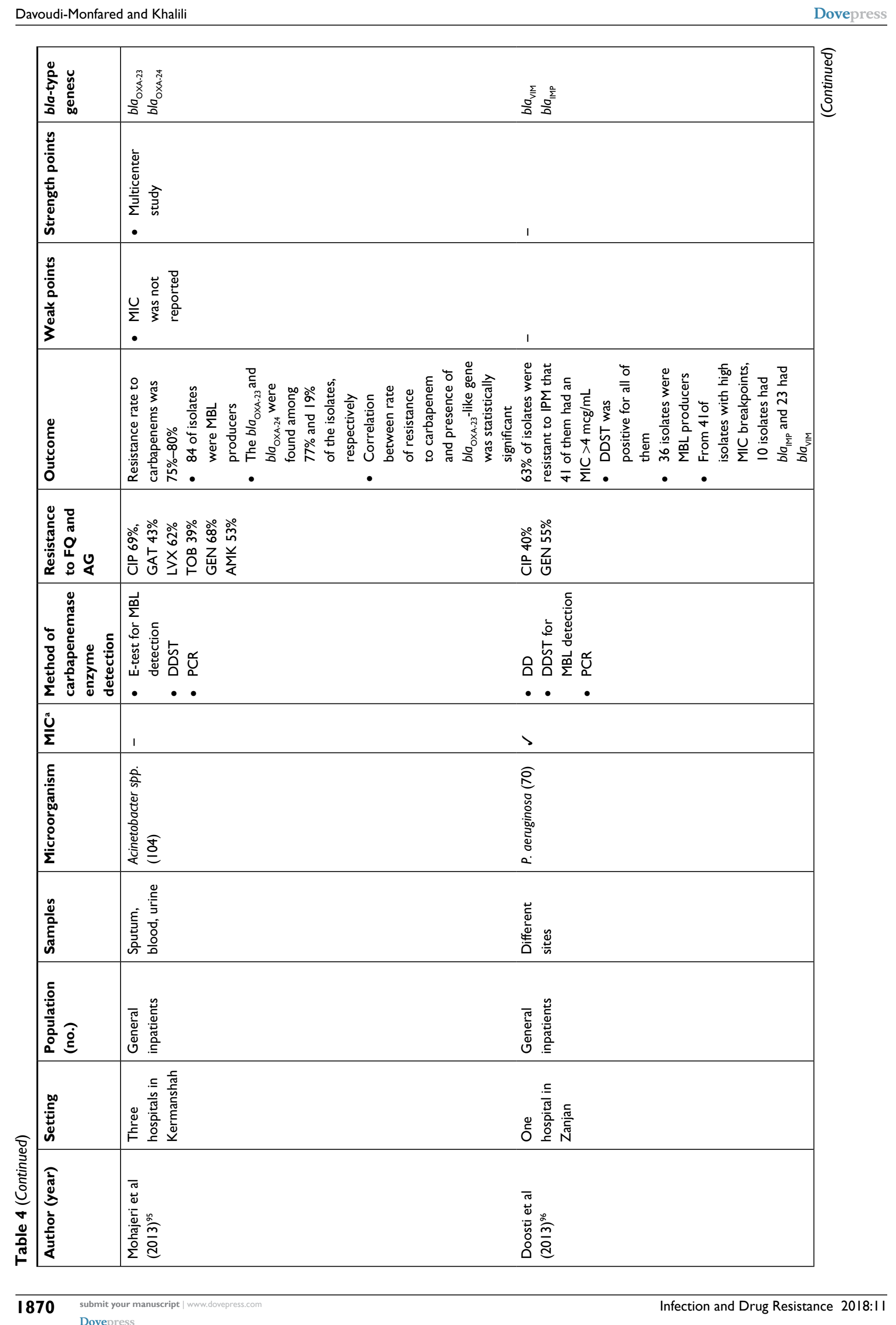


Dovepress

Carbapenem-resistant bacteria in Middle East

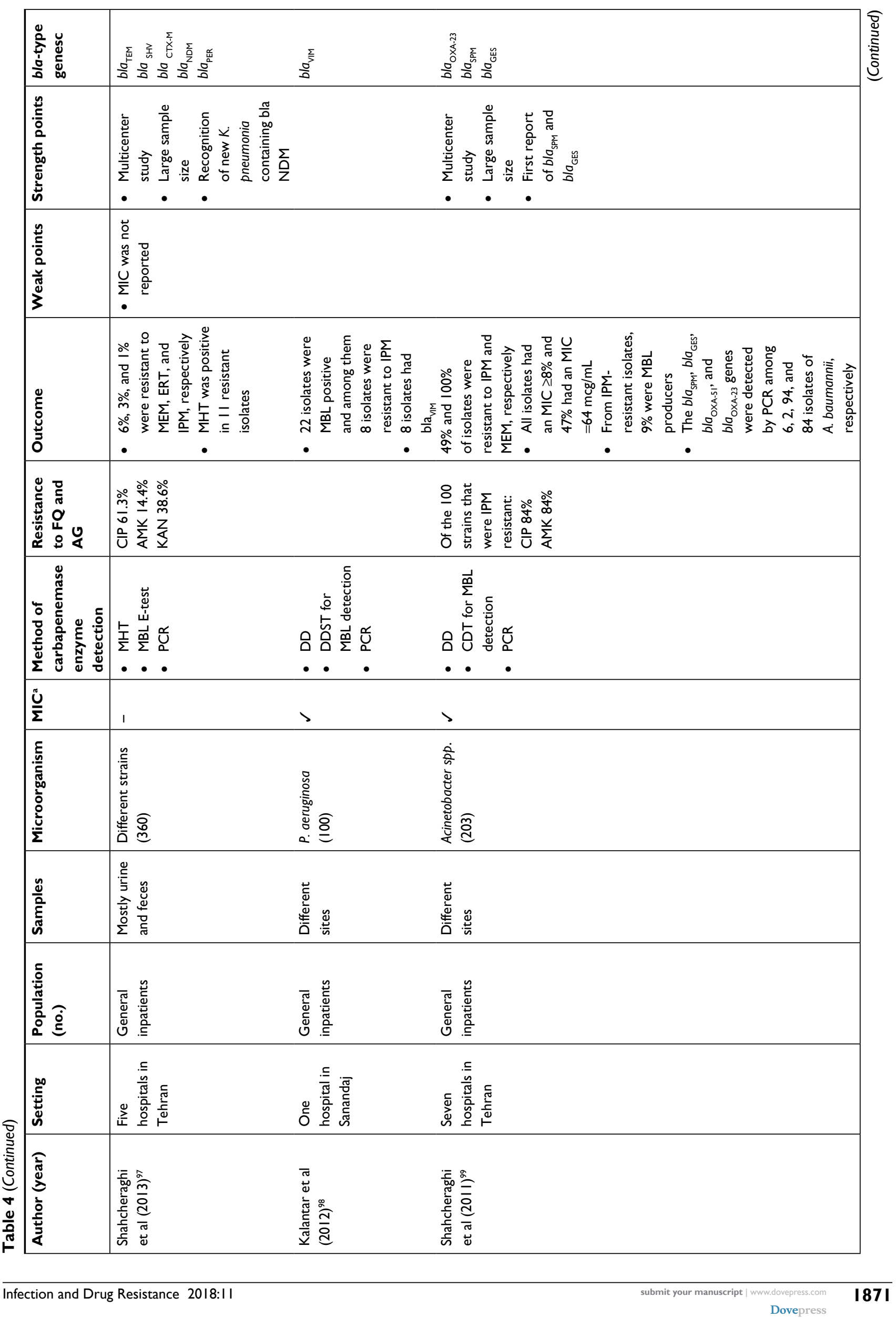




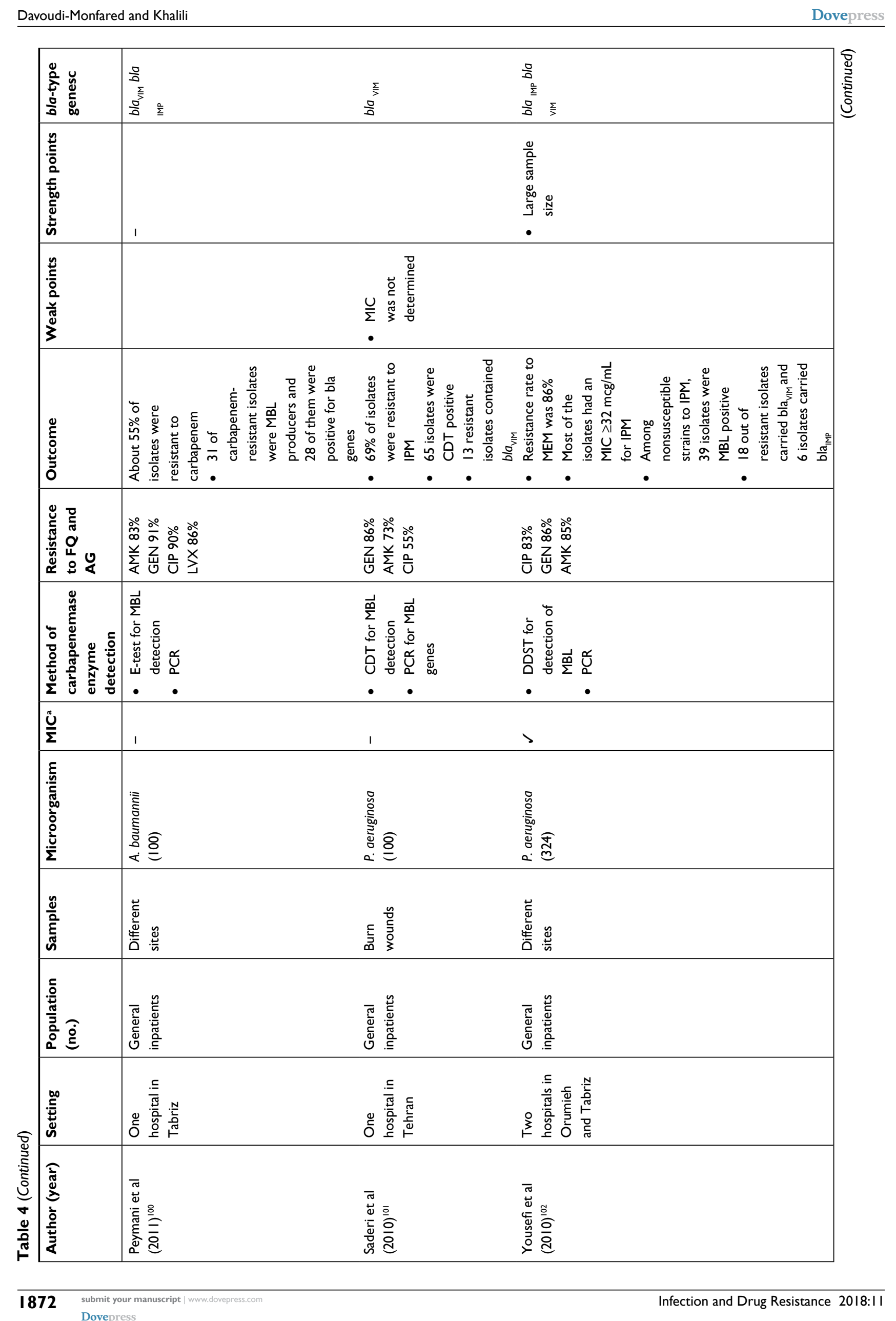




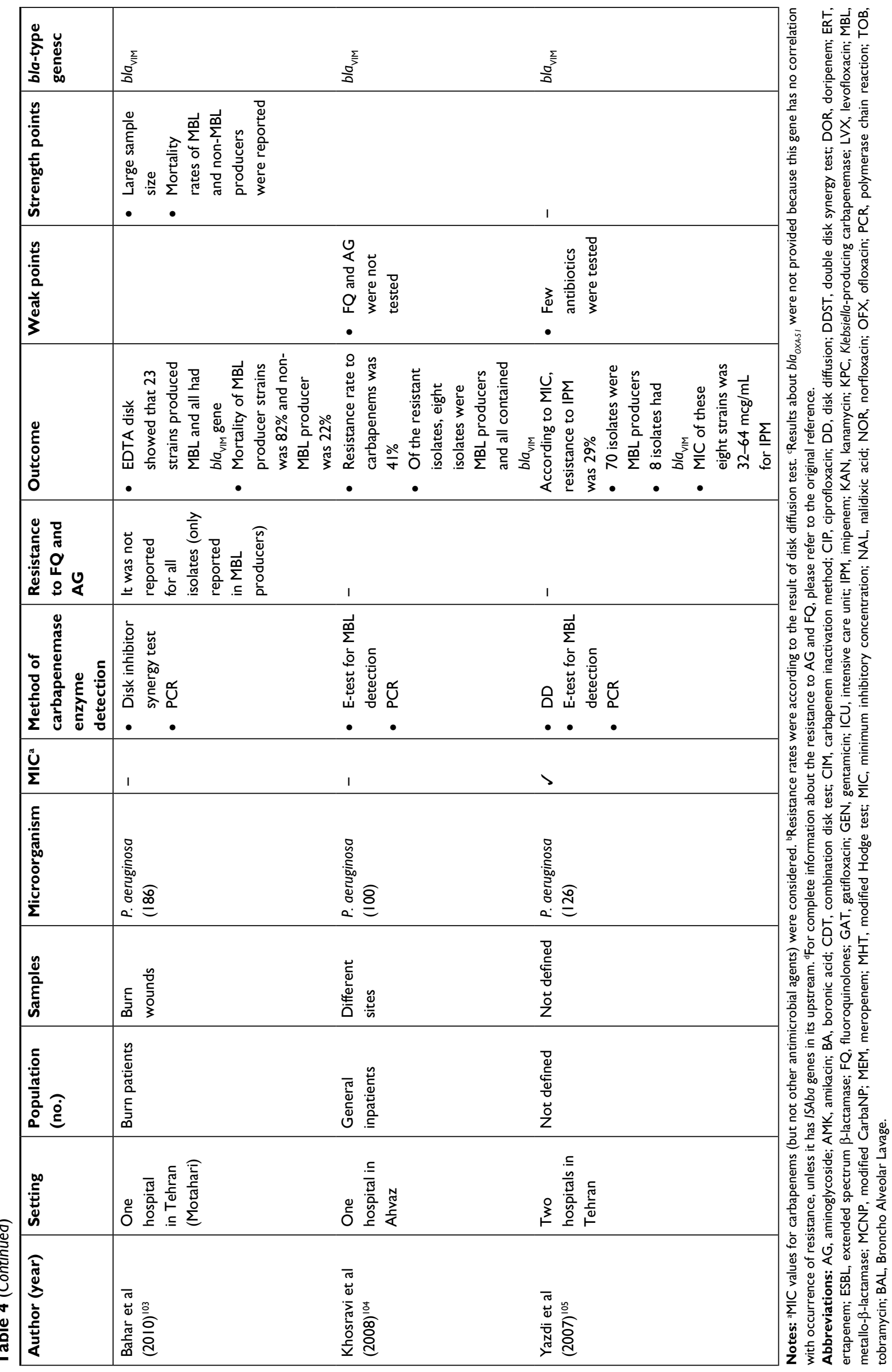




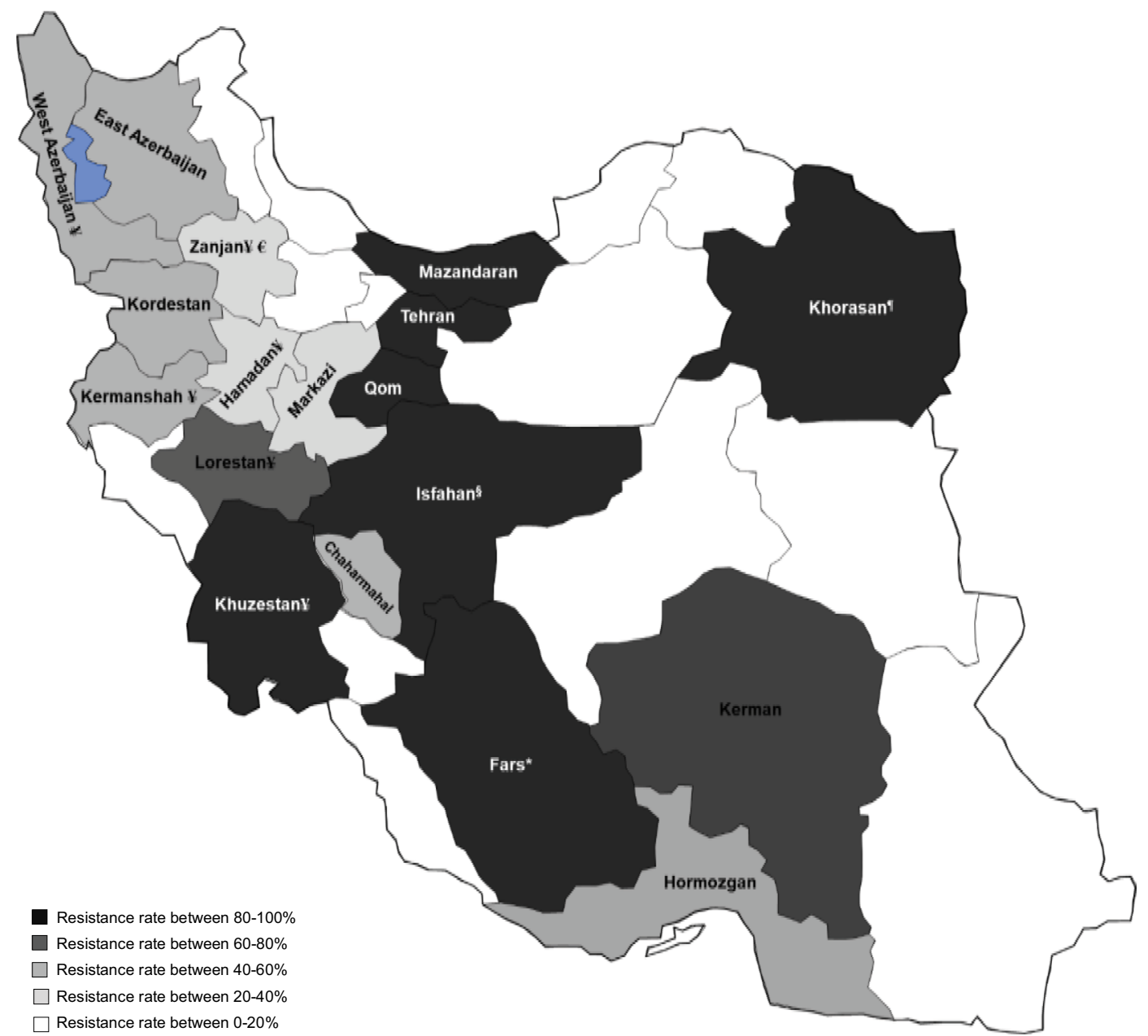

Figure 3 Carbapenem-resistance rates in different areas of Iran (according to the disk diffusion method).

Notes: The data were extracted from the latest available studies. Multicenter studies from different cities were not considered for mapping due to pooled data. The studies in the special populations (ie, pediatrics or cystic fibrosis) and outpatients were excluded. *Reported resistance rates from Fars province were conflicting ( $13.7 \%$ in 2017 and $96 \%$ in 2016). ${ }^{\S}$ Data for Isfahan province were obtained from both Kashan (a city around Isfahan) and Isfahan itself, although the sample size for Isfahan was very small. "Data

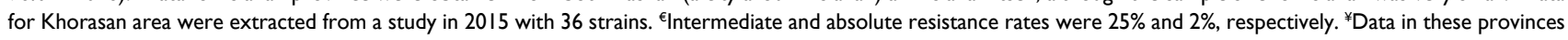
were for 2010-2014 studies.

Most studies included biological samples from different sites like urine, trachea, and wounds. However, sites with highest or lowest resistant rates were not defined, except in a few studies. In study by Nobari et al, urine was the source with more resistant strains ${ }^{87}$ In the study by Khorvash et al, one $P$. aeruginosa strain that was isolated from urine samples harbored both $b l a_{I M P}$ and $b l a_{V I M}$ genes. ${ }^{67}$

Lack of clinical insight was the main limitation of almost all studies. Only in three studies, mortality rates in patients infected with resistant strains were addressed. Mortality rate of patients infected with carbapenem-resistant $K$. pneumonia isolates was 33\% in 2013 (Rastegar Lari et al study). ${ }^{25}$ In the same year, infections with carbapenem-resistant $A$. baumannii strains caused $20 \%$ mortality. ${ }^{24}$ In the study by Bahar et al, the mortality rate of MBL-producer P. aeruginosa isolates vs non-MBL producers was $82 \%$ vs $22 \% .{ }^{103}$ In some studies, patients' conditions including requiring mechanical ventilation and days of hospital stay were considered, but no correlation between these data and acquiring carbapenemresistant strains was found. Also in most studies, difference between infection and colonization was not clear.

Restrictions in technical facilities and standard laboratories in small cities are important issues. Access to a standard microbiological laboratory is not feasible in most regions. Disk diffusion was the main method for detecting carbapenem resistance until recently. Also, MIC breakpoints were adapted from CLSI and national data regarding these cutoffs are lacking. National antimicrobial resistance surveillance studies have not been well organized. Interpreting data from different regions of a country, considering the local standards, is essential. 


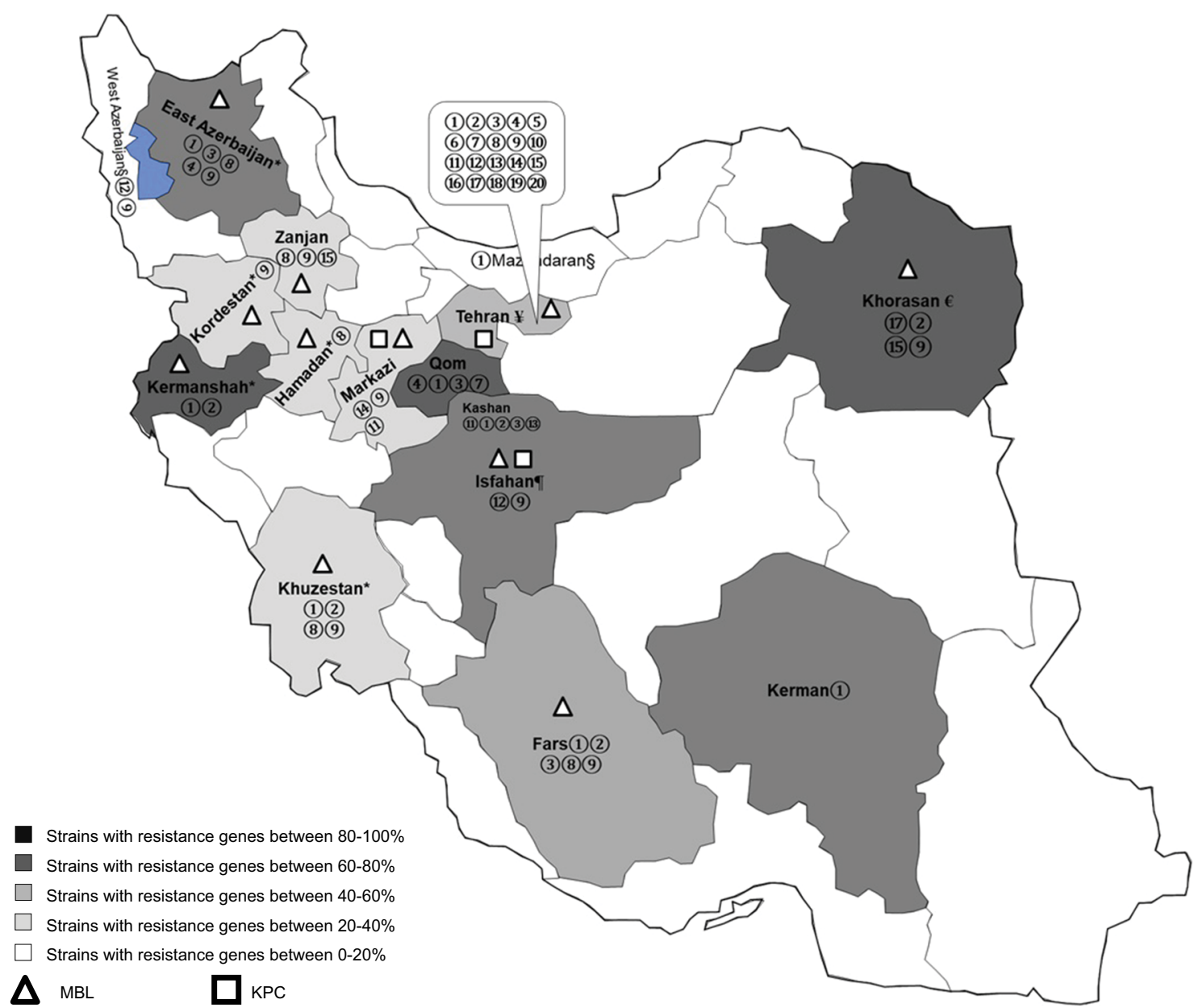

Figure 4 Carbapenem-resistant rates in different areas of Iran (according to the phenotypic and genotypic methods).

Notes: The data were extracted from the latest available studies. Multicenter studies from different cities were not considered for mapping due to pooled data. The studies in the special populations (ie, pediatrics or cystic fibrosis) and outpatients were excluded.

Some genes like blaSPM and blaSHV are mostly known as genes that encode ESBL enzymes, but they were included in this map, because these genes were assessed along with carbapenemase genes, and also overexpression of these genes concomitant with harboring efflux pump may be responsible for resistance to carbapenems. "Data for these five provinces were extracted from 2011 to 2014 articles, so new data are needed.

${ }^{€}$ Data were extracted from a 2015 study with 36 samples; another study in 2013 confirmed the presence of the genes of resistance in $4 \%$ of strains. ${ }^{*}$ Data from Tehran province were conflicting; genes encoding resistance were detected in 15\%-50\% of isolates through 2015-2016. "Data from Kashan (a city in Isfahan province) showed presence of resistance genes in $80 \%$ of isolates in 2015.

$\S$ In Mazandaran and West Azerbaijan, these genes were reported, but rates of resistance were not included because the studies included different cities from different provinces. (1) blaOXA-23 (2) blaOXA-24 (3) blaOXA-58 (4) blaOXA-40 (5) blaOXA-48 (6) blaOXA-10 (7) blaOXA-I43 (8) blalMP (9) blaVIM (10) blaSPM (11) blaGES (12) blaPER (13) blaNDM (14) blaKPC (15) blaTEM (16) blaSHV (11) blaADC (18) blaSIM (19) blaGIM.

Abbreviations: ESBL, extended spectrum $\beta$-lactamase; KPC, Klebsiella-producing carbapenemase; MBL, metallo- $\beta$-lactamase.

Pattern of antibiotic use can affect emergence of resistant microorganisms. Rational use of drugs, and specifically antibiotics, is a challenging issue in developing countries. Mean number of drugs per prescription in Iran was higher than the World Health Organization standards. ${ }^{13,114}$ Approximately, $50 \%$ of inpatients, prescriptions contained at least one antibiotic, and this percentage was even higher in outpatient settings. ${ }^{115}$ Overuse of antibiotics, especially injectable ones, and easy access to antibiotics without prescription is a warning alarm for future antibiotic resistance in developing countries.
Establishing antimicrobial stewardship's programs is new in our hospitals. Unfortunately, governmental rules and supports to restrict antibiotic access in community pharmacies and prescription by general physicians are limited.

Following issues may be considered in future studies. Considering combination of antimicrobials for assessing the resistance is an important finding. Evaluating effects of combination disks (ie, a carbapenem with an aminoglycoside or a fluoroquinolone) on resistant gram-negative bacilli may be helpful. ${ }^{116}$ Although combination therapy may increase the 
Table 5 Types of bla genes, first location of isolation, and the relevant microorganisms in Iran

\begin{tabular}{|l|l|l|l|l|l|}
\hline $\begin{array}{l}\text { Ambler } \\
\text { classes }\end{array}$ & $\begin{array}{l}\text { Types of pf bla } \\
\text { genes }\end{array}$ & First location of isolation & Year $^{\mathbf{a}}$ & Total genes $^{\mathbf{b}}$ & Microorganism $^{\mathbf{c}}$ \\
\hline A & GES & Tehran, by Shahcheraghi F. & 2011 & 12 & Mostly P. aeruginosa \\
& KPC & Tehran, by Nobari S. & 2014 & 61 & Mostly K. pneumonia \\
\hline B & NDM & Tehran, by Shahcheraghi F. & 2012 & 44 & Mostly K. pneumonia \\
& VIM & Tehran, by Rezaei Yazdi H. & 2007 & 437 & Mostly P. aeruginosa \\
& IMP & Tabriz and Orumieh, by Yousefi S. & 2010 & 271 & Mostly P. aeruginosa \\
& SIM & Tehran, By Maspi H. & 2016 & 2 & Only in A. baumannii \\
& GIM & Tehran, By Maspi H. & 2016 & 4 & Only in A. baumannii \\
\hline \multirow{2}{*}{ OXA-23 } & Tehran, by Taherikalani M. & 2008 & 1,287 & Only in A. baumannii \\
& OXA-24 & Tehran, by Taherikalani M. & 2008 & 213 & Only in A. baumannii \\
& OXA-58 & Tehran, by Taherikalani M. & 2008 & 96 & Only in A. baumannii \\
& OXA-40 & Tabriz, by Sohrabi N. & 2012 & 59 & Only in A. baumannii \\
& OXA-48 & Tehran, by Azimi L. & 2014 & 52 & In K. pneumonia and others \\
& OXA-10 & Tehran, by Pakbaten S. & 2015 & 12 & Only in P. aeruginosa \\
& OXA-143 & Qom, by Sharikhani Z. & 2017 & 14 & Ond baumannii \\
\hline
\end{tabular}

Notes: ${ }^{\text {a }}$ ear that the genes were isolated for the first time. ${ }^{\mathrm{b}}$ Total number of genes that were reported in Iranian studies. ${ }^{\mathrm{C}}$ The microorganisms in which the genes were isolated.

risk of side effects, it remains an initial therapeutic option for MDR isolates. Another issue is studying of antibiotics' resistance pattern in health-care facilities. Remarkable increase in resistance rates among isolates from health-care facilities were reported. These strains may act as KPC-producing reservoirs. ${ }^{117} \mathrm{~A}$ higher resistance rate in long-term care facilities in comparison with intensive care units has been identified. ${ }^{118}$ Although some studies in Iran have included outpatients to evaluate carbapenem resistance, patients in long-term healthcare facilities have not been included.

\section{Authors' contributions}

All authors contributed to data analysis, drafting and revising the article, gave final approval of the version to be published, and agree to be accountable for all aspects of the work.

\section{Disclosure}

The authors report no conflicts of interest in this work.

\section{References}

1. Walsh TR, Toleman MA, Poirel L, Nordmann P. Metallo-betalactamases: the quiet before the storm? Clin Microbiol Rev. 2005;18(2):306-325.

2. Chan JD, Graves JA, Dellit TH. Antimicrobial treatment and clinical outcomes of carbapenem-resistant Acinetobacter baumannii ventilatorassociated pneumonia. J Intensive Care Med. 2010;25(6):343-348.

3. Sun K, Xu X, Yan J, Zhang L. Evaluation of six phenotypic methods for the detection of carbapenemases in gram-negative bacteria with characterized resistance mechanisms. Ann Lab Med. 2017;37(4):305-312.

4. Ambler RP. The structure of b-lactamases. Philos Trans R Soc Lond B Biol Sci. 1980;289:321-331.
5. Mcmullen AR, Yarbrough ML, Wallace MA, Shupe A, Burnham CD. Evaluation of genotypic and phenotypic methods to detect carbapenemase production in gram-negative Bacilli. Clin Chem. 2017;63(3):723-730.

6. Pletz MW, Wellinghausen N, Welte T. Will polymerase chain reaction (PCR)-based diagnostics improve outcome in septic patients? A clinical view. Intensive Care Med. 2011;37(7):1069-1076.

7. Meletis G, Exindari M, Vavatsi N, Sofianou D, Diza E. Mechanisms responsible for the emergence of carbapenem resistance in Pseudomonas aeruginosa. Hippokratia. 2012;16(4):303-307.

8. Douraghi M, Ghalavand Z, Nateghi Rostami M, et al. Comparative in vitro activity of carbapenems against clinical isolates of Acinetobacter baumannii. J Appl Microbiol. 2016;121(2):401-407.

9. Ghasemian R, Ahanjan M, Fatehi E, Shokri M. Prevalence and antibiotic resistance pattern of Acinetobacter isolated from patients admitted in ICUs in Mazandaran, Northern Iran. Glob J Health Sci. 2016;8(11):112-119.

10. Shakibaie MR, Adeli S, Salehi MH. Antibiotic resistance patterns and extended-spectrum $\beta$-lactamase production among Acinetobacter spp. isolated from an intensive care unit of a hospital in Kerman, Iran. Antimicrob Resist Infect Control. 2012:1:1.

11. Yousefi S, Farajnia S, Nahaei MR, et al. Class 1 integron and Imipenem Resistance in Clinical Isolates of Pseudomonas aeruginosa: Prevalence and Antibiotic Susceptibility. Iran J Microbiol. 2010; 2(3): 115-121.

12. Rahbar M, Kabeh-Monnavar M, Khadem Vatan K, Fadaei-Haqi A, Shakerian F. Carbapenem resistance in gram-negative Bacilli isolates in an Iranian 1000-bed tertiary hospital. Pak J Med Sci. 2008;24(4):537-540.

13. Babamahmoodi F, Ahangarkani F, Davoudi A. Hospital-acquired infections, bacterial causative agents and antibiotic resistance pattern in intensive care units at teaching hospitals in north of Iran. Int J Med Invest. 2015;4(1):152-160.

14. Mohajeri P, Rezaei Z, Sharbati S, et al. Frequency of adhesive virulence factors in carbapenemase-producing Acinetobacter baumannii isolated from clinical samples in West of Iran. Asian J Biol Sci. 2014;7(4):158-164.

15. Mobaraki S, Aghazadeh M, Soroush Barhaghi MH, et al. Prevalence of integrons 1, 2, 3 associated with antibiotic resistance in Pseudomonas aeruginosa isolates from Northwest of Iran. Biomedicine. 2018; 8(1):2-7. 
16. Ghanbari F, Khademi F, Saberianpour S, et al. An epidemiological study on the prevalence and antibiotic resistance patterns of bacteria isolated from urinary tract infections in central Iran. Avicenna J Clin Microbiol Infect. 2017;4(3):e42214.

17. Chahoofard A, Dehghan F, Karmostaji A, Zolghadri N. Hospitalacquired urinary tract infection, microbial causative agents and antibiotic resistance pattern in southern Iran: a prospective study. $J$ Glob Pharma Tech. 2017;1(9):52-58.

18. Ansari H, Doosti A, Kargar M, Bijanzadeh M, Jafarinya M. Antimicrobial resistant determination and prokaryotic expression of smpA Gene of Acinetobacter baumannii isolated from admitted patients. Jundishapur J Microbiol. 2017;10(11):e59370.

19. Babakhani S, Shokri Derikvand S, Nazer MR, Kazemi MJ. Comparison frequency and determination antibiotic resistance pattern of Klebsiella spp. isolated from Nosocomial infection in Khorramabad Shohadaye Ashayer hospital. Bull Env Pharmacol Life Sci. 2014;3(12): 149-154.

20. Kamalbeik S, Kouchek M, Baseri Salehi M, Fallah F, Malekan MA, Talaie H. Prevalence of Class 2 integrons in multidrug-resistant $\mathrm{Aci}$ netobacter Baumannii in toxicological ICU patients in Tehran. Iran J Toxicol. 2013;7(22):900-906.

21. Hashemi SH, Esna-Ashari F, Tavakoli S, Mamani M. The prevalence of antibiotic resistance of Enterobacteriaceae strains isolated in community- and hospital-acquired infections in teaching hospitals of Hamadan, West of Iran. J Res Health Sci. 2013;29(13):75-80.

22. Rahbar M, Mehragan H, Haji Ali Akbari N. Prevalence of drug resistance in nonfermenter gram-negative Bacilli. Iran J Pathol. 2010;5(2):90-96.

23. Soroush S, Haghi-Ashtiani MT, Taheri-Kalani M, et al. Antimicrobial resistance of nosocomial strain of Acinetobacter baumannii in Children's Medical Center of Tehran: a 6-year prospective study. Acta Med Iran. 2010;48(3):178-184.

24. Lari AR, Mohammadi Barzelighi H, Arjomandzadegan M, Nosrati $\mathrm{R}$, Owlia P. Distribution of Class I integron among isolates of $\mathrm{Aci}$ netobacter baumannii recovered from burn patients. J Med Bacteriol. 2013;2(1):1-11.

25. Rastegar Lari A, Azimi L, Rahbar M, Fallah F, Alaghehbandan R. Phenotypic detection of Klebsiella pneumoniae carbapenemase among burns patients: first report from Iran. Burns. 2013;39(1):174-176.

26. Ghotaslou R, Sadeghi M, Akhi M, Hasani A, Asgharzadeh M. Prevalence and antimicrobial susceptibility patterns of ESBL, AmpC and carbapenemase-producing Enterobacteriaceae isolated from hospitalized patients in Azerbaijan, Iran. Iran J Pharm Res. 2018;17(Special Issue):79-88.

27. Saadatian Farivar A, Nowroozi J, Eslami G, Sabokbar A. RAPD PCR profile, antibiotic resistance, prevalence of armA Gene, and detection of KPC enzyme in Klebsiella pneumoniae isolates. Can J Infect Dis Med Microbiol. 2018;Article ID 6183162:7.

28. Moosavian M, Shams N, Sirous M. Detection of carbapenemases emerging in Acinetobacter baumannii clinical isolates by modified Hodge test. J Med Microbiol Infect Dis. 2014;2(4):163-166.

29. Jonaidi Jafari N, Izadi M, Hajia M, Qorbanalizadgan M, Saburi A. The susceptibility evaluation of multiresistant Gram-negative Bacilli to meropenem and imipenem. Int J Travel Med Global Health. 2014;2(1):1-3.

30. Ghadiri H, Vaez H, Razavi-Azarkhiavi K, et al. Prevalence and antibiotic susceptibility patterns of extended-spectrum ß-lactamase and metallo-ß-lactamase-producing uropathogenic Escherichia coli isolates. Lab Med Fall. 2014;45:290-294.

31. Fazeli H, Kamali Dolatabadi R, Taraghian A, Nasr Isfahani B, Moghim S, Norouzi M. Carbapenem resistance pattern of multiple drugresistant and extended-spectrum beta-lactamase-positive Klebsiella pneumonia in Isfahan. Int J Enteric Pathogens. 2014;2(4):e21495.

32. Mirsalehian A, Kalantar-Neyestanaki D, Nourijelyani K, et al. Detection of AmpC- $\beta$-lactamases producing isolates among carbapenem resistant $P$. aeruginosa isolated from burn patient. Iran J Microbiol. 2014;6(5):306-310.
33. Moayednia R, Shokri D, Mobasherizadeh S, Baradaran A, Fatemi SM, Merrikh A. Frequency assessment of $\beta$-lactamase enzymes in Escherichia coli and Klebsiella isolates in patients with urinary tract infection. J Res Med Sci. 2014;19(1):S41-S45.

34. Erfani Y, Farahbakhsh M, Godarzi H, Eslami G, Hashemi A. Detection of metallo-B-lactamase (MBL) producing Acinetobacter at 3 hospitals in Iran, Tehran. Res J Biol Sci. 2013;8(4):88-93.

35. Safari M, Saidijam M, Bahador A, Jafari R, Alikhani MY. High prevalence of multidrug resistance and metallo-beta-lactamase $(\mathrm{M} \beta \mathrm{L})$ producing Acinetobacter baumannii isolated from patients in ICU Wards, Hamadan, Iran. J Res Health Sci. 2013;13(2):162-167.

36. Masaeli M, Faraji T, Ramazanzadeh R. Risk factors associated with resistance in metalo beta-lactamase producing Enterobacteriaceae isolated from patients in Sanandaj Hospitals. Curr Drug Ther. 2012;7(3) 179-183.

37. Japoni-Nejad A, Sofian M, van Belkum A, Ghaznavi-Rad E. Nosocomial outbreak of extensively and pan drug-resistant Acinetobacter baumannii in Tertiary Hospital in Central Part of Iran. Jundishapur J Microbiol. 2013;6(8):e9892.

38. Ahangarzadeh Rezaee M, Langarizadeh N, Aghazadeh M. First Report of Class 1 and Class 2 integrons in multidrug-resistant Klebsiella pneumoniae isolates from Northwest Iran. J Infect Dis. 2012;65:256-259.

39. Haji Hashemi B, Farzanehkhah M, Dolatyar A, et al. Study on prevalence of KPC producing from Klebsiella pneumoniae using modified Hodge test and CHROMagar in Iran. Ann Biol Res. 2012;3(12):5659-5664.

40. Azimi L, Lari AR, Alaghehbandan R, Alinejad F, Mohammadpoor $\mathrm{M}$, Rahbar M. KPC producer gram negative bacteria among burned infants in Motahari hospital, Tehran: first report from Iran. Ann Burns Fire Disasters. 2012;25(2):74-77.

41. Japoni A, Alborzi A, Kalani M, Nasiri J, Hayati M, Farshad S. Susceptibility patterns and cross-resistance of antibiotics against Pseudomonas aeruginosa isolated from burn patients in the South of Iran. Burns. 2006;32(3):343-347.

42. Taherikalani M, Fatolahzadeh B, Emaneini M, Soroush S, Feizabadi MM. Distribution of different carbapenem resistant clones of Acinetobacter baumannii in Tehran hospitals. New Microbiol. 2009;32(3):265-271.

43. Azizi O, Shakibaie MR, Modarresi F, Shahcheraghi F. Molecular detection of class-D OXA carbapenemase genes in biofilm and non-biofilm forming clinical isolates of Acinetobacter baumannii. Jundishapur $J$ Microbiol. 2015;8(1):e21042.

44. Bahador A, Raoo An R, Farshadzadeh Z, et al. The prevalence of IS Aba 1 and IS Aba 4 in Acinetobacter baumannii species of different international clone lineages among patients with burning in Tehran, Iran. Jundishapur J Microbiol. 2015;8(7):e17167.

45. Sarikhani Z, Nazari R, Nateghi Rostami M. First report of OXA143-lactamase producing Acinetobacter baumannii in Qom, Iran. Iran J Basic Med Sci. 2017;20(11):1282-1286.

46. Mohammadi M, Soroush S, Delfani S, et al. Distribution of class $\mathrm{D}$ carbapenemase and extended-spectrum $\beta$-lactamase genes among Acinetobacter baumannii isolated from burn wound and ventilator associated pneumonia infections. J Clin Diagn Res. 2017;11(7):DC19-DC23.

47. Kooti S, Motamedifar M, Sarvari J. Antibiotic resistance profile and distribution of oxacillinase genes among clinical isolates of Acinetobacter baumannii in Shiraz teaching hospitals, 2012-2013. Jundishapur J Microbiol. 2015;8(8):e20215.

48. Mahdian S, Sadeghifard N, Pakzad I, et al. Acinetobacter baumannii clonal lineages I and II harboring different carbapenem-hydrolyzing$\beta$-lactamase genes are widespread among hospitalized burn patients in Tehran. J Infect Public Health. 2015;8(6):533-542.

49. Farsiani H, Mosavat A, Soleimanpour S, et al. Limited genetic diversity and extensive antimicrobial resistance in clinical isolates of Acinetobacter baumannii in north-east Iran. J Med Microbiol. 2015;64(7):767-773. 
50. Nasrolahei M, Zahedi B, Bahador A, et al. Distribution of bla OXA23, IS Aba, aminoglycosides resistant genes among burned \& ICU patients in Tehran and Sari, Iran. Ann Clin Microbiol Antimicrob. 2014;13(1):38.

51. Safari M, Alikhani MY, Arabestani MR, Kamali Kakhki R, Jafari R. Prevalence of metallo- $\beta$-lactamases encoding genes among Pseudomonas aeruginosa strains isolated from the bedridden patients in the intensive care units. Avicenna J Clin Microbiol Infect. 2014;1(1):e19216.

52. Bahador A, Raoofian R, Taheri M, Pourakbari B, Hashemizadeh Z, Hashemi FB. Multidrug resistance among Acinetobacter baumannii isolates from Iran: changes in antimicrobial susceptibility patterns and genotypic profile. Microb Drug Resist. 2014;20(6):632-640.

53. Karmostaji A, Najar Peerayeh S, Hatef Salmanian A. Distribution of OXA-type class D $\beta$-Lactamase genes among nosocomial multi drug resistant Acinetobacter baumannii isolated in Tehran hospitals. Jundishapur J Microbiol. 2013;6(5):e8219.

54. Shoja S, Moosavian M, Peymani A, Tabatabaiefar MA, Rostami S, Ebrahimi N. Genotyping of carbapenem resistant Acinetobacter baumannii isolated from tracheal tube discharge of hospitalized patients in intensive care units, Ahvaz, Iran. Iran J Microbiol. 2013;5(4): 315-322.

55. Sohrabi N, Farajnia S, Akhi MT, et al. Prevalence of OXA-type $\beta$-lactamases among Acinetobacter baumannii isolates from Northwest of Iran. Microb Drug Resist. 2012;18(4):385-389.

56. Sepehriseresht S, Boroumand MA, Pourgholi L, Sotoudeh Anvari M, Habibi E, Sattarzadeh Tabrizi M. Detection of vim- and ipm-type metallo-beta-lactamases in Pseudomonas aeruginosa clinical isolates. Arch Iran Med. 2012;15(11):670-673.

57. Forozsh Fard M, Irajian G, Takantape Moslehi Z, Fazeli H, Salehi M, Rezania S. Drug resistance pattern of Pseudomonas aeruginosa strains isolated from cystic fibrosis patients at Isfahan AL Zahra hospital, Iran (2009-2010). Iran J Microbiol. 2012;4(2):94-97.

58. Peymani A, Higgins PG, Nahaei M-R, Farajnia S, Seifert H. Characterisation and clonal dissemination of OXA-23-producing Acinetobacter baumannii in Tabriz, northwest Iran. Int J Antimicrob Agents. 2012;39(6):526-528.

59. Asadollahi P, Akbari M, Soroush S, et al. Antimicrobial resistance patterns and their encoding genes among Acinetobacter baumannii strains isolated from burned patients. Burns. 2012;38(8):1198-1203.

60. Feizabadi MM, Fathollahzadeh B, Taherikalani M, et al. Antimicrobial susceptibility patterns and distribution of blaOXA genes among Acinetobacter spp. isolated from patients at Tehran hospitals. Jpn $J$ Infect Dis. 2008;61(4):274-278.

61. Taherikalani M, Etemadi G, Geliani KN, Fatollahzadeh B, Soroush S, Feizabadi MM. Emergence of multi and pan-drug resistance Acinetobacter baumannii carrying blaOXA-type -carbapenemase genes among burn patients in Tehran, Iran. Saudi Med J. 2008;29(4):623-624.

62. Hosseinzadeh Z, Sedigh Ebrahim-Saraie H, Sarvari J, et al. Emerge of blaNDM-1 and blaOXA-48-like harboring carbapenem-resistant Klebsiella pneumoniae isolates from hospitalized patients in southwestern Iran. J Chin Med Assoc. 2018;81(6):536-540.

63. Bina M, Pournajaf A, Mirkalantari S, Talebi M, Irajian G. Detection of the Klebsiella pneumoniae carbapenemase (KPC) in K. pneumoniae isolated from the clinical samples by the phenotypic and genotypic methods. Iran J Pathol. 2015;10(3):199-205.

64. Lari AR, Azimi L, Soroush S, Taherikalani M. Low prevalence of metallo-beta-lactamase in Pseudomonas aeruginosa isolated from a tertiary burn care center in Tehran. Int J Immunopathol Pharmacol. 2015;28(3):384-389.

65. Bagheri Josheghani S, Moniri R, Firoozeh F, Sehat M, Dasteh Goli Y. Susceptibility pattern and distribution of oxacillinases and blaPER-1 genes among multidrug resistant Acinetobacter baumannii in a teaching hospital in Iran. $J$ Pathog. 2015;957259:7.

66. Solgi H, Badmasti F, Aminzadeh Z, et al. Molecular characterization of intestinal carriage of carbapenem-resistant Enterobacteriaceae among inpatients at two Iranian university hospitals: first report of co-production of bla ${ }_{\text {NDM-7 }}$ and bla ${ }_{\text {OXA-48. }}$. Eur J Clin Microbiol Infect Dis. 2017;36(11):2127-2135.
67. Khorvash F, Yazdani M, Shabani S, Soudi A. Pseudomonas aeruginosaproducing metallo- $\beta$-lactamases (VIM, IMP, SME, and AIM) in the clinical isolates of intensive care units, a university hospital in Isfahan, Iran. Adv Biomed Res. 2017;30(6):147.

68. Akhi MT, Khalili Y, Ghotaslou R, et al. Carbapenem inactivation: a very affordable and highly specific method for phenotypic detection of carbapenemase-producing Pseudomonas aeruginosa isolates compared with other methods. J Chemother. 2017;29(3):144-149.

69. Falahat S, Shojapour M, Sadeghi A. Detection of KPC carbapenemase in Pseudomonas aeruginosa isolated from clinical samples using Modified Hodge Test and boronic acid phenotypic methods and their comparison with the polymerase chain reaction. Jundishapur $J$ Microbiol. 2016;9(9):e27249.

70. Mohammadzadeh M, Tavakoli M, Mohebi A, Aghayi S. Phenotypic and genotypic detection of metallo-beta-lactamases among imipenem resistant gram negative isolates. J Med Bacteriol. 2016;5(1-2):36-42.

71. Tarashi S, Goudarzi H, Erfanimanesh S, Pormohammad A, Hashemi A. Phenotypic and molecular detection of metallo-beta-lactamase genes among imipenem resistant Pseudomonas aeruginosa and Acinetobacter baumannii strains isolated from patients with burn injuries. Arch Clin Infect Dis. 2016;11(4):e39036.

72. Maspi H, Mahmoodzadeh Hosseini H, Amin M, Imani Fooladi AA. High prevalence of extensively drug-resistant and metallo betalactamase-producing clinical Acinetobacter baumannii in Iran. Microb Pathog. 2016;98:155-159.

73. Moghadam M, Motamedifar M, Sarvari J, Sedigh E-SH, Mousavi SM, Moghadam F. Emergence of multidrug resistance and metallo-betalactamase producing Acinetobacter baumannii isolated from patients in Shiraz, Iran. Ann Med Health Sci Res. 2016;6(3):162-167.

74. Pakbaten Toupkanlou S, Najar Peerayeh S, Pirhajati Mahabadi R. Class $\mathrm{A}$ and D extended-spectrum $\beta$-lactamases in imipenem resistant $P$ seudomonas aeruginosa isolated from burn patients in Iran. Jundishapur J Microbiol. 2015;8(8):e18352.

75. Eftekhar F, Naseh Z. Extended-spectrum $\beta$-lactamase and carbapenemase production among burn and non-burn clinical isolates of Klebsiella pneumoniae. Iran J Microbiol. 2015;7(3):144-149.

76. Azimi L, Talebi M, Owlia P, et al. Tracing of false negative results in phenotypic methods for identification of carbapenemase by real-time PCR. Gene. 2016;576(1 Pt 1):166-170.

77. Azimi L, Talebi M, Pourshafie M-R, Owlia P, Rastegar Lari A. Characterization of carbapenemases in extensively drug resistance Acinetobacter baumannii in a burn care center in Iran. Int $J$ Mol Cell Med. 2015;4(1):46-53.

78. Fazeli H, Norouzi-Barough M, Ahadi AM, Shokri D, Solgi H. Detection of New Delhi Metallo-Beta-Lactamase-1 (NDM-1) in carbapenemresistant Klebsiella pneumoniae isolated from a university hospital in Iran. Hippokratia. 2015;19(3):205-209.

79. Khoshvaght H, Haghi F, Zeighami H. Extended spectrum betalactamase producing enteroaggregative Escherichia coli from young children in Iran. Gastroenterol Hepatol Bed Bench. 2014;7(2):131-136.

80. Noori M, Karimi A, Fallah F, et al. High prevalence of metallo-betalactamase producing Acinetobacter baumannii isolated from two hospitals of Tehran, Iran. Arch Pediatr Infect Dis. 2014;2(1):e15439.

81. Vali P, Shahcheraghi F, Seyfipour M, Zamani MA, Allahyar MR, Feizabadi MM. Phenotypic and genetic characterization of carbapenemase and ESBLs producing gram-negative bacteria (GNB) isolated from patients with cystic fibrosis (CF) in Tehran hospitals. J Clin Diag Res. 2014;8(1):26-30.

82. Azimi L, Nordmann P, Lari AR, Bonnin RA. First report of OXA48-producing Klebsiella pneumoniae strains in Iran. GMS Hyg Infect Control. 2014;7:9.

83. Hashemi A, Fallah F, Erfanimanesh S, Hamedani P, Alimehr S, Goudarzi $\mathrm{H}$. Detection of $\beta$-lactamases and outer membrane porins among Klebsiella pneumoniae strains isolated in Iran. Scientifica. 2014;726179:6.

84. Japoni-Nejad A, Ghaznavi-Rad E, van Belkum A. Characterization of plasmid-mediated AmpC and carbapenemases among Iranian nosocomial isolates of Klebsiella pneumoniae using phenotyping and genotyping methods. Osong Public Health Res Perspect. 2014;5(6):333-338. 
85. Farajzadeh Sheikh A, Rostami S, Jolodar A, et al. Detection of metallo-beta lactamases among carbapenem-resistant Pseudomonas aeruginosa. Jundishapur J Microbiol. 2014;7(8):e12289.

86. Aghamiri S, Amirmozafari N, Fallah Mehrabadi J, Fouladtan B, Samadi Kafil H. Antibiotic resistance pattern and evaluation of metallo-beta lactamase genes including bla- ${ }_{I M P}$ and bla- ${ }_{V I M}$ types in Pseudomonas aeruginosa isolated from patients in Tehran Hospitals. ISRN Microbiol. 2014;2014(1):1-6.

87. Nobari S, Shahcheraghi F, Rahmati Ghezelgeh F, Valizadeh B. Molecular characterization of carbapenem-resistant strains of Klebsiella pneumoniae isolated from Iranian patients: first identification of bla ${ }_{K P C}$ gene in Iran. Microb Drug Resist. 2014;20(4):285-293.

88. Hakemi Vala M, Hallajzadeh M, Hashemi A, et al. Detection of Ambler class A, B and D B-lactamases among Pseudomonas aeruginosa and Acinetobacter baumannii clinical isolates from burn patients. Ann Burn Fire Disast. 2014;27(1):8-13.

89. Tavajjohi Z, Moniri R, Zarrabi M. Detection of GES-2, a class A $\beta$-lactamase produced by Pseudomonas aeruginosa in a teaching hospital in Iran. Jundishapur J Microbiol. 2013;6(10):e8166.

90. Azimi L, Lari AR, Talebi M, Ebrahimzadeh Namvar A, Soleymanzadeh-Moghadam S. Evaluation of phenotypic methods for detection of Klebsiella Pneumoniae carbapenemase-producing K. Pneumoniae in Tehran. J Med Bacteriol. 2013;2(3-4):26-31.

91. Noori N, Vandyosefi J, Sabet F, Ashrafi S, Ghazvini K. Frequency of IMP-1 and VIM genes among metallo-beta-lactamase producing Acinetobacter spp. isolated from health care associated infections in Northeast of Iran. J Med Bacteriol. 2013;2(3-4):11-16.

92. Azimi L, Lari AR, Talebi M, Namvar AE, Jabbari M. Comparison between phenotypic and PCR for detection of OXA-23 type and metallo-beta-lactamases producer Acinetobacter spp. GMS Hyg Infect Control. 2013;8(2):Doc16.

93. Pajand O, Rezaee MA, Nahaei MR, et al. Study of the carbapenem resistance mechanisms in clinical isolates of Acinetobacter baumannii: comparison of burn and non-burn strains. Burns 2013;39(7):1414-1419.

94. Azami S, Abdi Ali A, Asgarani E. Association between metallo- $\beta$ lactamases and integrons with multi-drug resistance in Pseudomonas aeruginosa isolates. J Med Microbiol Infect Dis. 2013;1(1):46-51.

95. Mohajeri P, Farahani A, Feizabadi MM, Ketabi H, Abiri R, Najafi F. Antimicrobial susceptibility profiling and genomic diversity of Acinetobacter baumannii isolates: a study in western Iran. Iran J Microbiol. 2013;5(3):195-202.

96. Doosti M, Ramazani A, Garshasbi M. Identification and characterization of metallo- $\beta$-lactamases producing Pseudomonas aeruginosa clinical isolates in University Hospital from Zanjan Province, Iran. Iran Biomed J. 2013;17(3):129-133.

97. Shahcheraghi F, Nobari S, Rahmati Ghezelgeh F, et al. First report of New Delhi metallo-beta-lactamase-1-producing Klebsiella pneumoniae in Iran. Microb Drug Resist. 2013;19(1):30-36.

98. Kalantar E, Torabi V, Salimizand H, Soheili F, Beiranvand S, Soltan Dallal MM. First survey of metallo- $\beta$-lactamase producers in clinical isolates of Pseudomonas aeruginosa from a Referral Burn Center in Kurdistan Province. Jundishapur J Nat Pharm Prod. 2012;7(1):23-26.

99. Shahcheraghi F, Abbasalipour M, Feizabadi M, Ebrahimipour G, Akbari N. Isolation and genetic characterization of metallo- $\beta$ lactamase and carbapenamase producing strains of Acinetobacter baumannii from patients at Tehran hospitals. Iran J Microbiol. 2011;3(2):68-74

100. Peymani A, Nahaei MR, Farajnia S, et al. High prevalence of metallo-beta-lactamase-producing Acinetobacter baumannii in a teaching hospital in Tabriz, Iran. Jpn J Infect Dis. 2011;64(1):69-71.
101. Saderi H, Lotfalipour H, Owlia P, Salimi H. Detection of metallo$\beta$-lactamase producing Pseudomonas aeruginosa isolated from burn patients in Tehran, Iran. Lab Med. 2010;41(10):609-612.

102. Yousefi S, Farajnia S, Nahaei MR, et al. Detection of metallo- $\beta$ lactamase-encoding genes among clinical isolates of Pseudomonas aeruginosa in northwest of Iran. Diagn Microbiol Infect Dis. 2010;68(3):322-325.

103. Bahar MA, Jamali S, Samadikuchaksaraei A. Imipenem-resistant Pseudomonas aeruginosa strains carry metallo-beta-lactamase gene bla(VIM) in a level I Iranian burn hospital. Burns. 2010;36(6):826-830.

104. Khosravi AD, Mihani F. Detection of metallo-beta-lactamase-producing Pseudomonas aeruginosa strains isolated from burn patients in Ahwaz, Iran. Diagn Microbiol Infect Dis. 2008;60(1):125-128.

105. Yazdi HR, Nejad GB, Peerayeh SN, Mostafaei M. Prevalence and detection of metallo- $\beta$-lactamase (MBL)-producing Pseudomonas aeruginosa strains from clinical isolates in Iran. Ann Microbiol. 2007;57(2):293-295.

106. Al Johani SM, Akhter J, Balkhy H, El-Saed A, Younan M, Memish Z. Prevalence of antimicrobial resistance among gram-negative isolates in an adult intensive care unit at a tertiary care center in Saudi Arabia. Ann Saudi Med. 2010;30(5):364-369.

107. Kempf M, Rolain JM. Emergence of resistance to carbapenems in Acinetobacter baumannii in Europe: clinical impact and therapeutic options. Int J Antimicrob Agents. 2012;39(2):105-114.

108. Cantón R, Akóva M, European Network on Carbapenemases, et al. Rapid evolution and spread of carbapenemases among Enterobacteriaceae in Europe. Clin Microbiol Infect. 2012;18(5):413-431.

109. Castanheira M, Deshpande LM, Costello A, Davies TA, Jones RN. Epidemiology and carbapenem resistance mechanisms of carbapenemnon-susceptible Pseudomonas aeruginosa collected during 2009-11 in 14 European and Mediterranean countries. J Antimicrob Chemother. 2014;69(7):1804-1814.

110. Clinical and Laboratory Standards Institute. Performance Standards for Antimicrobial Susceptibility Testing. Wayne, PA: CLSI; 2018:M100-S17.

111. Kuchibiro T, Komatsu M, Yamasaki K, et al. Evaluation of the modified carbapenem inactivation method for the detection of carbapenemaseproducing Enterobacteriaceae. J Infect Chemother. 2018;24(4): 262-266

112. Pirbonyeh N, Zardosht M, Emami A, Rostampour S, Moattari A, Keshavarzi A. Emergence of storm resistant mechanisms in Pseudomonas aeruginosa isolated from burn patients hospitalized in Ghotbeddin Shirazi Burn Hospital. Nova J Med Biol Sci. 2016;5(1).

113. Karimi A, Haerizadeh M, Soleymani F, Haerizadeh M, Taheri F. Evaluation of medicine prescription pattern using World Health Organization prescribing indicators in Iran: a cross-sectional study. J Res Pharm Pract. 2014;3(2):39-45.

114. Mousavi S, Zargarzadeh AH. Rational drug use in Iran: a call for action. J Pharm Care. 2014;2(2):47-48

115. Sefidani Forough A, Hosseini SR, Jabbari S. Antibiotic utilization evaluation of inpatient and outpatient prescriptions in a rural general hospital in Iran. Int J Basic Clin Pharmacol. 2015;4(3):531-536.

116. Leite GC, Neto LVP, Gaudereto JJ, et al. Effect of antibiotic combination and comparison of methods for detection of synergism in multiresistant gram-negative bacteria. J Inf Dis Ther. 2015;3(2):207.

117. Munoz-Price LS, Poirel L, Bonomo RA, et al. Clinical epidemiology of the global expansion of Klebsiella pneumoniae carbapenemases. Lancet Infect Dis. 2013;13(9):785-796.

118. Viau R, Frank KM, Jacobs MR, et al. Intestinal carriage of carbapenemase-producing organisms: current status of surveillance methods. Clin Microbiol Rev. 2016;29(1):1-27. 


\section{Publish your work in this journal}

Infection and Drug Resistance is an international, peer-reviewed openaccess journal that focuses on the optimal treatment of infection (bacterial, fungal and viral) and the development and institution of preventive strategies to minimize the development and spread of resistance. The journal is specifically concerned with the epidemiology of antibiotic resistance and the mechanisms of resistance development and diffusion in both hospitals and the community. The manuscript management system is completely online and includes a very quick and fair peerreview system, which is all easy to use. Visit http://www.dovepress.com/ testimonials.php to read real quotes from published authors.

Submit your manuscript here: https://www.dovepress.com/infection-and-drug-resistance-journal 